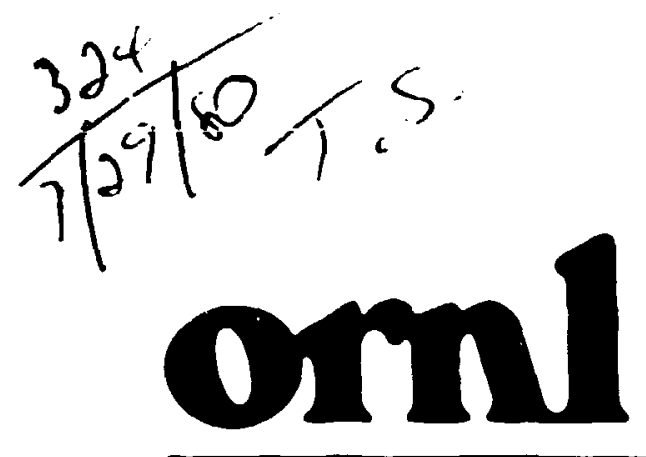

OAK

RIDGE

NATIONAL

LABORATORY

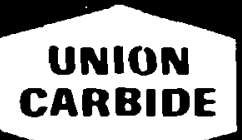

12 ifi. 156

ORNL-5522

\title{
Transport and Dispersion of Pollutants in Surface Impoundments: A Finite Element Model
}

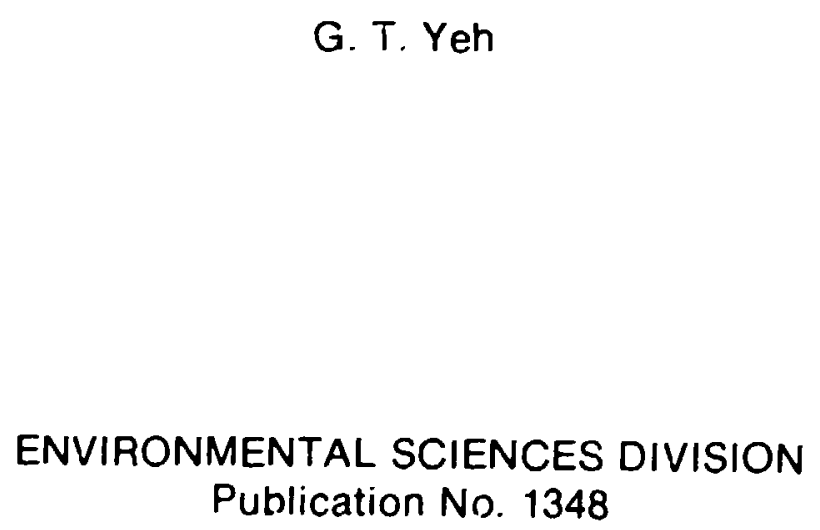

OPERATEO BY

UNION CARBIOE CORPORATION

FOR THE UNITED STATES

DEPARTMENT OF EMERGY

\section{MASTER}

\section{Publication No. 1348 \\ ENVIRONMENTAL SCIENCES DIVISION}

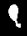

4

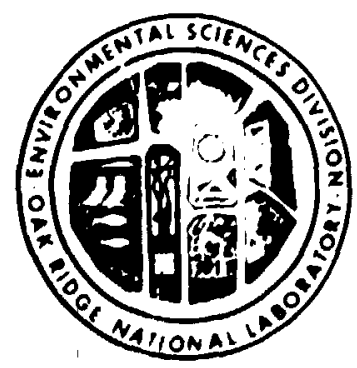


ORNL -5522

Distribution Category $\mathrm{SC}-70$

Contract No. W-7405-eng-26

TRAWSPORT AND DISPERSION OF POLLUTANTS IN SURFACE IMPOUNDMENTS: A FINITE ELEMENT MODEL

G. T. Yeh

ENVIRONMENTAL SCIENCES DIVISIO:i

Publication No. 1348

LOW-LEVEL WASTE MANAGEMENT PROGRAM

(Activicy No. AR 051515 O; ONL-HLO9)

Date Published: July 1980

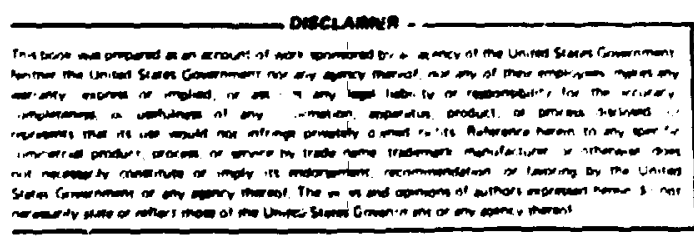

OAK RIDGE MATIONAL LABORATORY

Oak Ridge, Tennessee 37830

operated by

UNION CARBIDI: COPPORATION

for the

DEPARTMENi OF ENERGY 
YEH, G. T. 1980. Transport and dispersion of pollutants in surface impoundments: A finite element model. ORNL-5222. Oak Ridge Mational Laboratory, Oak Ridge, Tennessee. $120 \mathrm{pp}$.

A surface impoundment mode 1 in finite element (SIMFE) is presented to enable the simulation of flow circulations and poilutant transport and dispersion in natural or artificial lakes, rescrvoirs or ponds with any number of islands. This surface impoundment model consists of two sb-models: hydrodynamic and pollutant transport models. Both swomodels are simulated by the finite element method. While the hydroaynamic mode! is solved by the standard Galerkin finite element scheme, the pollutant transport model can be solved by any of the twelve optional finite element schemes built in tne program. Theoretical approximations and the numerical algorithm of SIMFE are described. Detai! instruction of the application are given and listing of FORTRAN IV source fiugram are piovided. Two sample problems are given. One is for an idealized system with a known solution to show the accuracy and partial validation of the models. The other is applied to Prairie Island for a set of hypothetical input data, typifying a class of problems to wich SIFFE may be applied. 
TAP! I OF CONTENTS

Page

ABSTRACT ..............................

LIST of TABLES ...................... vìi

LIST of FIGLRES ....................... vii

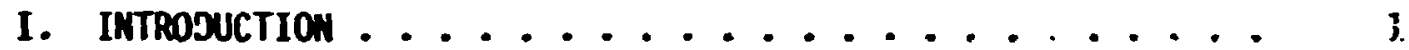

II. MODEL DEVELOPHERT .................. 4

II.1 Hydrodynamic Model ................ 4

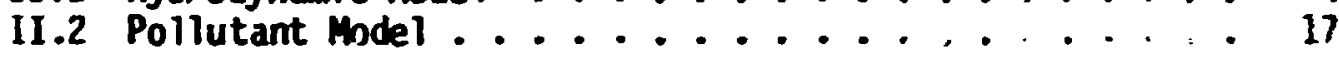

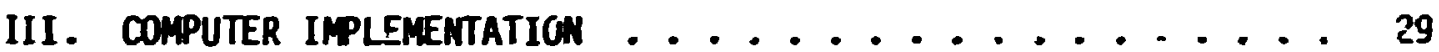

IV. RESULTS ....................?

IV.1 Ideal System Application ............ 32

IV.2 Prairie Island Application ...........

v. notation ....................... 40

VI. REFERENCES .......................... 42

VII. APPERDICES ..................... 47

APPEMCIX A. Applicability of the Model ........ 48

APPEMDIX B. Data Input Guide ........... 53

APPEMDIX C. Input and Output of an Ideally Hypothetical

System ................. 59

APPEMDIX D. Inpur and Output at Prairie Isiand ..... 67

APPERDIX E. Listing of FCRTRAN Program ........ $7 \mathrm{~s}$ 


\section{LIST OF TABLES}

Table

Page

1 Optional finite element schemes $\ldots 28$

\section{LIST OF FIGURES}

Figure

Page

1 e-th finite element in global and local coodinates... 11

2 Application of dirichlet cnnditions ........ 16

3 Subroutine of SIMFE ............. 30

4 Finite element discretization of an ideal channel . . 33

5 Velocity vector field in an ideal system ....... 34

6 Nomaiized iso-concentration as predicted by SIMFE

(_) and analytical solution (॰) ........ 35

7 Finite element directization of Prairie Island .... 37

8 Flon rate vecturs as predicted by the model ...... 38

9 Iso-concentration lines of 0issolved 0xygen (DO)

at Prairie as predicted by the model ........ 39 


\section{INTRODUCTION}

Areas near surface impounding waters, either natural or man-made, have traditionally been the centers of industrial growth. A basic reason has been their capacity to receive, dilute, and assimilate all kinds of unwanted eff luerts. In recent years, however, the rapidly increasing quantities of such effluents and the growing concern over conservation of environmental quality have led to the necessity for rational planning of the utilization of imp - waters, instead of allowing uncontrolled expansion.

A major technical problem associated with such planning strategies is the prediction of how an effluent will spread in a given body of water. The answer to this question is by no means simple. It involves knowledge of the flow field on one hand and the characteristics and possible interactions of the pollutants on the other. The flow patterns in the surface waters are usually extremely complex and depend on meteorological conditions, bottom topography, boundary geometry, inflows and outflows. To gain insight into the processes that take place in nature, three approaches may be followed: (1) direct measurements, (2) hydraulic modeling, and (3) mathematical modeling.

Measurements in water bodies are normally very expensiva and mostly site and time specific such that they rarely provide ar adequats overview of the processes of interest. However, they are necessary in confunction with modeis of categories (2) and (3), since they provide Jata required for input or verification. Hydraulic models can yieid a very detailed picture of the phenomena, but considerable difficl:ties 

have emerged (Wang and Connor 1975, Christodou lo et al. 1976). Finite element methods offer two great advantages: (1) flexitility in the representation of complex geometries and (2) ease in the treatment of Neumann or third type boundary conditions. This report presents the development of an algorithms of the surface impoundment model by finite element (SIMFE).

From a practical vieupoint, the main interrest is not the flow field, but rather the transport and dispersion of some substance due to a given flc field. Therefore, the information obtained from the hydrodynamic model of SIMFE is subsequent ly used as input to the transport mode1. The latter normally solves some form of the advective-diffusion equation, expressing the mass balance of the constituent of interest. The standard Galerkin finite element method is used for the hydrodynamic model wile twelve optional finite element techniques are used for the pollutant transport model. 


\section{MODEl DEVELOPMENT}

The spatial variations of the velocity from discharges, intakes inflows and outflows are simulated with a two-dimensional steady state hydrodynamic model. This is a modified version of the model developed

previously (Yeh et al. 1973). The temporal and spatial variations of a pollutant constituent are calculated with the aid of mamerical solution of mass transport equation. The solution method for both the hydrodynamic and, lutant models are the finite element method.

\section{II .I Hydrodynamic Model}

\section{II.1.1 Governing Equations}

The characteristics in a shallow impoundment can be fairly app:aximated by the following assumptions: (1) the velocity distribution in the vertical direztion is fairly uniform, (2) the pressure distribution in the vertical direction is hydrostatic, (3) the fluctuation of the water surface is much smaller than the water depth, (4) the flow is steady state, (5) the nonlinear convection is very small rimared to the bottom frictional force and (6) the botton stress is proportional to the velocity. A discussion on the validity of these assumption has been presented in a previous report (Yeh 1979). It is recaptulated in Appendiy $A$.

Under the above assumptions, the vertically integrated form of the conservation equations of mass and momentum in a Cartesian coordinate system with $x$ and $y$ on the horizontal plane can be reduced to (Yeh et a) 1973): 


$$
\begin{gathered}
\frac{\partial^{2} \Psi}{\partial x^{2}}+\frac{\partial^{2} \Psi}{\partial y^{2}}-\left(\frac{2}{h} \frac{\partial h}{\partial x}+\frac{f}{k} \frac{\partial h}{\partial y}\right) \frac{\partial \Psi}{\partial x}-\left(\frac{2}{\hbar} \frac{\partial h}{\partial y}-\frac{f}{K} \frac{\partial h}{\partial x}\right) \frac{\partial \Psi}{\partial y}= \\
\frac{h^{2}}{\rho K} \frac{\partial}{\partial x}\left(\frac{\tau_{y}^{w}}{h}\right)-\frac{h^{2}}{\rho k}-\frac{\partial}{\partial y}\left(\frac{\tau_{x}^{w}}{h}\right)
\end{gathered}
$$

where $\Psi$ is the stream function; $\rho$ is the water density; $f$ is the coriolis coefficient; $K$ is the linear bottom stress coefficient; $h$ is the water depth; and $\tau_{x}^{W}$ and $\tau_{y}^{W}$ are the wind stress components in the $x$ - and $y$-directions, respectively. Equation (1) represents the balance between three forces. The first two terms and the third and fifth terms are the bottom frictional forces. The fourth and sixth terms are the coriolis force. The last two terms on the right hand side are the wind driven forces. Another important driving force wich is not appearing explicitly in the equation is the inflow and outflow of the region, which resemble the pressure gradient force.

After Eq. (1) is scived for the stream function, the flow rate components, $U$ and $V$, can be computed as follows:

$$
U=\overline{u h}=-\frac{\partial \Psi}{\partial y} ; \quad V=\bar{v} h=\frac{\partial \Psi}{\partial x}
$$

where $\bar{u}$ and $\bar{v}$ are the vertically averaged velocity components in the $x-$ and $y$-directions, respectively. The flow rate components, $U$ and $V$, along with the topography and the bathymetry of the water body, will serve as inputs to the pollutant model. 
Boundary conditions to complete the solution of Eq. (1) are determined by tire requirenents that every water-land interface is a streamline whose values can be prescribed from the information of inflows and outflows. The conditions at open boundaries such as intake channel, discharge cannal, influx and efflux lines are determined by assuming the mormal fiow to the lines prevailing. To write these conditions in mathematical terms, they are described by the following equations:

$$
\Psi=\Psi_{L}(x, y) \quad \text { at } \quad L(x, y)=0
$$

and

$$
\frac{\partial \Psi}{\partial x} n_{x}+\frac{\partial \Psi}{\partial y} n_{y}=f_{s}(x, y)=0 \text { at } S(x, y)=0
$$

where $L(x, y)=0$ is the curve of water-1 and interface; $S(x, y)=0$ is the curve of open water boundaries; and $n_{x}$ and $n_{y}$ are directional cosines of a unit vector normal to the curve, $S(x, y)=0$. An option is also given that

$$
\Psi=\Psi_{S} \quad \text { on } S(x, y)=0
$$

In Eqs. (3) and (4a) $\Psi_{L}$ and $\Psi_{S}$ are two known functions desr.ribing boundary values of $\Psi$.

\section{II.1.2 Finite Element Approximations}

The method that will be used in the integration of Eq. (1) is a special case of the broad category called weighted residual methods. These methods, in the fir classical form, approximate the solution to the differential equations and satisfy the boundary conditions exactly. The differential equation may be written in the general form:

$$
L(\$)=0
$$


where $L$ is a differential operator and $\Phi$ is the dependent variable. The weighted residual approximate solution $\hat{\Phi}$ over the region $R$ is obtained from the equation

$$
\int_{R} H_{i} \cdot L(\hat{\Phi}) d R=0 \quad \text { for } \quad i=1,2, \ldots, n
$$

The $H_{i}$ 's comprise a set of $n$ weighting functions, and the trial solution, $\hat{\phi}$, has the form

$$
\hat{\Phi}=\sum_{j=0}^{n} \Phi_{j}-N_{j}
$$

where $N_{j}$ 's are the base functions (interpolating functions); $\Phi_{j}$ 's are unknown values of the trial solution at the nodal points, $j$ 's, and $L(\Phi) \neq 0$ is the residual. Since Eq. (1) is an ellipitic type, the weighting function will be chosen as the interpolating function and the method is thus called Galerkin method. In fact, the equation for the Galerkin method

$$
\int_{R} N_{i} L\left(\sum_{j=1}^{n} N_{j} \Phi_{j}\right) d R=0, \quad i=1,2, \ldots, n
$$

requires that the residual of the differential equation be made orthugonal to each term in the trial solution. Coefficients of $\Phi_{j}$ 's 
are obtained by integrating Eq. (8). The integration yields a set of $n$-algebrâic equations, whose solution gives $\Phi_{j}$ 's.

In the classical Galerkin method, each of the interpolating functions, $N_{i}$, extends over the entire domain $R$ and must satisfy all boundary conditions. Hence, the method is restricted to simply shaped, simply connected regions with homogeneous material properties. However, the power and generality of the Galerkin method ran be extendes considerably by combining $i$ with a finite element discretization in wich the region of integration is represented by an assemblage of sub-domains. These sub-domains are called elements, and the ir corners, or connection points: are called notes. In this approach, the family of the base functions consists of subfamilies of very simple functions. The $\Phi_{j}$ 's satisfy boundary conditions, and not the base iunctions: $N_{j} ' s$, wici are non-zero on only one of the subdomains. The coefficients, $\Phi_{j}$ 's become the amplitudes of the unknown function at the nodes. Th is finite $t$ iement approach, in effect, is a piecewise Galerkin approximation whicr permits the application of the Galerkin metnod to complex geometries and non-hornogeneous media. A more cietililed discussion of the Galerkin finite element method is given by Hutton and Anderson (1971).

The Galerkin method applied to a quadrilateral element e may be written as:

$$
\int_{R_{e}} N_{i} \cdot L\left(\sum_{j=1}^{4} \Phi_{j} N_{j}\right) d R, \quad i=1,2,3,4
$$


Substituting the differential operator in Eq. (1) into (9) and integrating the second order derivatives by parts, one obtains:

$$
\left[S_{i j}\right]\left\{\psi_{j}\right\}+\left\{D_{i}\right\}+\left\{Q_{i}\right\}=0
$$

where

$$
\begin{aligned}
& S_{i j}=\int_{R_{e}}\left\{\left(\frac{\partial N_{i}}{\partial x} \frac{\partial N_{j}}{\partial x}+\frac{\partial N_{i}}{\partial y} \frac{\partial N_{j}}{\partial y}\right) \div N_{i}\left(\frac{2}{h} \frac{\partial h}{\partial x}+\frac{j}{\rho K} \frac{\partial h}{\partial y}\right) \frac{\partial N_{j}}{\partial x}\right. \\
& \left.\quad+N_{i}\left(\frac{2}{h} \frac{\partial h}{\partial y}-\frac{f}{\rho K} \frac{\partial h}{\partial x}\right) \frac{\partial N_{j}}{\partial y}\right\} d R \\
& D_{i}=\int_{R_{e}}\left\{\frac{h^{2}}{\rho K} N_{i} \frac{\partial N_{j}}{\partial x}\left(\frac{\tau_{y}^{W}}{h}\right)_{j}-\frac{h^{2}}{\rho K} N_{i} \frac{\partial N_{j}}{\partial y}\left(\frac{\tau_{x}^{W}}{h}\right)_{j}^{W}\right\} d R
\end{aligned}
$$

and

$$
Q_{i}=-\int_{B_{e}}\left(N_{i} \frac{\partial \Psi}{\partial x} n_{x}+N_{i} \frac{\partial \Psi}{\partial y} n_{y}\right) d B
$$

in which $\left(\tau_{x}^{W} / h\right)_{j}$ and $\left(\tau_{y}^{w / h} /\right)_{j}$ are the values of $\left(\tau_{x}^{w} / h\right)$ and $\left(\tau_{y}^{W} / h\right)$ evaluated at point $j ; R_{e}$ and $B_{e}$ are the region and boundaries of the element $e$, respectively. Equation (13) applies to only those elements having one or more sides on the glokal boundary, $s(x, y)=0$. 


\section{II.1.3 Numerical Inplementation}

Quadrilateral bilinear element are used to descretize the region of interest. The base function for the $i$-th node may be written in terms of local nomalized coordinates as:

$$
N_{i}=\frac{1}{4} \cdot\left(1+\xi_{j} \xi\right) \cdot\left(1+n_{i} \eta\right) \quad i=1,2,3,4
$$

where $\xi_{j}$ and $\eta_{i}$ are the local coordinates of the corner nodes, wich are numbered 1 to 4 progressing around the element in a counterclock-wise dircction as shom in Fig. 1. In the local coordinate system the element is square regardiess the shape of the quadrilateral element in global coordinates. The global coordinates at any point within element $g$ are given in terms of local coordinates by the following transformation:

$$
x=\sum_{j=1}^{4} x_{j} N_{j}
$$

and

$$
y=\sum_{j=1}^{4} y_{j} N_{j}
$$

where $x_{f}$ and $y_{f}$ are the global coordinates of the nodes of the e-th element. $N_{j}$ 's are function of the local coordinates of $\xi$ and $n$ as in Eq. (14). 


\section{ORNL-DWG 78- 19276}
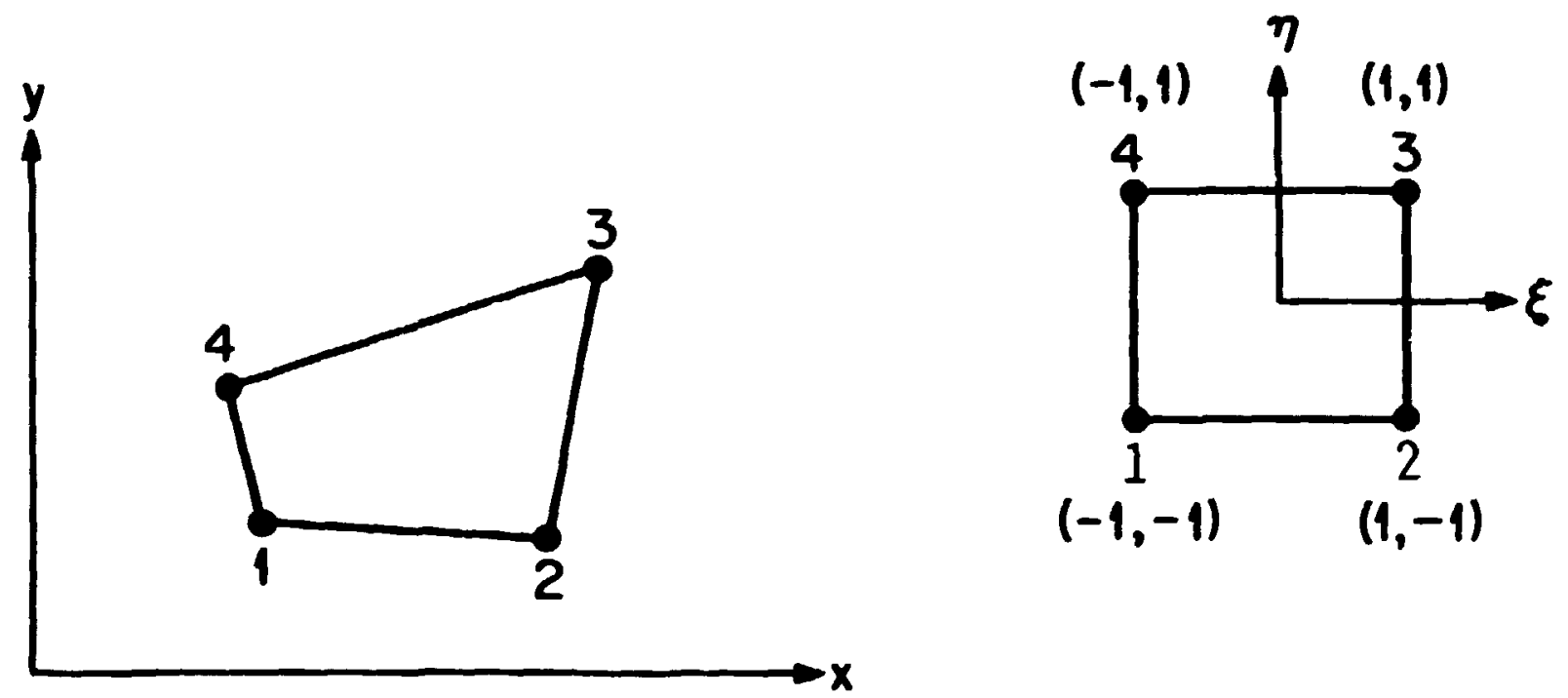

Fig. 1. e-th finite element in global and local coodinates. 
ORIL-5522

12

The shape function, $M_{i}$ 's, of the coordinate transformation in Eq. (15) is the same as the base function, $N_{j}$ 's of Eq. (7); hence this element formulation is termed isoparametric. The Jacobian for the transformation from global to local coordinates is expressed as:

$$
[J]=\left[\begin{array}{ll}
\frac{\partial x}{\partial \xi} & \frac{\partial y}{\partial \xi} \\
\frac{\partial x}{\partial \eta} & \frac{\partial y}{\partial \eta}
\end{array}\right]
$$

Substitution of Eq. (15) into the determinant of this expression yields:

$$
\mathrm{J}=\operatorname{Det}[J]=\left(x_{j} \frac{\partial N_{j}}{\partial \xi}\right) \cdot\left(y_{k} \frac{\partial N_{k}}{\partial \eta}\right)-\left(y_{j} \frac{\partial N_{j}}{\partial \xi}\right) \cdot\left(x_{k} \frac{\partial N_{k}}{\partial \eta}\right)
$$

Equation (17) is used for numerical evaluation of the determinant of the Jacobian. The integrals of Eq. (11) and (12) taken over line area of the eth element may now be written in local coordinates using the determinant of the Jacobian to transform the element area:

$$
\begin{gathered}
s_{i j}=\int_{-1}^{1} \int_{-1}^{1}\left\{\left(\frac{\partial N_{i}}{\partial x} \frac{\partial N_{j}}{\partial x}+\frac{\partial N_{i}}{\partial y} \frac{\partial N_{j}}{\partial y}\right)+N_{i}\left(\frac{2}{h} \frac{\partial h}{\partial x}+\frac{f}{k} \frac{\partial h}{\partial y}\right) \cdot \frac{\partial N_{j}}{\partial y}\right. \\
\left.+N_{i}\left(\frac{2}{h} \frac{\partial h}{\partial y}-\frac{f}{R} \frac{\partial h}{\partial x}\right) \cdot \frac{\partial N_{j}}{\partial y}\right\} \mathrm{J} d \xi d \eta
\end{gathered}
$$

and

$$
D_{i}=\int_{-1}^{1} \int_{-1}^{1}\left\{\frac{h^{2}}{\partial K} \cdot N_{i} \cdot \frac{\partial N_{j}}{\partial x}\left(\frac{\tau_{j}^{w}}{\hbar}-\right)_{j}+\frac{h^{2}}{\partial K} \cdot N_{i} \cdot \frac{\partial N_{j}}{\partial y}\left(\frac{\tau_{x}^{w}}{h}\right)_{j}\right\} J d \xi d \eta
$$


Integration of these equations is exsily carried cut using Ex: Carssizm points. A linear algeb aic equation, Eq. (9), results.

In order to evaluate $\left[S_{i j}\right]$ and $\left\{D_{i}\right\}$, expression for the

spatial derivative of the interpolation function. with. resfist to $x$ and $y$ in terms of $\xi$ and $n$ are necessary. The chain ivle:

$$
\left\{\begin{array}{l}
\frac{\partial}{\partial \xi} \\
\frac{\partial}{\partial \eta}
\end{array}\right\}=[J] \cdot\left\{\begin{array}{l}
\frac{\partial}{\partial x} \\
\frac{\partial}{\partial y}
\end{array}\right\}
$$

may be inverted to yield

$$
\left.\left\{\begin{array}{l}
\frac{\partial}{\partial x} \\
\frac{\partial}{\partial y}
\end{array}\right\} \cdot\left[\begin{array}{ll}
\frac{\partial y}{\partial \eta} & \frac{\partial y}{\partial \xi} \\
\frac{\partial x}{\partial \eta} & \frac{\partial x}{\partial \xi}
\end{array}\right]||_{\frac{\partial}{\partial \eta}}^{\frac{\partial}{\partial \xi}}\right\}
$$

using the definition of [J] in Eq. (16).

When the top row of Eq. (21) is applied to the base function, $N_{f}$, the following is obtained:

$$
\frac{\partial N_{i}}{\partial x}=\frac{1}{J}\left[\left(y_{j} \frac{\partial N_{j}}{\partial \eta}\right) \cdot \frac{\partial N_{i}}{\partial \xi}-\left(y_{j} \frac{\partial N_{j}}{\partial \xi}\right) \cdot \frac{\partial N_{j}}{\partial \eta}\right]
$$


where $\left(\partial W_{j} / \partial \xi\right)$ and $\left(a w_{j} / \partial n\right)$ are given as:

$$
\frac{\partial N_{i}}{\partial \xi}=\frac{1}{4} \cdot \ddot{\xi}_{i}\left(1+n_{j} n\right)
$$

and

$$
\frac{\partial N_{i}}{\partial n}=\frac{1}{4} \cdot n_{i}\left(1+\xi_{i} \xi\right)
$$

by taking the derivatives of Eq. (14) with respect to $\xi$ and $\eta$, respectively. Similarily, applying the bottom row of Eq. (21) to the base function, one obtains:

$$
\frac{\partial N_{i}}{\partial y}=\frac{1}{j} \cdot\left[-\left(x_{j} \frac{\partial N_{j}}{\partial \eta}\right) \cdot\left(\frac{\partial N_{j}}{\partial \xi}\right)+\left(x_{j} \frac{\partial N_{j}}{\partial \xi}\right) \cdot\left(\frac{\partial N_{j}}{\partial \eta}\right)\right]
$$

Equations (23) and (24) are in a form suitable for numerical evaluation. These equations are used to evaluate the integrands of Eqs. (18) and (19).

\section{II.1.4 Assembling of Element Matrix}

Equations (10) through (13) are developed for an element. Direct stiff matrix procedure is then used to assumble over all the elements to form a system of algebraic equations as:

$$
\left[T_{i j}\right]\left\{\Psi_{j}\right\}=\left\{X_{i}\right\}-\left\{B_{f}\right\}=\left\{Y_{i}\right\}
$$


where $\left[T_{i j}\right]$ and $r_{i}$ are the global matrix and load vector, respectively. The matrix $\left[\pi_{i j}\right]$ is a singular matrix if the boundar: conditions are not incorporated.

\section{II.1.5 Incorporation of Boundary Conditions}

At nodes there Dirichlet boundary conditions, Eq. (3), are imposed, an identity equation is then generated for each of ricli nodes and included in the matrix of Eq. (26) (Hang and Connor 1975! Computationally, this is done as sketched in Fig. 2. If the k-th variable is prescribed, the $k$-th colum in the coefficient matrix $\left[T_{i j}\right]$ is stored, then the $k$-th row and colum in $\left[T_{i j}\right]$ are set to zero and the diagonal entry set equal to one. Finally, the stored colum matrix is inltiplied by the priscribed value $r^{*}$ and substracted from the right hand side of Eq. (26). This procedure effectively replace the $k$-th equation by the prescribed constant.

At nodes where the Meumann boundary conditions are applied, a surface integral term, $B_{j}$, must be subtracted from the vector, $x_{i}$. In this case, nothing should be done since the normal derivative on $S$ is zero.

On the is land nodal points, special care should be made. Recall that, each island is a streamline but its stream function value is not prescribed. Therefore, for each island, the straam function at a designinated nodal point, say the first point encountered, should be considered unknown. Those at all other points on the same island are set equal to the designated one. Hence, for each island, one equation corresponding to the desigriated nodal point has to be modified vecause 

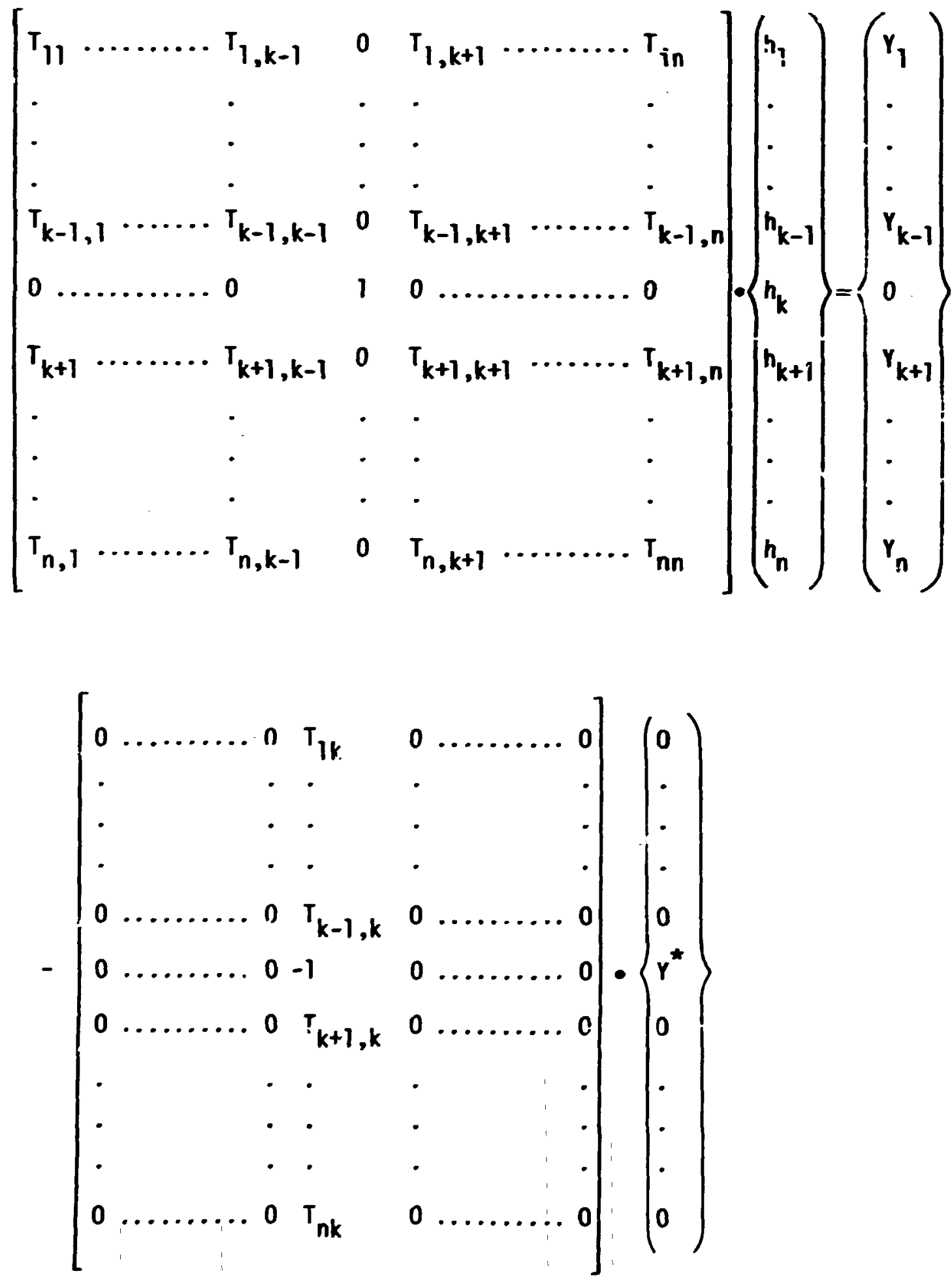

Fig. 2. Application of dirichlet conditions. 
the boundary integral, $\left\{B_{j}\right\}$, are no longer zero but are depending on the stream function. Substituting Eq. (7) into Eq. (13), one obtains:

$$
\left\{Q_{i}\right\}=\left[E_{i j}\right]\left\{\mathbf{P}_{j}\right\}
$$

where

$$
E_{i j}=-\int_{B_{e}} N_{i}\left(\frac{\partial N_{j}}{\partial x} n_{x}+\frac{\partial N_{j}}{\partial y} n_{y}\right) d B
$$

The surface integral, $\left[E_{i j}\right]$, after assembly over all elements having the designated point as one of the ir nodal points, is added to the matrix, $\left[\boldsymbol{T}_{\mathbf{i j}}\right]$.

\subsubsection{Solution of Assembled Equations}

Gaussian elemination algor ithm is used to solve the matrix equation, Eq. (26).

\section{II.2 Pollutant Model}

\section{II.2.1 Governing Equations}

The variations of pollutants with space and time are simulated with a transient two-dimensional advective-dispersion equation. The model is developed according to the mass conservation relationship:

$$
\frac{\partial h c}{\partial t}+\frac{\partial U c}{\partial x}+\frac{\partial V c}{\partial y}=\frac{\partial}{\partial x}\left(h K_{x} \frac{\partial c}{\partial x}\right)+\frac{\partial}{\partial y}\left(h K_{y} \frac{\partial c}{\partial y}\right)+\frac{M}{\rho}-\left(K_{m}+\lambda\right) h c
$$


where $c$ is the concentration; $K_{\mathrm{m}}$ is the first order reaction rate of pollutants with waier; $\lambda$ is the decay constant, if the pollutant is radioactive; $K_{x}$ and $K_{y}$ are the dispersion coefficient in the $x$ - and $y$-directions, respectively; $\rho$ is the water density; $M$ is the source or sink term, wich may result from the discharge, intake, river inflows and outflows. in Eq. (27), the first term represents the time rate of change of the pollutant in a differential voiume. The second and third terws represent the flux by the advection. The first two ter is on the right hand side represent the dispersive fluxes by anbient turbulence and shear forces. Pollutant degeneration by chemical reaction or biological action is characterized by $K_{n}$.

Variables involved in Eq. (27) are U, $V, K_{x}, K_{y}, K_{m}, h, \lambda$ and $c . c$ is the unknown to be determined. Among those variables, $h$, and $k_{m}$ are input variables. $U$ and $V$ are flow rate components wich are obtained from the output of hydrodynamic model. $k_{x}$ and $k_{y}$ are related to the hydrodynamic variables, $U$ and $V$, as follows:

$$
h k_{x}=a_{T} W+\left(a_{L}-a_{T}\right) U^{2} M+h D_{m}
$$

and

$$
h k_{y}=a_{T} H+\left(a_{L}-a_{T}\right) v^{2} / W+h D_{m}
$$

where $a_{L}$ and $a_{T}$ are the longitudinal and transverse eddy diffusivities, respectively; $W=\sqrt{u^{2}+V^{2}}$; and $D_{m}$ is the molecular diffusion coefficient. 
To complete the description of the concentration distribution, initial and boundary conditions are required in addition to Eq. (27). Three types of boundary conditions are considered in the present formulation. The first one is the Dirichlet boundary where the concentration is given:

$$
c=c_{1}(x, y, t) \quad \text { on } \quad B_{1}
$$

where $c_{1}$ is a known function of time, $t$, and the spatial coordinaies, $(x, y)$, on th curve $B_{1}$. The second one is the Neumann boundary where the normal gradient of the concentration is zero, thus yieiding the concentration dependent conditions and can be written as:

$$
\left(-h k_{x} \frac{\partial c}{\partial x}+U c\right) \cdot n_{x}+\left(-h k_{y} \frac{\partial c}{\partial y}+V c\right) \cdot n_{y}=U c n_{x}+V c n_{y} \text { on } B_{2}
$$

where $n_{x}$ and $n_{y}$ are the directional cosines of the outward unit vector normal to the curve $B_{2}$. The last one is the mixed boundary where the normal flux is prescribed:

$$
\left(-h k_{x} \frac{\partial c}{\partial x}+U c\right) \cdot n_{x}+\left(-h k_{y} \frac{\partial c}{\partial y}+V c\right) \cdot n_{y}=q_{1}(x, y, t) \text { on } B_{3}
$$

\section{I1.2.2 Finite Element Approximations}

It may be expected that in a surface impoundment, the advection may be as important as the dispersion. Under such circunstances, it is advantageous to use weighting functions different from the base 
functions. For example, the upstream weighting function is one of such candidates (Huyakorn 1976). In the present finite element formulation, two options are provided: one is the standard Galerkin finite element described in the section of hydrodynamic model, the other is the upstream weighting finite element. The detailed derivation of the upstream weighting function for a quadrilateral bilinear element can be found elsewhere (Huyakorn 1976). Thus, the method of the weighted residual applied to the mass transport equation for an element e may be mitten as:

$$
\int_{R_{e}} H_{j} \cdot L\left(\sum_{j=1}^{4} N_{j} \Phi_{j}\right) d R=0, \quad i=1,2,3,4
$$

Substituting the differential operator in Eq. (27) into Eq. (32), and integrating the second order derivatives by part, one obtains:

$$
\left[M_{i j}\right]\left\{\dot{c}_{j}\right\}+\left[S_{i j}\right]\left\{c_{j}\right\}+\left\{D_{i}\right\}+\left\{Q_{i}\right\}=0
$$

where

$$
\dot{c}=\frac{d c}{d t}
$$

and

$$
M_{f j}=\int_{-1}^{1} \int_{-1}^{1} H_{i} h N_{j} J d \xi d \eta
$$




$$
S_{i j}=\int_{-1}^{1} \int_{-1}^{1}\left\{\frac{\partial H_{i}}{\partial x}\left(K_{x} \frac{\partial N_{j}}{\partial x}-U N_{j}\right)+\frac{\partial H_{i}}{\partial y}\left(K_{y} \frac{\partial N_{j}}{\partial y}-V N_{j}\right)\right\} J d \xi d n
$$

$$
+\int_{-1}^{1} \int_{-1}^{1}(K+\lambda) W_{j} h N_{j} J d \xi d \eta
$$

$$
D_{i}=-\int_{-1}^{1} \int_{-1}^{1} H_{i} M J d \xi d n
$$

$$
Q_{i}=\int_{B_{e}} H_{i}\left(\left(-h k_{x} \frac{\partial c}{\partial x}+U c\right) n_{x}+\left(-h k_{y} \frac{\partial c}{\partial y}+V c\right) n_{y}\right\} d B
$$

in wich $B_{e}$ is the side or sides of the element e. It should be noted that Eq. (38) appears only for those elements having one or more sides on $B_{2}$. The application of this boundary equation will be discussed later.

The weighting function, $W_{i} ' s$, for the Galerkin option is given by

$$
H_{i}=N_{i}, \quad i=1,2,3,4
$$

and for the upstream weighting option is given by (Huyakorn 1976),

$$
\begin{aligned}
& w_{1}=\frac{1}{16}\left[(1+n)\left(3 \beta_{2} n-3 \beta_{2}-2\right)+4\right]\left[(1+\xi)\left(3 \alpha_{1} \xi-3 \alpha_{1}-2\right)+4\right] \\
& W_{2}=\frac{1}{16}\left[(1+n)\left(3 \beta_{1} n-3 \beta_{1}-2\right)+4\right]\left[(1+\xi)\left(-3 \alpha_{1} \xi+3 \alpha_{1}+2\right)\right] \\
& w_{3}=\frac{1}{16}\left[(1+n)\left(-3 \beta_{1}{ }^{n+3 \beta} 1^{+\cdot 2)}\right][i 1+\xi)\left(-3 \alpha_{2} \xi+3 \alpha_{2}+2\right)\right] \\
& W_{4}=\frac{1}{16}\left[(1+n)\left(-3 \beta_{2}{ }^{n+3 \beta_{2}}+2\right)\right]\left[(1+\xi)\left(3 \alpha_{2} \xi-3 \alpha_{2}-2\right)+4\right]
\end{aligned}
$$


were $\alpha_{1}, a_{2}, B_{1}$ and $B_{2}$ are weighting factors for the bottom, top, right and left sides, respectively, of the element $e$.

The derivatives of $W_{i}$ 's with respect to $x$ and $y$ in terms of local coordinates are given by Eqs. (22) and (23) replacing $\mathrm{N}_{\mathbf{i}}$ 's with $H_{i}$ s. The derivatives of $H_{i}$ 's with respect to $\xi$ and $n$ are given by the following equations (Huyakorn 1976):

$$
\begin{aligned}
& \frac{\partial W}{\partial \xi}=\frac{1}{8}\left[(1+n)\left(3 \beta_{2} n-3 \beta_{2}-2\right)+4\right](3 x \xi-1) \\
& \frac{\partial H_{2}}{\partial \xi}=-\frac{1}{8}\left[(1+. .)\left(3 \beta_{1} n-3 \beta_{1}-2\right)+4\right]\left(3 \alpha_{1} \xi-1\right) \\
& \frac{\partial W_{3}}{\partial \xi}=-\frac{1}{8}\left[(1+n)\left(-3 \beta_{1}{ }^{n+3 \beta_{1}}+2\right)\right]\left(3 \alpha_{2} \xi-1\right) \\
& \frac{\partial W_{4}}{\partial \xi}=\frac{1}{8}\left[(1+n)\left(-3 \beta_{2} n+3 \beta_{2}+2\right)\right]\left(3 \alpha_{2} \xi-1\right) \\
& \frac{\partial W}{\partial \eta}=\frac{1}{8}\left[(1+\xi)\left(3 \alpha_{1} \xi-3 \alpha_{1}-2\right)+4\right]\left(3 \beta_{2} n-1\right) \\
& \frac{\partial W_{2}}{\partial n}=\frac{1}{8}\left[(1+\xi)\left(-3 \alpha_{1} \xi+3 \alpha_{1}+2\right)\right]\left(3 \beta_{1} n-1\right) \\
& \frac{\partial W_{3}}{\partial \eta}=-\frac{1}{8}\left[(1+\xi)\left(-3 \alpha_{2} \xi+3 \alpha_{2}+2\right)\right]\left(3 \beta_{1} 11-1 ;\right. \\
& \frac{\partial W_{4}}{\partial \eta}=-\frac{1}{8}\left[(1+\xi)\left(3 \beta_{2} \xi-3 B_{2}-2\right)+4\right]\left(3 \alpha_{2} n-1\right)
\end{aligned}
$$

Referring to the mass matrix $\left[M_{i j}\right]$ in Eq. (33), une notes that this is a un it matrix if the finite difference formulation is used in the spatial discretization. Hence by suttable scailng, the mass matrix 
may be reduced to a finite differences equivalent if it is lumped (Clough 1971). The lumping of mass matrix in many instances results in more accurate solution than no lumping, especially when it is used in conjunction with central or backward time marching (Gureghian et al. 1978). Therefore, an option is provided for the lumping of the mass matrix, $\left[M_{i j}\right]$. More explicitly, $\left[M_{i j}\right]$ will be lumped according to the foliowing formulae:

$$
\begin{aligned}
& M_{i j}=\sum_{j=1}^{4} \int_{-1}^{1} \int_{-1}^{1} W_{i} h N_{j} d A \\
& M_{i j}=0 \text { if } i \neq j
\end{aligned}
$$

\section{II.2.3 Time Marching Methods}

Two most important advantages in finite element approximation over the finite difference approximation are its easiness to hand le the complex boundaries and the normal derivatives therein. In the time dimension, llone of these advantages is evident. Thus, the simple and easy finite difference methods are normally used in approximating the time derivative and in marching the solution. Three optional time marching methods are used in this report. The first one is the central or Crank-Nicolson formulation:

$$
\begin{gathered}
{\left[M_{i j}\right]\left(\left\{c_{j}\right\}_{t+\Delta t}-\left\{c_{j}\right\}_{t}\right) / \Delta t+\frac{1}{2}\left[s_{i j}\right]\left(\left\{c_{j}\right\}_{t+\Delta t}+\left\{c_{j}\right\}_{t}\right)+} \\
+\left\{D_{i}\right\}+\left\{Q_{i}\right\}=0
\end{gathered}
$$


where $\left[M_{i j}\right],\left[S_{i j}\right],\left\{D_{i}\right\}$ and $\left\{Q_{i}\right\}$ are evaluated at time, $t+\Delta t / 2$. The second option is the backward difference formulation:

$$
\left[M_{i j}\right]\left(\left\{c_{j}\right\}_{t+\Delta t}-\left\{c_{j}\right\}_{j}\right) / \Delta t+\left[s_{i j}\right]\left\{c_{j}\right\}_{t+\Delta t}+\left\{D_{i}\right\}+\left\{Q_{i}\right\}=0
$$

where $\left[\boldsymbol{M}_{\mathbf{i j}}\right],\left[S_{\mathbf{i j}}\right],\left\{\boldsymbol{D}_{\mathbf{i}}\right\}$ and $\left\{Q_{\mathbf{i}}\right\}$ are evaluated at time, $t+\Delta t$. The third option is the mid-difference formulation (Gureghian et al. 1978) in wich the value of the unknown $c_{j}$ 's are assumed to vary linearly with time in the time interval, $\Delta t$. The recurrence formula for this method is:

$$
\left(2\left[M_{i j}\right] / \Delta t+\left[s_{i j}\right]\right)\left\{c_{j}\right\}_{t+\Delta t / 2}-\frac{2}{\Delta t}\left[M_{i j}\right]\left\{c_{j}\right\}_{t}+\left\{D_{i}\right\}+\left\{Q_{i}\right\}=0
$$

and

$$
\left\{c_{j}\right\}_{t+\Delta t}=2\left\{c_{j}\right\}_{t+\Delta t / 2}-\left\{c_{j}\right\}_{t}
$$

where $\left[M_{i j}\right],\left[S_{i j}\right],\left\{D_{i}\right\}$ and $\left\{Q_{i}\right\}$ are evaluated at time, $t+\Delta t / 2$. In fact, Eqs. (43) through (45) can be written in a general form as:

$$
\left[C_{i j}\right]\left\{c_{j}\right\}=\left\{R_{i}\right\}-\left\{Q_{i}\right\}
$$




\section{2.4 Assembling of the Element Matrices}

Equation (47) is written for an element and t'en assembled over all the elements in the region of interest to yield a global matrix equation:

$$
\left[T_{i j}\right]\left\{c_{j}\right\}=\left\{X_{i}\right\}-\left\{B_{i}\right\}=\left\{Y_{i}\right\}
$$

During the assembling process, the columan matrix $\left\{Q_{i}\right\}$ resulting from the boundary conditions is ignored since they would cancelled each other except on the boundary elements. After the assembling, the toundary conditions are then incorporated in Eq. (48) to be discussed in the following.

\section{II.2.5 Application of Boundary Conditions}

At nodes where Dirichlet boundary conditions are applied, an identity equation is generated for each node and included in the matrices of Eq. (48). The generation of identity equation follows the procedure described in the section of hydrodynamics.

Boundaries on wich the Neumarn boundary conditions are imposed are either the flow-through boundaries or the water-land interfaces. For the latter case, the entries $\left\{B_{1}\right\}$ is zero and no boundary conditions have to be applied. For the former case, the corresponding entries in $\left\{B_{i}\right\}$ are then linear function of the unknown concentration. Such terms must therefore be incorporated into the $\left[T_{i f}\right]$ matrix in Eq. (48). Substituting Eq. (30) into Eq. (38), one obtains: 


$$
\left\{Q_{i}\right\}=\left[E_{i j}\right]\left[c_{j}\right\} \quad i=1,2 \text { and } j=1,2
$$

where

$$
E_{i j}=\int_{B_{e}} W_{i}\left(U n_{x}+V n_{y}\right) K_{j} d B
$$

For the backward difference and mid-difference time marching algorithm, $\left[E_{i j}\right]$ after assembly over all boundary elements of $B_{2}$ is added to the matrix $\left[T_{i j}\right]$. For the central difference time marching algorithm, half of $\left[E_{i j}\right]$ after assenbly over the boundary elements is added to the matrix $\left[T_{i j}\right]$ while the other half is multiplied by $\left\{c_{j}\right\}$ of the previous time and then substracted from $\left\{x_{i}\right\}$.

Boundaries on which the mixed type boundary conditions, Eq. (31), are imposed, of course, yield concentration-independent entries in the colum matrix $\left\{Q_{j}\right\}$. These entries are evaluated by direct application of substituting Eq. (31) into Eq. (38) to yield normal element fluxes. This is then followed by assembling over all boundary elements of $B_{3}$ to yield a global colum matrix $\left\{B_{i}\right\}$. The results are then subtracted from the $\left\{X_{i}\right\}$ to form $\left\{Y_{i}\right\}$.

\section{II.2.6 Solution of Assembled Equation}

Gaussian elimination algorithm is used to solve the matrix equation, Eq. (48). 


\section{II.2.7 Optional Numerical Schemes}

Depending on the type of weighting functions (Galerkin or upstrean weighting), the methods of time marching (Crank-Micolson, or backward difference, or mid-difference), and the treatment of the mass matrix (luming or no-luming), there are twelve optional fin ite element numerical schemes reported in the present model as show in Table 1. 
Table 1. Optional finite element schemes

\begin{tabular}{|c|c|c|c|c|c|c|c|}
\hline & \multicolumn{3}{|c|}{ Time Marching Methods } & \multicolumn{2}{|c|}{ Weighting Function } & \multicolumn{2}{|c|}{ Mass Matrix Lumping } \\
\hline & Crank-Nicolson & Backward & Mid-difference & Galerkin & Upstream & No & Yes \\
\hline 1 & $x$ & & & $x$ & & $x$ & \\
\hline 2 & $x$ & & & & $x$ & $x$ & \\
\hline 3 & $x$ & & & $x$ & & & $x$ \\
\hline 4 & $x$ & & & & $x$ & & $x$ \\
\hline 5 & & $x$ & & $x$ & & $x$ & \\
\hline 6 & & $x$ & & & $x$ & $x$ & \\
\hline 7 & & $x$ & & $x$ & & & $x$ \\
\hline 8 & & $x$ & & & $x$ & & $x$ \\
\hline 9 & & & $x$ & $x$ & & $x$ & \\
\hline 10 & & & $x$ & & $x$ & $x$ & \\
\hline 11 & & & $x$ & $x$ & & & $x$ \\
\hline 12 & & & $x$ & & $x$ & & $x$ \\
\hline
\end{tabular}




\section{COMPUTER IMPLEMEMTA:IOW}

The computer progran consists of the thirteen (13) different subprograms shom in fig. 3. As is implied by its naare, the routine MAIN performs the control function for the program. In it, input-output operations are coordinated with priaary and support computations as the calculation is stepped sequentially over the time variable. All input data are read in through subroutine DATAIN. MAIN then calls two subrutines HYORON and POLLU.

The subroutine tryoror sets up a system of algebraic equations for the stream function. In doing so, it has to call subroutine Q4H: which calculates the element matrix, $\left[S_{i j}\right]$, and the element load vector, $\left\{\mathrm{O}_{j}\right\}$. After the setup of the system of equatons, Dirich let boundary conditions are applied to the nodes with prescribed stream functions. The nodes on one island are set equal to each other. Subroutine SOLVE is then called to solve the resulting system for the stream function at all nodal points. DERIF is finally called by HYOROM to compute the partial derivatives of the stream function with respect to $x$ and $y$, respectively. This subroutine first call Q4DI to evaluate the element matrix and load vector wich are resulted from applying the Galerkin finite element method to Eq. (2). It then assemble the element matrix and load vector to form a global matrix and load vector. No boundary conditions are required in this subroutine since no spatial derivat?ves are involved in the unknowns. Finally, DERIF calls SOLVE to vield the solutions of the partial derivatives of stream function at all nodal points, thus giving the flow rate components, $U$ and $V$. 
OANL-OMG ra-1e27s

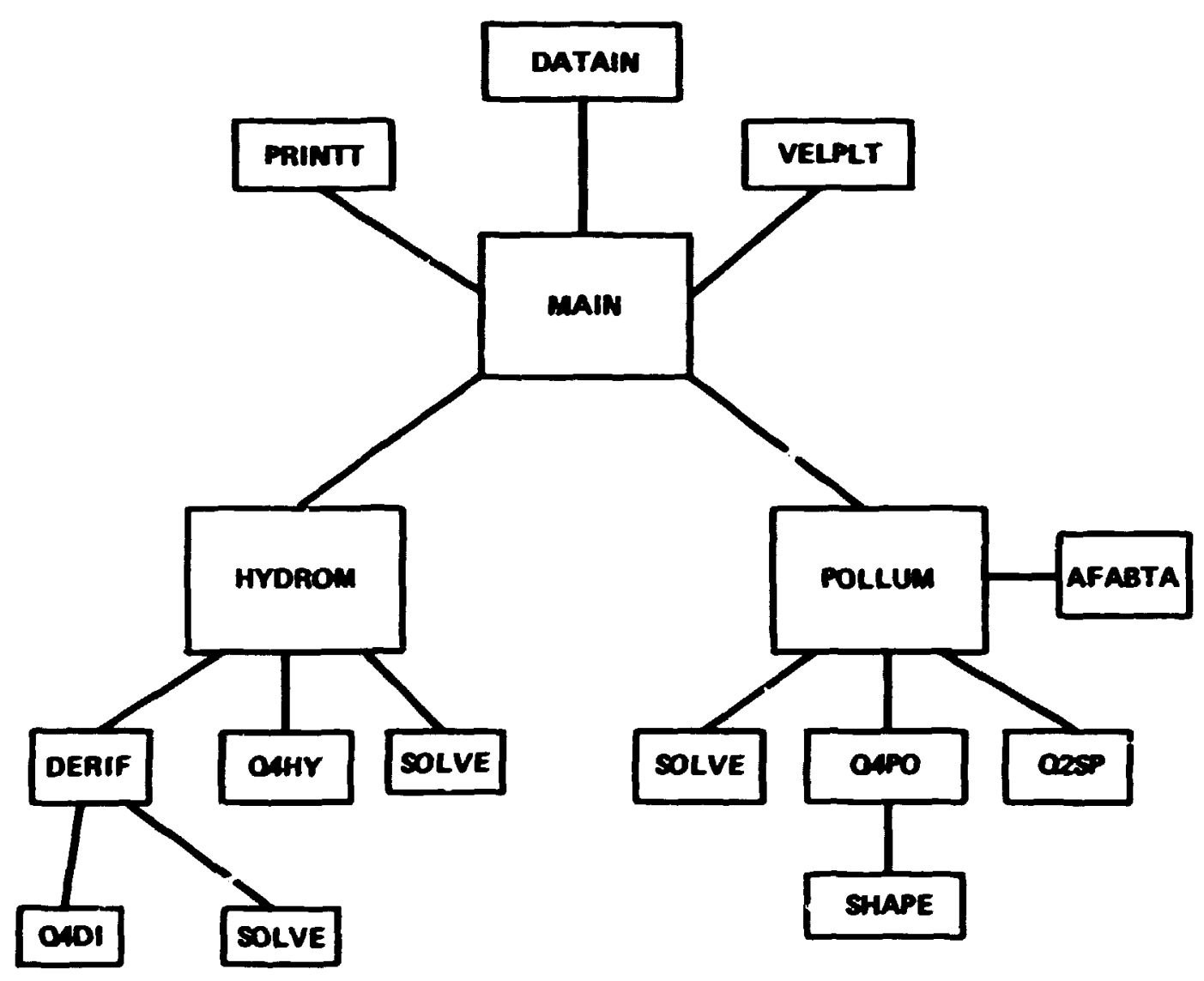

Fig. 3. Subroutine of SIMFE. 
The resulting hydrodynamic variables from HrDROA are common-blocked thrcusth MIN to the PoLLCM, wich is called by the MAIN to simulate the distribution of pollutants. The main function of PoulM is to assemble the element matrices, $\left[\mathrm{H}_{\mathbf{i j}}\right]$ and $\left[\mathrm{S}_{\mathbf{i j}}\right]$, and the load vector, $\left\{D_{i}\right\}$ over all the elements to form the global matrix $\left[T_{i j}\right]$ and load vector $x_{i}\left[M_{i j}\right],\left[S_{i j}\right]$, and $\left[0_{i}\right\}$ are calculated by the subroutine Q4PO. The boundary conditions are also applied in the poLUM. In the segment that incorporates the boundary conditions, Q2SP is called to campute the element flux and the boundary element atrix, $\left\{Q_{i}\right\}$ and $\left\{E_{i j}\right\}$. A subroutine AFABTA is called from PoLlM to compute the weighting factors $a_{1}, a_{2}, \beta_{1}$ and $\beta_{2}$. These four factors are needed in the subroutine SHAPE to evaluate the upstream meighting functions and their derivatives. SHAPE is called by Q4PO. 


\section{RESULTS}

In this chapter, two simulations are made. The first one is applied to an ideal system to test the code. The second one is applied to the Prairie Island, Mississippi River, wich typifing a class of problems that SIMFE may be applied. Guidance for preparing the input data is given in Appendix B. The source progran listing is given in Appendix E.

\section{IV.1 Ideal Systea Application}

The ideal system is consisting of a straight channel with 150 meters wide and 270 meters long and 3 meters deep. The region is covered by 45 elements and 60 nodal points as in Fig. 4. Assume a flow rate of $90 \mathrm{~m}^{3} \mathrm{~s}^{-1}$ passes through the channel at its entrance. The velocity field as simulated by SIMFE is show in Fig. 5. Uniform velocity of $0.2 \mathrm{~ms}^{-1}$ is obtained as expected. For one case, constant concentration is assumed at all six nodal points at the channel entrance. Computer printouts in Appendix $C$ show that the normalized concentration is accurate to six digits. Thus, the accuracy of the model is assured and the internal consistancy of the computer code is verified. For another case, constant concentration is assumed only at mdal points 3 and 4 wile zero concentration is maintained at nodal points, 1, 2, 5, and 6 . The iso-concentration line for this latter case is shown in Fig. 6. The results are corpared with those obtained by analytical solution (Yeh and Tsai 1976) denoted by the symbol - in Fig. 6. The alnost identical agreenent partially validates the model. 
ORNL- DWG 78-19274

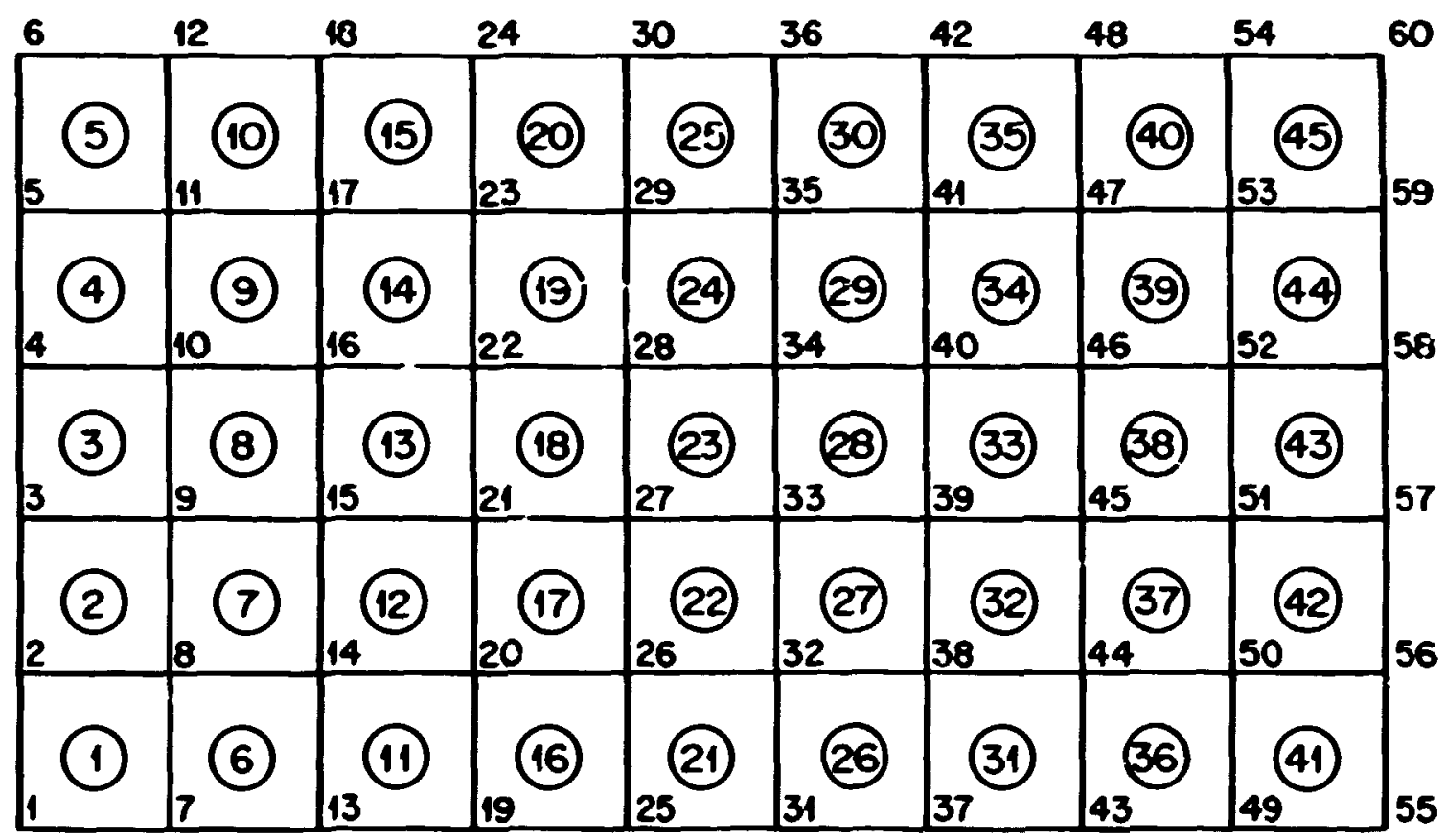

Fig. 4. Finite element discretization of an ideal channel. 


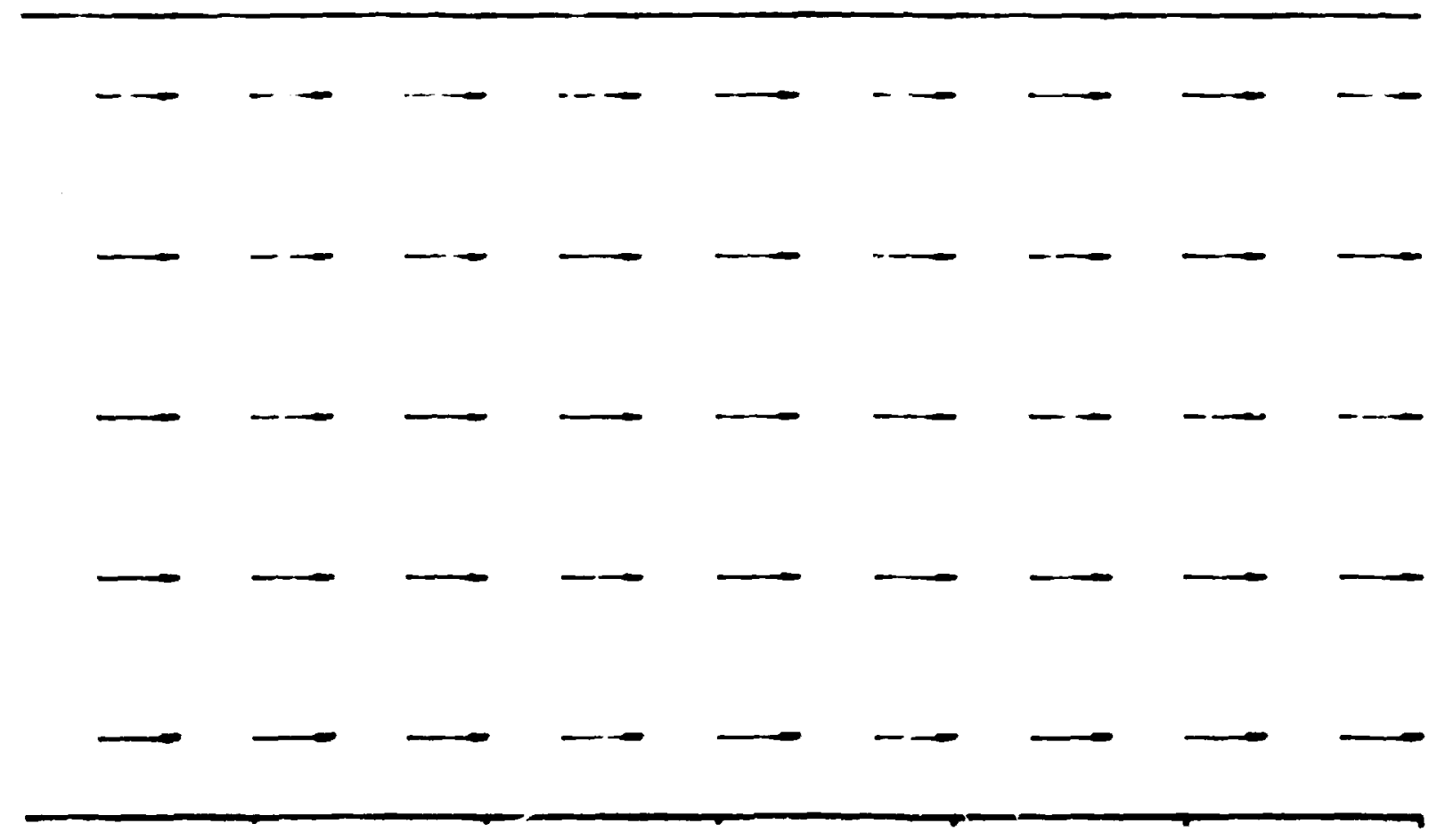

Fig. 5. Velocity vector field in an ideal system. 
ORNL-DWG 78-19273R

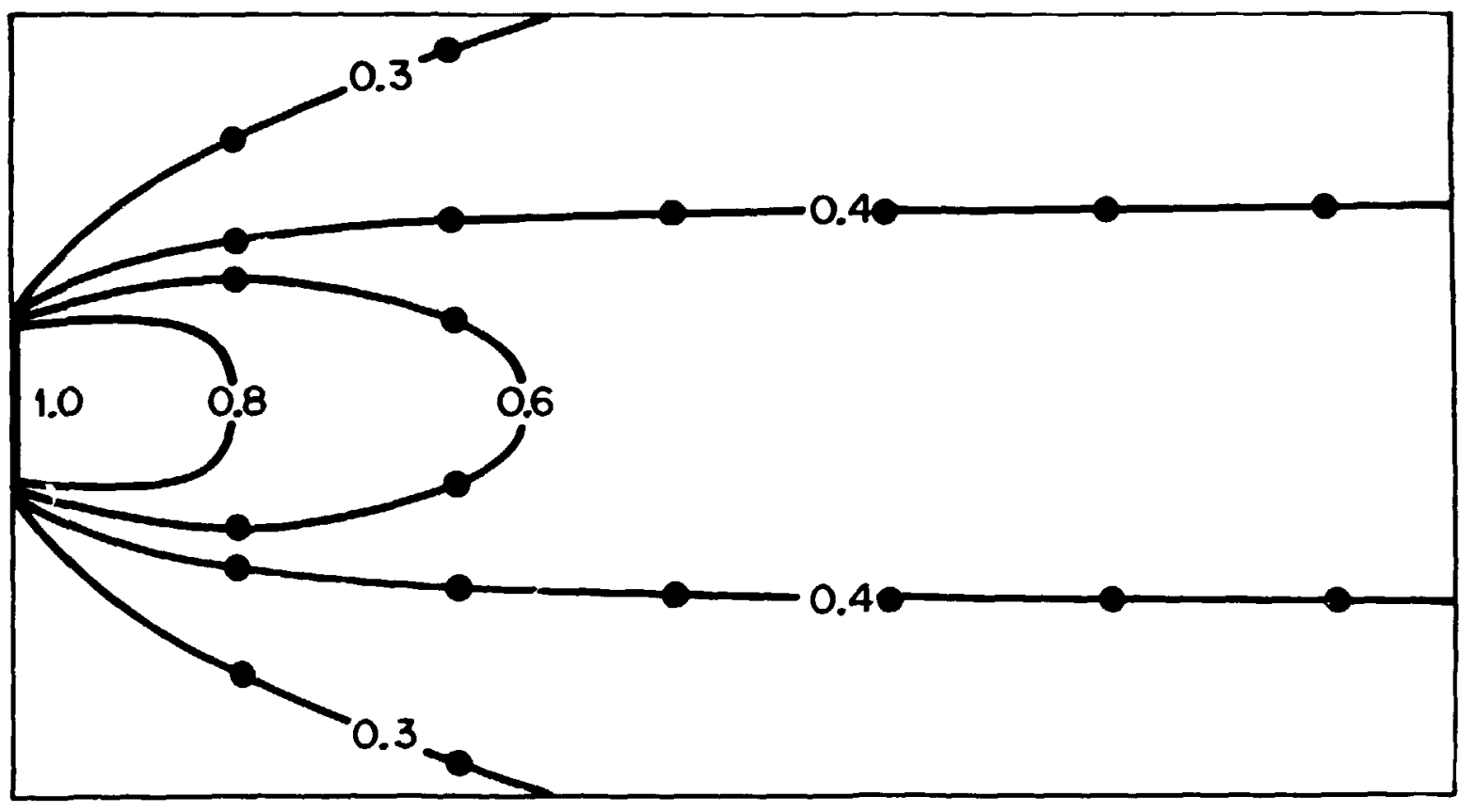

Fig. 6. Normalized iso-concentration as predicted by SIMFE (_ _ ) and analytical solution $(\bullet)$. 


\section{IV.2 Prairie Island Application}

The Prairie Island vicinity area is enclosed on the west by the river bank, on the east by Prairie Island. It extends to Sturgeon Lake on the north and to Barney's point on the south as shown in Fig. 7. During the month of Jure, 1976, a typical continuous flow rate of 13.7 $\mathrm{m}^{3} \mathrm{~s}^{-1}$ is discharged to the region through discharge channel and 31 $\mathrm{m}^{3} \mathrm{~s}^{-1}$ is returned to the plant through intake canal. For this month, a flow of $23.8 \mathrm{~m}^{3} \mathrm{~s}^{-1}$ is drawn from Sturgeon Lake passing EF to the region, $4.0 \mathrm{~m}^{3} \mathrm{~s}^{-1}$ and $18.8 \mathrm{~m}^{3} \mathrm{~s}^{-1}$ of flows are returned to the Mississippi River through sections $A B$ and $C D$, respectively. These inflows and outflows are obtained according to the flow net analys is (Stefan and Anderson 1977).

The area of interest is discretized by $9 i$ elements arid 127 nociuii points as in Fig. 7. Using the above inflow and outfliw information a long with the goometry and bathymetry of the impoundment: the hydrodynamic model generates the flow field as shown in Fig. 8.

Assume that the discharge from the channel is maintained at a constant Dissolved Oxygen (DO) concentration of $1.00 \mathrm{ppm}$. A value of Do depletion rate of $3.2 \times 10^{-5} \mathrm{~s}^{-1}$ and typical dispersivities of $a_{L}=a_{T}=99 \mathrm{~m}$ are used to represent the physical pararraters in the system. The iso-concentration line as simulated by the pollutant transport model is shown in Fig. 9. These iso-lines are consistent with the flow pattern in iggure 8. The irput and output data for this simulation is given in Appendix $D$.

It must be cautioned that the model should be verified and calibrated against all the system parameters, such as $K_{m}, a_{T}, a_{L}$, etc., before it is applied to a practical problem. 


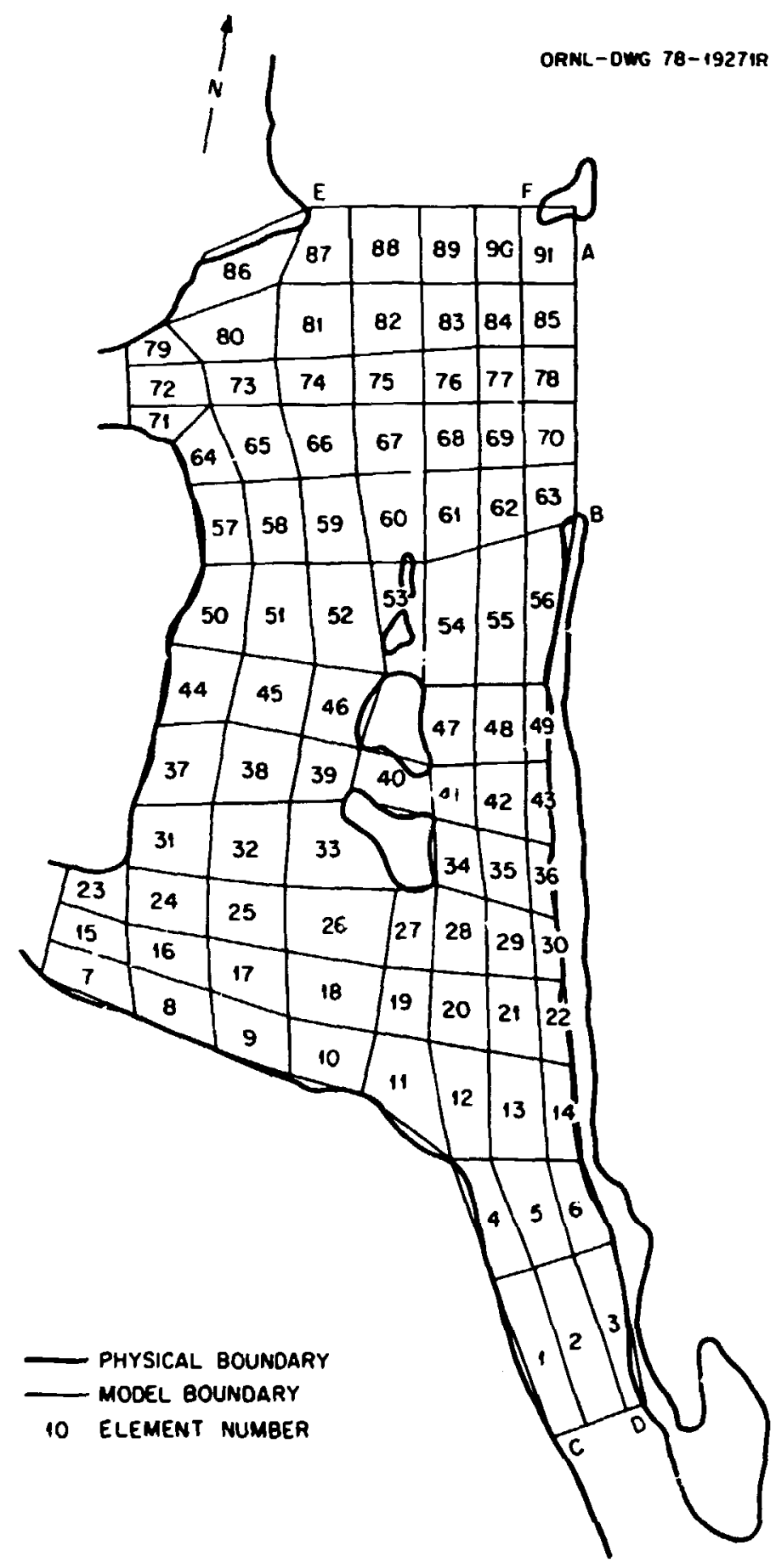

Fig. 7. Finite element directization of Prairie Island. 
ORRL-5522

38

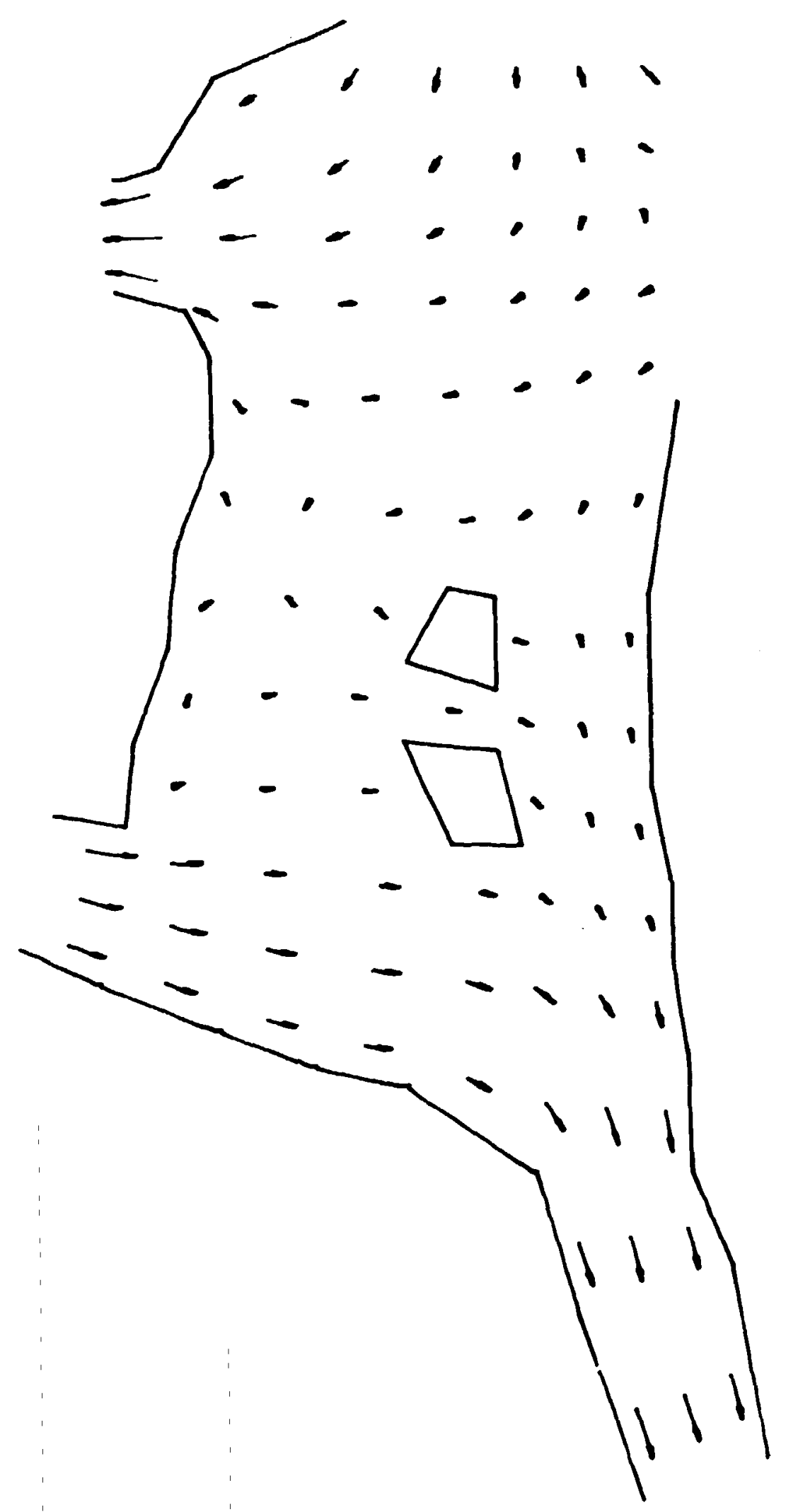

Fig. 8. Flan rate vectors as predicted by the model. 
39

RQMIL-5522

ORNL-DWG $78-2$ CORR

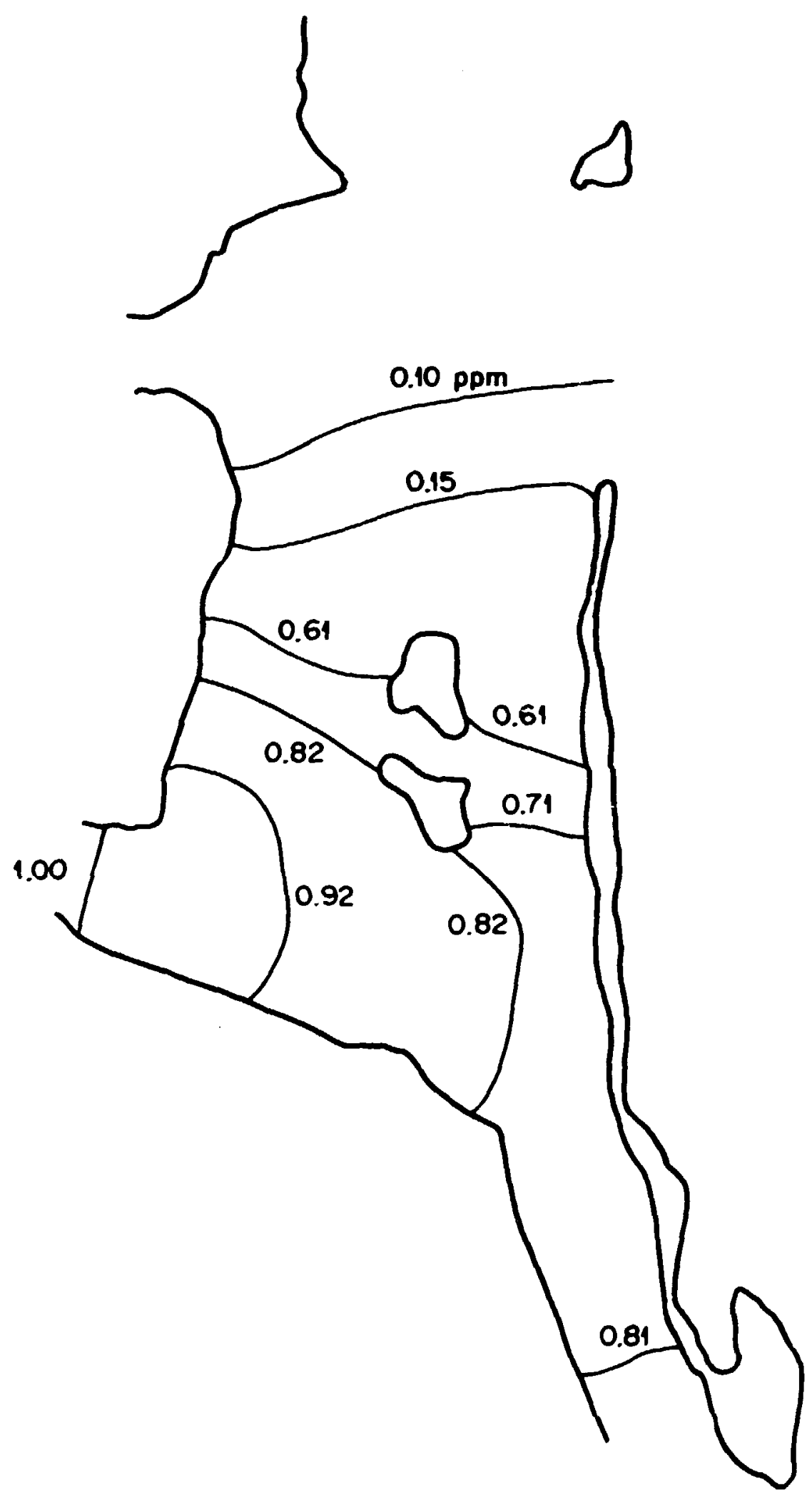

Fig. 9. Isu-concentration lines of Dissolved Oxygen (DO) at Prairie as predicted by the model. 


\section{v. NOTATION}

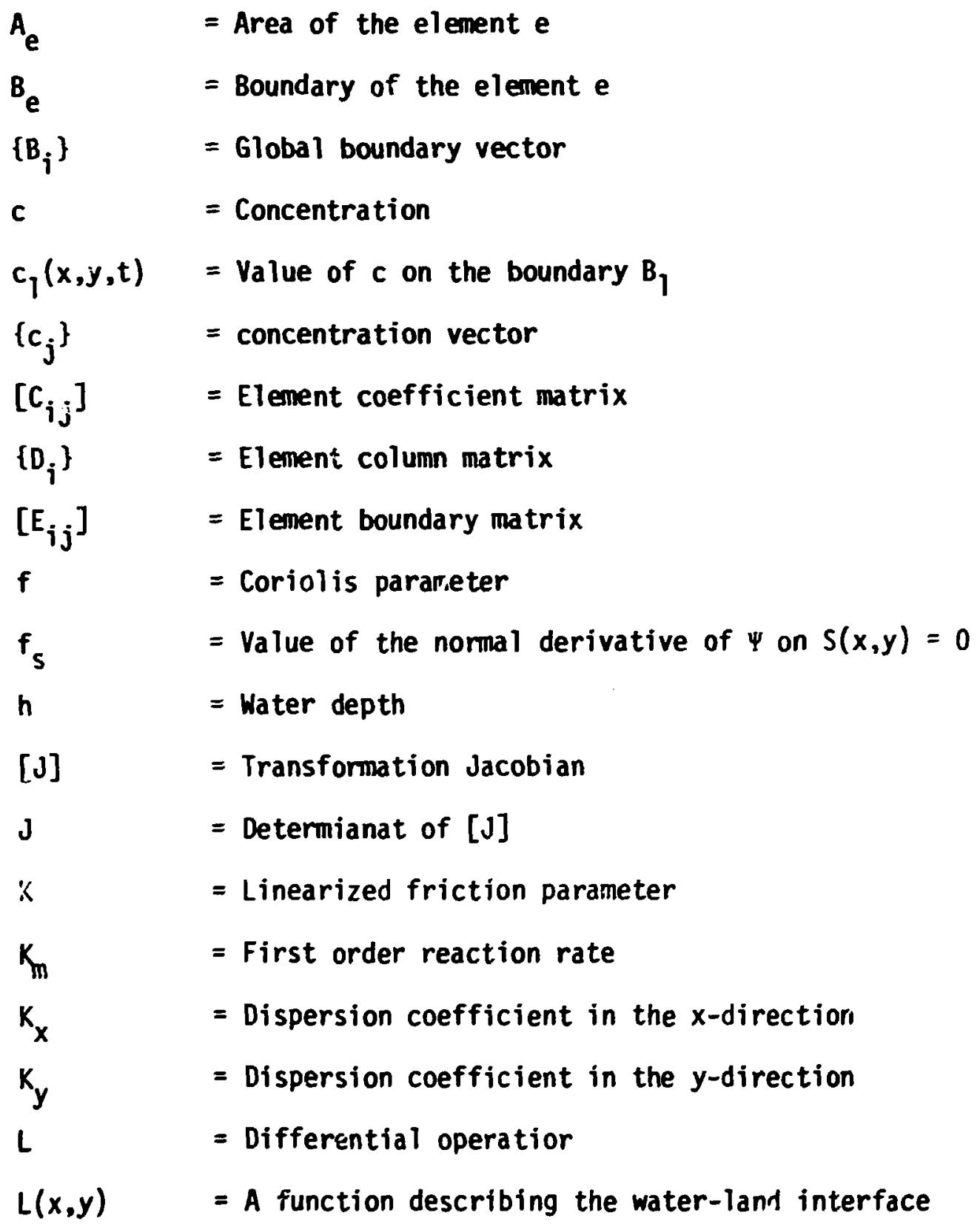


M

$\left[\mathbf{H}_{\mathbf{i j}}\right]$

$N_{i}$

$n_{x}$

$n_{y}$

$q_{1}(x, y, t)$

$\left\{Q_{\mathbf{i}}\right.$

$\mathbf{R}$

$R_{\text {e }}$

$\left\{R_{i}\right\}$

$S(x, y)$

$\left[S_{\mathbf{i j}}\right]$

$\mathbf{t}$

$\left[T_{\mathbf{i j}}\right]$

$\Delta t$

$\mathbf{U}$

$\overline{\mathbf{u}}$

V

$\bar{v}$

$u_{i}$

$x$

$x_{i}$

$\left\{x_{i}\right\}$

= Artificial source or sink of pollutant mass

= Element mass matrix

= Base function at nodal point $i$

$=$ Directional cosine in the $x$-direction

$=$ Directional cosine of a curve in the $y$-direction

$=$ Total flas of the pollutant through the boundary $B_{3}$

= Element boundary colum matrix

= The region of interest

$=$ Region of the element $e$

= Modified element column matrix

= A function describing the open water boundaries

= Element stiff matrix

$=$ Time

= Global coefficient matrix

= Time step

$=X$-component flow rate, or a velocity scale

= Vertically averaged $x$-component velocity

$=\gamma$-component flow rate

= Vertically averaged $y$-component velocity

= Weighting function of nodal point $\mathfrak{i}$

= ine of the global spatial coordinates

= Global $x$-coordinate of nodal point $i$

= Global load vector before applying boundary condition 


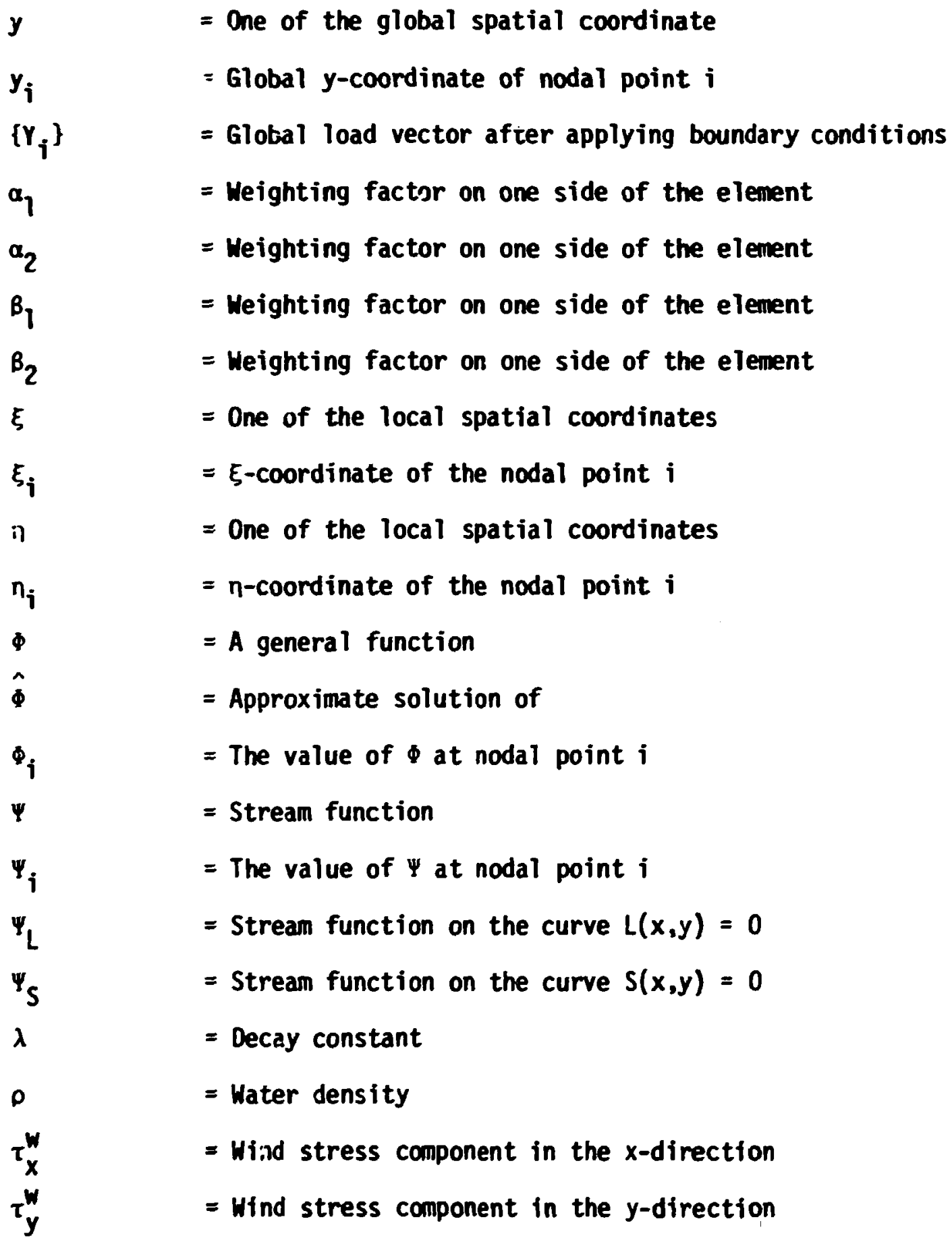




\section{REFERENCES}

1. Abbott, M. B., et al. 1975. Systems Modeling of Stratified Fluids, Symposium on Modeling Techniques, Modeling 75, San Francisso, California.

2. Christodou lou, G. C., J. J. Connor, B. R. Pearce. 1976. Methematical Modeling of Dispersion in Stratified Waters, Report No. MITSG 76-14, MIT, Cambridge, Mass.

3. Clough, R. W. 1971. Analysis of Structural Vibrations and Dynamic Response, in Recent Advances in Matrix Methods of Structural Analys is and Design, R. H. Gallagher, y. Yamado, and J. T. Oden (eds.), Univeristy of Alabama Press, Huntsville, Alabama.

4. Gureghian, A. M., D. S. Ward, and R. H. Cleary, 1978. A Finite Element Model for the Migration of Leachate from a Stationary Landfill in Long Island, ilew York, Submitted for Publication.

5. Hutton, S., and D. Anderson. 1971. Finite Element Method: A Galerkin Approach, J. Eng. Mech., ASCE. Vo 1. 96, 1503-1519.

6. Huyakorn, P. S. 1976. An Upwind Finite Element Scheme for Imporved Solution of the Convective-Diffusion Equation, Research Report No. 76-WR-2, Dept. of Civil Engineering, Princeton University, Princeton, New Jersey.

7. Lanb, Sir Horace. 1932. Hydrodynamics. Dover Publications, New York, New York. pp. 738.

8. Lee, K. K. 1972. Wind-induced and Thermally-induced Currents in Great Lakes, Water Resources Research, Vol. 8, No. 6. 
9. Leendertse, J. J. 1970. A Water-quality Simulation Model for Hell-mixed Estuaries and Coastal Seas: Yol. 1, Principles of Computations, RH-6230-RC, Rand Corporation, Sasta Monica, California.

10. Liggett, J. A. 1975. Stratified Lake Circulation Calculations by the Finite Element Method. Proceedings of XVI I.A.H.R. Congress, Sao Paulo.

11. Schlichting, H., and J. Kestin. 1968. Boundary-layer Theory. McGraw-Hill Book Company, New York. pp. 747.

12. Simons, T. J. 1973. Development of three-dimensiona? numer ical models of the Great Lak'zs. Scientific Series, Mo. 12, Canada Center for Inland Lakes, Burlington, Ontario.

13. Stefan, H., and K. Anderson. 1977. Analysis of Flow Through Sturgen Lake and Backwater Channel of Mississippi River Pool No. 3 near Red Wing, Minnesota. Project Report No. 165, St. Anthony Falls Hydraulic Laboratory, University of Minnesota, Minneapolis, Minnesota.

14. Kang, J. D., and J. J. Connor. 1975. Mathematical Modeling of Near Coastal Circulation, Report No. MITSG 75-13, MIT, Cambridge, Mass.

15. Yeh, G. T. 1976. Tro-dimensional Hydrodynamic Mode1, Computer Progran Development and Documentation, Report No. EN-122, Stone and Webster Engineering Corporation, Boston, Mass.

16. Yeh, G. T. 1980 . Transport and Dispersion of Pollutants in Surface Impoundments: A Finite Difference Mode1. ORNL-5521. Oak Ridge National Laboratory, Oak Ridge, Tennessee. 
17. Yeh, 6. T., A. P. Yena, and F. H. Lai. 1973. Unsteady Texperature Prediction for Cooling Ponds, Water Resources Research Yol. 9, No. 6 .

18. Yeh, 6. T., and Y. J. Tsai. 1976. Analytical three-dimensional trasient wodeling of effluent Jischarges, Mater Resources Researcl Vol. 12, No. 3. 533-540. 
Entr-5522

VII. APPENDICES 


\section{APPENDIX A. APPLICABILITY OF THE MSOEL}

The applicability of the present model lies on the assumptions made for the hydrodynamic mode! in Section II.1. While assumptions (1) through (3) are obvious, assumptions (4) through (6) require some elaboration. To discuss those assumptions, one must refer to he govern ing equations from which Eq. (1) is derived. Under assumptions (1) through (3), the equations of motion are obtained by taking the ensemble average of the Havier-Stakes equations and witten as follows:

$$
\begin{gathered}
\frac{\partial u}{\partial t}+u \frac{\partial u}{\partial x}+v \frac{\partial u}{\partial y}+w \frac{\partial u}{\partial z}=f v-\frac{1}{\rho} \frac{\partial p}{\partial x}+\frac{1}{\rho} \frac{\partial \tau}{\partial z} \\
\frac{\partial u}{\partial t}+u \frac{\partial v}{\partial x}+v \frac{\partial v}{\partial y}+w \frac{\partial v}{\partial z}=f u-\frac{1}{\rho} \frac{\partial p}{\partial y}+\frac{1}{\rho} \frac{\partial \tau y z}{\partial z} \\
\frac{\partial p}{\partial z}+\rho g=0
\end{gathered}
$$

were $u, v$, and $w$ are the ensemble average velocity components in the $x-, y-$, and $z$-derections, respectively; $p$ is the pressure; $g$ is the gravitational acceleration; $f$ is the eoriolis coefficient; $t$ is the time; and $\tau_{x z}$ and $\tau_{y z}$ are the combined apparent and viscous stress components in the $x$ - and $y$-directions, respectively (Schlichting and Kestin 1968). It must be noted that terms $\partial \tau_{x x} / \partial x, \partial \tau_{x y} / \partial y$ and $\partial \tau_{y x} / x x, \partial \tau_{x} / \partial y$, in Eqs. (A1) and (A2), respectively, have been onitted because they are small compared to terms, $\partial \tau_{x z} / \partial z$ and $\partial \tau_{y z} / \partial z$, respecicively.

The equation of continuity of an incompressible fluid mass may be witten as: 


$$
\frac{\partial u}{\partial x}+\frac{\partial v}{\partial y}+\frac{\partial w}{\partial z}=0
$$

The number of unknowns in Eqs. (AI) through (A4) exceeds the number of equations for the problem. The problem can be closed by relating the stress components, $\tau_{x z}$ and $\tau_{y z}$ to the velocity components, $u$ and $v$ through the concept of the eddy visocity. For the present problem, this can be written as

$$
\tau_{x z}=\rho v_{e} \frac{\partial u}{\partial z}
$$

and

$$
\tau_{y z}=\rho v_{e} \frac{\partial v}{\partial z}
$$

where $v_{e}$ is the total vertical eddy viscosity.

Ii has been pninted out (Lamb 1932) that the effects of wind on a water body, to wich Eqs. (A1) through (A6) are applicable, would approach steady state for a time scale, $t_{e}$,

$$
\iota_{e}=4 h^{2} /\left(\pi^{2} v_{e}\right)
$$

In the mean time, it has been shown (Lamb 1932) that the effect of earth rotation on the water body would approach steady for a time scale, $t_{f}$

$$
t_{t}=\frac{h}{\sqrt{v_{e} f}}
$$


A third time scale one has to consider for steady motion is the resident time of the water particle in the water body. This resident time, $t_{Q}$, cari be approximated by:

$$
t_{Q}=\frac{v}{Q}=\frac{h L^{2}}{Q}
$$

where $v$ is the volume of water body under consideration, $Q$ is the total flow-through rate, and $L$ is the representative horizontal length.

If the assumption of steady motion is to be vaiid, the time scales, $t_{F}$ 's for the respectively applied external forces must be greater than those given in Eqs. (A7) through (A9). It can be seen that all conditions presented above can be met fo: most of the surface impoundments. Take for example, a typical value of $v_{e}=100$ $\mathrm{cm}^{2} / \mathrm{sec}\left(0.1 \mathrm{ft}^{2} / \mathrm{sec}\right), \mathrm{h}=500 \mathrm{~cm}(15 \mathrm{ft})$, and $\mathrm{f}=10^{-4} \mathrm{~s}^{-1}$ would yield $t_{e}=17$ minutes and $t_{f}=1.4$ minutes. The time for constant flow operation is normally longer than that given by Eq. (A9). Thus, assumption (4) is a valid one.

The ratio of the convective-inertia force to the turbulent shear stress in Eqs. (A1) and (A2) can be characterized by a modified Reynolds number, $R_{N}^{\star}$.

$$
R_{N}^{\star}=\frac{U_{s} h}{v_{e}} \frac{h}{L}
$$

where $U_{S}$ is a representative velocity scale. This characterization is made based on the analysis of relative magnitude of order of the convective-inertia and turbulent shear stress. If this $R_{N}^{\star}$ is much 
less than unit, then assumption (5) is valid. inde $: d, R_{N}^{\star}$ is much less than unit for most of the surface impoundments. Expressed in the C. G. S. Un ir. $U_{S}$ is in the order of $10^{\circ}, h$ is in the order of $10^{2}$, and $\nu_{e}$ is in the order of $10^{2}$. Thus, $R_{N}^{*}$ is in the order of $\mathrm{h} / \mathrm{L}$, which is much smaller than un it for practically all surface impoundments. Hence, assumption (5) is a va?id one.

The linearization of the botcon stresses results in a mathenatical simplification of analysis. It is justifiable for small values of velocity in a typical surfäce impoundment (Simon 1973). 
APPENDIX B. DATA INPUT GUIDE

CARD GROUP I

TITLE

CARD GROUP II

iNP

NEL

NTI

KVEL

KBY

KSOS

KSTR

ITRANS

MREAD

IWET

ILUMP

IMID
Format (20A4)

= Any characters on column $1-80$

Format (16I5)

= Total numbers of nodal points

= Total numbers of elements

= Total numbers of time steps

= velocity input control or hydrodynamic simulation control: $=0$ ior steady state velocity

$=1$ for unsteady state velocity

= Boundary value input control for pollutant mode l:

$=1$ for transient boundary value,

$=0$ for constant coundary value,

$=$ Source/sink input control:

$=0$ for constant source/sink

$=1$ for transient source/sink

$=$ Output control:

$=0$ no output on disk,

$=1$ with output on disk

= Transient simulation control:

$=0$ steady state solution of conceritiation,

$=1$ transient solution for concentration

= veiocity input control, every RREAD steps read velocity from field from hydrodynamic simulation

= Weighting function control:

$=0$ Galerkin wighting function,

$=1$ Upstrean weighting function

$=$ Mass matrix lumping contro1:

$=0$ no lumping

$=1$ lumping

$=$ Tine marching control:

= 0 central or backward difference,

- 1 mid-difference 
CARO GROUP III

OHEGA

DELT

Tmax

DELTMA

CHNG

EPS

CAPO GROUP IV

KPRO

KPR(I)

CARD GROUP $V$

I

I1

HAH (I1)

H(I)

\section{Format (8F10.0)}

$=$ Time meighting paraneter:

$=0.5$ for central difference

$=1.0$ for backwird difference

$=$ Time step size

= Maximum simulation time

= Maxim time step size allowed

$=$ Percentage of tine step changed

$=$ Error allowance for iteration

Format (80I1)

$=$ Line printout control for initial time:

$=0$ print nothing

$=1$ print stream function

$=2$ print siream function and velocity

$=3$ print concentration

$=4$ print concentration and material flux

$=5 p$-int everything

= Same as KPRO but for I-th time step

Format $(I 5, F 5.0,3 F 10.0, I 5, F 5.0,3 F 10.0)$

$=$ l-th nodal no.

$=$ Initial concentrtion of I-th node

$=\quad X$-coordinate of $I$-th node

$=Y$-coordinate of I-th node

$=$ Il-th nodal no.

$=$ Initial concentration of I1-th node

$=x$-coordinate of 11 -th node

$=Y$-coordinate of IIth node

$=$ Hater depth of I1-th node

= Hater depth of I-th node 
CARO GROUP VI

H

$\operatorname{IE}(M, 1)$

IE $(M, 2)$

$\operatorname{IE}(M, 3)$

IE $(M, 4)$

CAPD GPOUP UII

$\operatorname{ISIDE}(I, 1)$

$\operatorname{ISIDE}(I, 2)$

I SIDE $(I, 3)$

$\operatorname{ISIDE}(I, 4)$

$\operatorname{ISIDE}(I, 5)$

$\operatorname{ISIDE}(I, 6)$
(Format (5I5)

$=$ M-th elewent

$=$ Global nodal no. of the first node of element $M$

$=$ Global nodal no. of the second node of e lement $M$

$=$ Global nodal no. of the third node of element $M$

$=$ Global nodal no. of the fourth node of element $M$

= Global nadal no. of the beginning point of I-th side

= Global nodal no. of the ending point of I-th side

$=$ Element no. of the I-th side

= Local nodal no. of the beginning point of the I-th side

= Local nodal no. of the ending point of the $i$-th side

$=$ Indicator specifying the location of boundary and type of boundary conditions applied:

$=1$ open boundary wish given concentration,

$=2$ open boundary with concentration dependent $B C$,

$=3$ open boundary with zero flux,

$=11$ closed boundary with given concentration,

$=12$ closed boundary with concentration dependent $B C$,

$=13$ closed boundary with zero flux

MSIDE

- Total numbers of sides

CARD GROUP VIII

Card 1

Format ( I5)

NILND

- Total numbers of is lands

Card 2

Format (1615) 


\begin{tabular}{|c|c|}
\hline $\operatorname{MNDS}(I)$ & $=$ Total nunbers of sides of the I-th is land \\
\hline Card 3 & Format (1615) \\
\hline $\operatorname{IILND}(\mathrm{I}, \mathrm{J}, 1)$ & $\begin{array}{l}=\text { Global nodal no. of the beginning point of J-th } \\
\text { side of I-th is land }\end{array}$ \\
\hline $\operatorname{IILNO}(\mathrm{I}, \mathrm{J}, 2)$ & $\begin{array}{l}=\text { Global nodal no. ef the Ending point of the } \\
\text { J-th side of I-th island }\end{array}$ \\
\hline $\operatorname{IILNO}(\mathrm{I}, \mathrm{J}, 3)$ & $=$ Element no. of the J-th side of the I-th island \\
\hline $\operatorname{IILND}(I, \mathrm{~J}, 4)$ & $\begin{array}{l}\text { Local nodal no. of the beginning point of the } \\
\text { J-th side of the I-th island }\end{array}$ \\
\hline $\operatorname{IILND}(I, J, 5)$ & $\begin{array}{l}=\text { Local nodal no. of the ending point of the J-th } \\
\text { side of the I-th is land }\end{array}$ \\
\hline
\end{tabular}

$\begin{array}{ll}\text { AL } & =\text { Longitudinal dispersivity } \\ \text { AT } & =\text { Transverse dispersivity } \\ \text { DD } & =\text { Molecular diffusion coefficient } \\ \text { RK } & =\text { First order reaction rate } \\ \text { RLAMD } & =\text { Decay constant }\end{array}$

CARD GROUP $X$ Format (8F10.0)

$\begin{array}{ll}\text { CORIL } & =\text { Coriolis parameter } \\ \text { RHOW } & =\text { Hater density } \\ \text { CKH } & =\text { Linearized bottom stress coefficient } \\ \text { RHOA } & =\text { Air density } \\ \text { CKA } & =\text { Wind stress coefficient } \\ \text { WIMANG } & =\text { Angle between the } x \text {-coordinate and wind velocity } \\ \text { WINVEL } & =\text { Wind speed } \\ \text { AVU } & =\text { Estimated average current speed }\end{array}$


CARO GROUP XI

BVH(I)

IBVH(I)

MBVH

CARD GROUP XII

$\operatorname{SOS}(I)$

ISOS(I)

nSOS

CARD GROUP YIII

BV (I)

IBV(I)

NBY

\section{MMELIST/BIDVHY}

= Boundary value of strean function of I-th Dirichlet point

= Global nodal mo. of I-th Dirichlet point

= Total nubers of points with given streanfunction values

$=$ Source/sink value of I-th source/sink point

= Global nodal no. of I-th source/sink point

= Total nubers of source/sink points

MAELIST/BADV/

= Given value of concentration of I-th Dirichlet point

= Global nodal no. of I-th point with known concentration

= Total nuber of the points with known concentratic. 


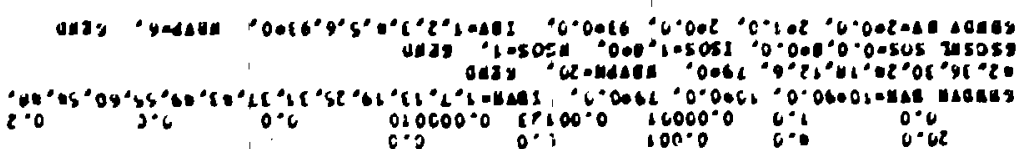
ans, expiase

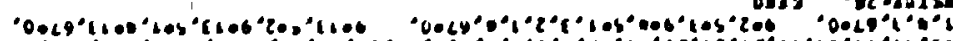

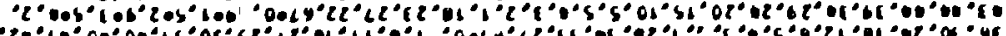
.t.

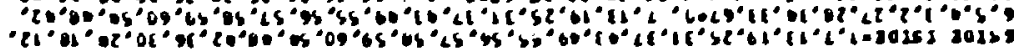

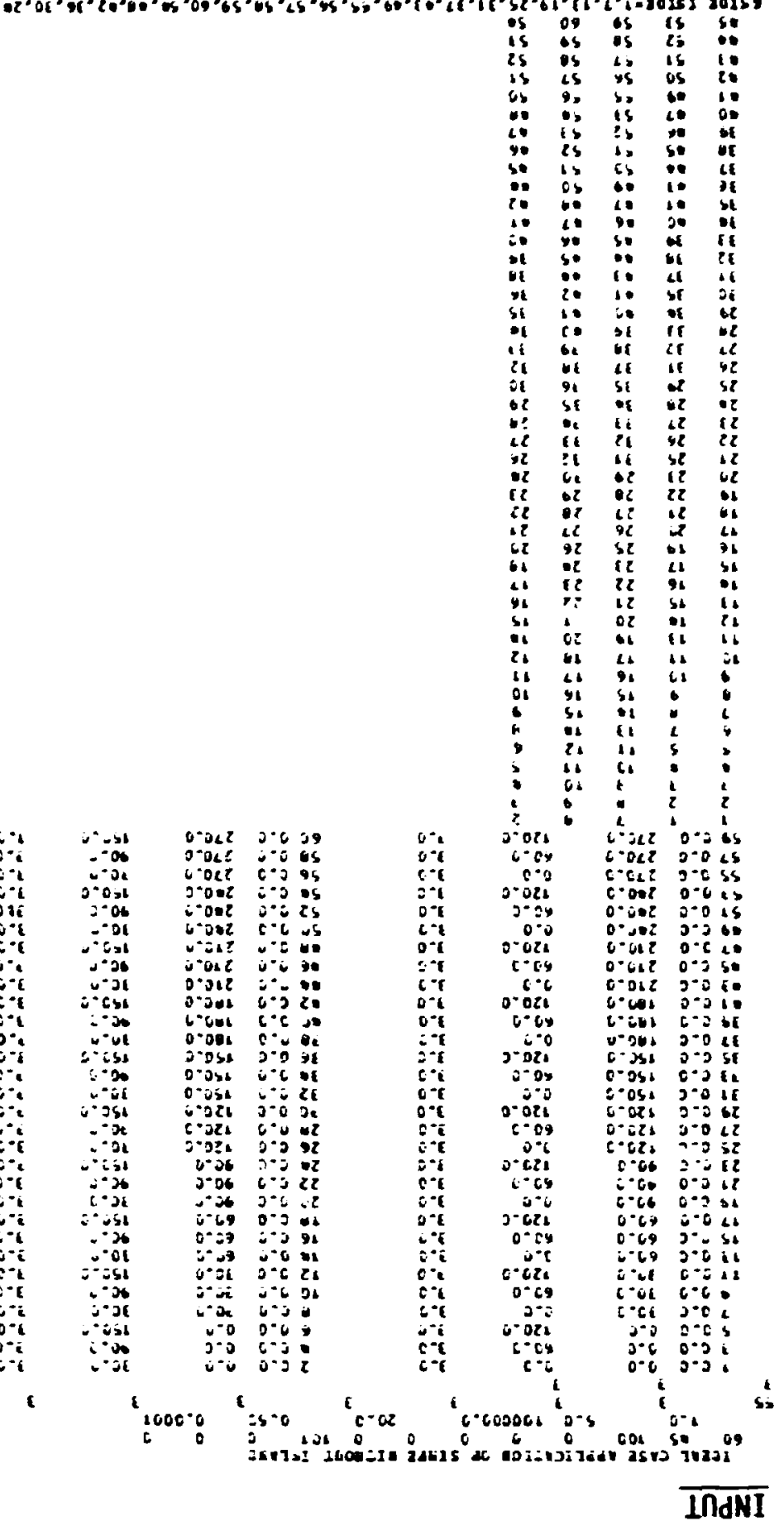

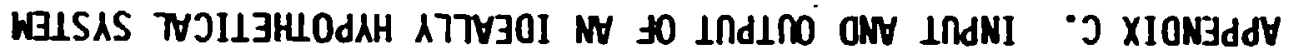




\section{APPËYDIX C. OUTPUT}

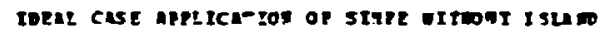

I3rot pote, enstc ensagerets

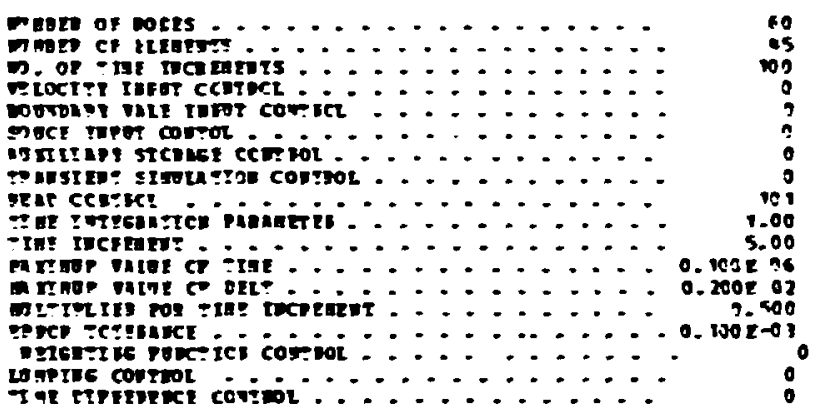

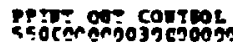

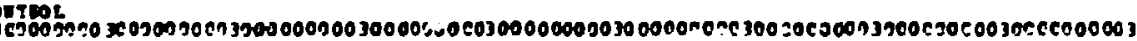

geot tabe 2 weode perte ont

\begin{tabular}{|c|c|c|c|}
\hline cne & $\pi$ & $\mathbf{T}$ & a \\
\hline $\begin{array}{l}1 \\
2 \\
3 \\
5\end{array}$ & $\begin{array}{l}n .0 \\
0.0 \\
0.0 \\
0.0 \\
0.0\end{array}$ & $\begin{array}{c}0.0 \\
30.0000 \\
60.0000 \\
90.0003 \\
120.0000\end{array}$ & $\begin{array}{l}3.9090 \\
3.9900 \\
3.0000 \\
3.9000 \\
3.0590\end{array}$ \\
\hline $\begin{array}{c}6 \\
\vdots \\
10\end{array}$ & $\begin{array}{l}0.0 \\
30.0000 \\
30.0290 \\
30.0390 \\
10.0920\end{array}$ & $\begin{array}{c}150.0000 \\
0.0 \\
30.2000 \\
50.0005 \\
90.0000\end{array}$ & $\begin{array}{l}3.0000 \\
3.0900 \\
3.0000 \\
3.2000 \\
3.2900\end{array}$ \\
\hline $\begin{array}{l}11 \\
12 \\
13 \\
10 \\
15\end{array}$ & $\begin{array}{l}3 C .0026 \\
20.0006 \\
60.9900 \\
60.2000 \\
60.0300\end{array}$ & $\begin{array}{c}120.0000 \\
150.0003 \\
6.0 \\
30.0000 \\
60.0000\end{array}$ & $\begin{array}{l}3.0000 \\
3.0000 \\
3.0000 \\
3.0000 \\
3.0000\end{array}$ \\
\hline $\begin{array}{l}16 \\
17 \\
19 \\
10\end{array}$ & $\begin{array}{l}10.0206 \\
60.000 C \\
6 C .0000 \\
90.0000 \\
90.0000\end{array}$ & $\begin{array}{c}90.0000 \\
120.0000 \\
190.0000 \\
0.0 \\
10.0000\end{array}$ & $\begin{array}{l}3.0000 \\
3.0000 \\
3.0000 \\
3.0000 \\
3.0000\end{array}$ \\
\hline $\begin{array}{l}21 \\
22 \\
23 \\
24 \\
24\end{array}$ & $\begin{array}{r}90.000 \% \\
\$ 0.0008 \\
90.0050 \\
90.0009 \\
120.0503 \\
.\end{array}$ & $\begin{array}{c}60.0000 \\
90.0000 \\
120.0600 \\
150.0000 \\
1.0\end{array}$ & $\begin{array}{l}.0000 \\
3.0000 \\
3.0000 \\
3.0900 \\
3.0000\end{array}$ \\
\hline $\begin{array}{l}26 \\
27 \\
79 \\
29 \\
90\end{array}$ & $\begin{array}{l}126.0006 \\
120.0005 \\
120.0000 \\
120.0006 \\
120.0000\end{array}$ & $\begin{array}{r}30.0009 \\
50.0009 \\
10.0009 \\
120.0000 \\
150.0000\end{array}$ & $\begin{array}{l}3.0000 \\
3.0000 \\
3.0000 \\
3.0000 \\
3.0000\end{array}$ \\
\hline $\begin{array}{l}31 \\
? 2 \\
31 \\
34\end{array}$ & $\begin{array}{l}15 r .0605 \\
150.0606 \\
150.5003 \\
150.0600 \\
150.0000\end{array}$ & $\begin{array}{c}0.0 \\
30.0000 \\
60.0000 \\
90.0000 \\
120.0000\end{array}$ & $\begin{array}{l}3.0000 \\
3.0900 \\
3.0000 \\
3.0000 \\
3.0000\end{array}$ \\
\hline $\begin{array}{l}36 \\
37 \\
19 \\
19 \\
00\end{array}$ & $\begin{array}{l}190.0000 \\
180.0000 \\
180.0000 \\
180.0000 \\
180.0000\end{array}$ & $\begin{array}{c}130.0000 \\
0.0 \\
30.0000 \\
60.0000 \\
10.0000\end{array}$ & $\begin{array}{l}3.0000 \\
3.0000 \\
3.0000 \\
3.0900 \\
3.0000\end{array}$ \\
\hline
\end{tabular}


APPENDIX C. OUTPUT (Continued)

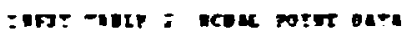

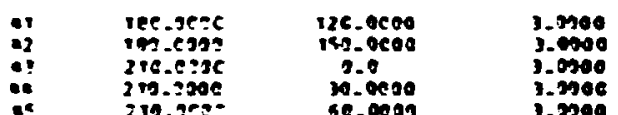

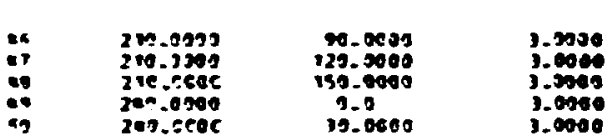

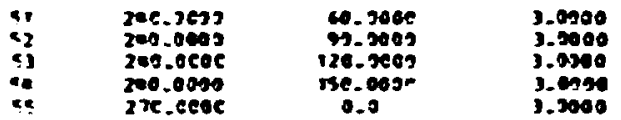

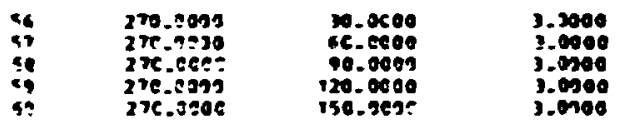

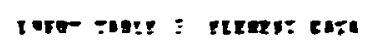

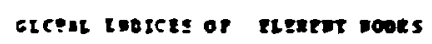

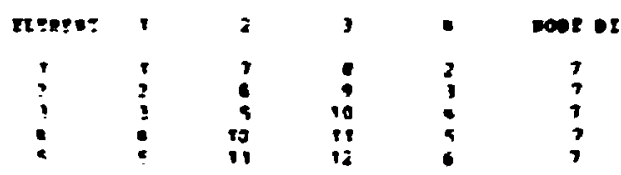

$$
\begin{aligned}
& \begin{array}{cccccc}
3 & 13 & 19 & 1 & ? \\
19 & 15 & 15 & 9 & ? \\
19 & 19 & 16 & 17 & 11 & ?
\end{array}
\end{aligned}
$$

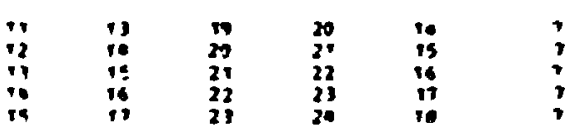

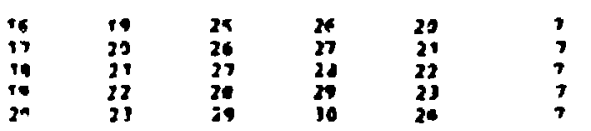

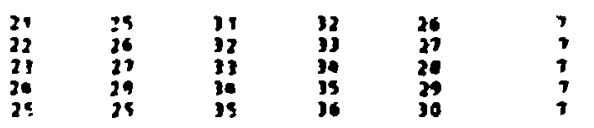

$$
\begin{aligned}
& \begin{array}{llllll}
26 & 31 & 37 & 10 & 32 & 7 \\
27 & 32 & 30 & 39 & 13 & 7 \\
20 & 31 & 39 & 10 & 10 & 7 \\
20 & 10 & 10 & 11 & 15 & 7 \\
39 & 15 & 11 & 12 & 16 & 7
\end{array}
\end{aligned}
$$

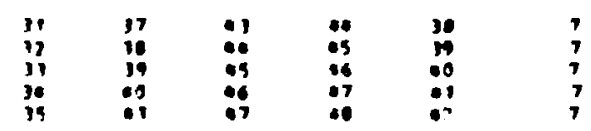

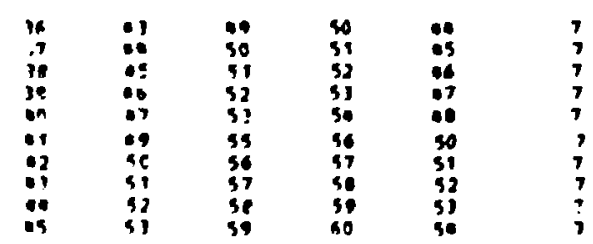




\section{APPENDIX C. OUTPUT (Continued)}

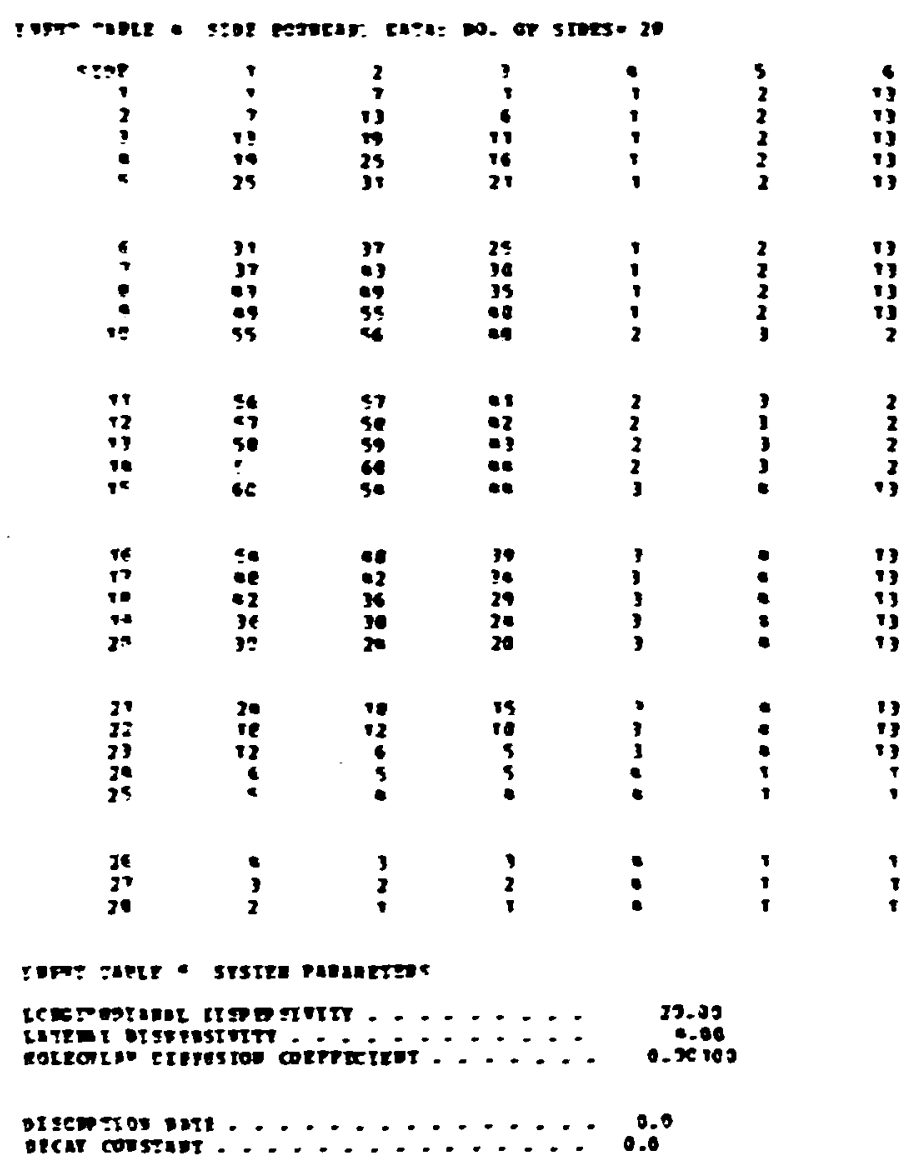

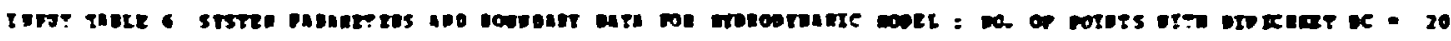

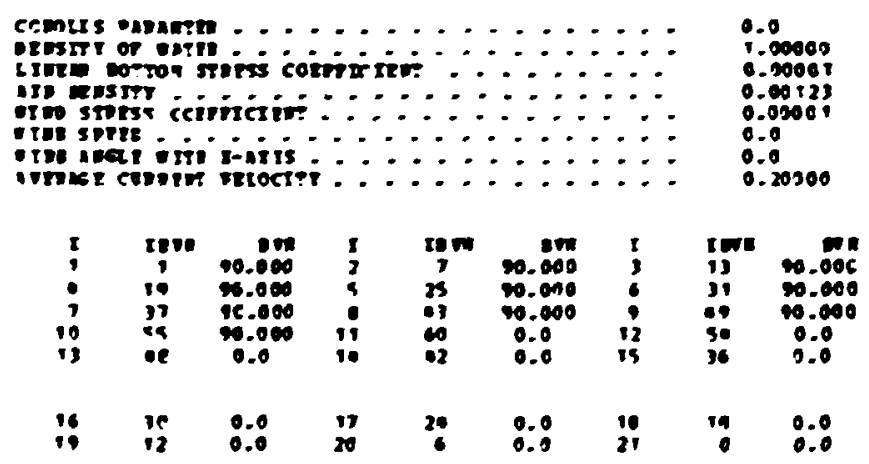

rerer rane, sonce bin

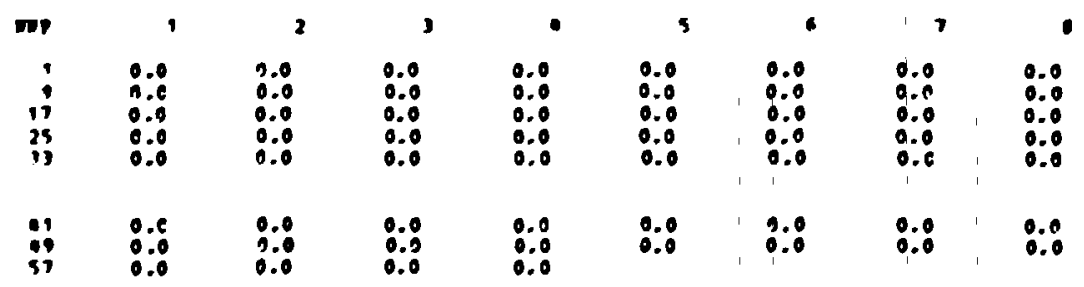


APPENOIX C. OUTPUT (Continued)

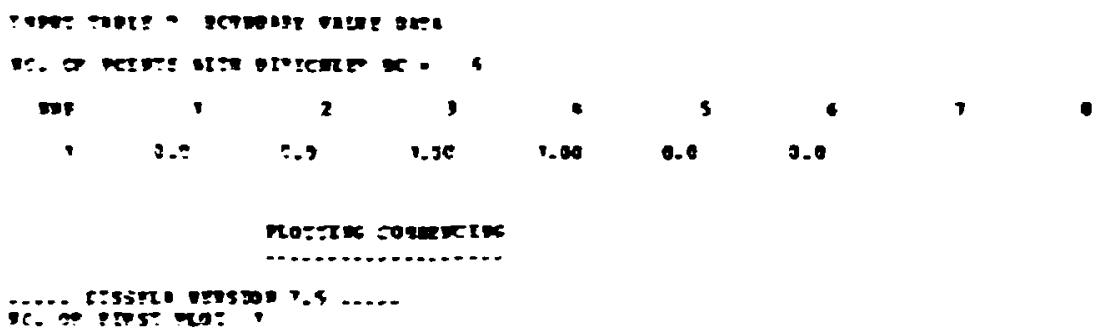

J.63at. or 0.0

$1.200 \cdots n$, $3.6050=0$ : 5. 2

7.20002 of $3.60502=1$
$1.6000 \mathrm{e}$ or p.eocor nit cone or 1.9010201
.00502 or

$3.00 c 02$ or r.no001
0.5

T.200e 10

3.60092 or

r.zocoe or

$3.6000=01$ 0.5
0.0050 or 3 coove 1. coser or .00002 or s. ec002 of

1.0000201 . .0000201
7.20008 of 3.60002 or 6.0 .20002
3.60008

0.0 7.20002 of

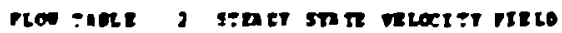

nt-I it woots

\begin{tabular}{|c|}
\hline $\begin{array}{l}00 c c 2-01 \\
00002-01 \\
00002-01 \\
\text { ceoce-01 } \\
0 c 0 c 2-01\end{array}$ \\
\hline $\begin{array}{l}6.00002-01 \\
6.00008-01 \\
6.00008-01 \\
.00062-01 \\
6.00002 \rightarrow 1\end{array}$ \\
\hline $\begin{array}{l}6.00008-01 \\
6.0002-01 \\
6.00002-01 \\
6.00052-01 \\
.00002-01\end{array}$ \\
\hline
\end{tabular}

$6.00002-01$ $.00002-01$
$.0000-01$ $0.00002-01$ $6.00002-01$
6.000050 $6.00002-01$

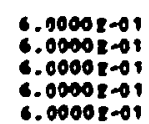

$6.00002-01$ $.00001-0$ $6.00008-01$ $6.00005-01$ 6.00002-0 I

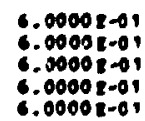

$0.00005-67$ $6.00008-01$ 6.00002-01 $00008-0$ !
$6.00008-0$ !
$6.0000 \mathrm{R}-\mathrm{C}$

$6.00002-6$

6.000020

$6.00008=0$

$6.00002-01$
6.00002-01 6.0005 ero 6.00002-01 6.00008-01

6. $2000 p-01$ $6.0000 \mathrm{t}-\mathrm{C} 1$ 6.0000 ror $6.00008-1$ $6.0000 \mathrm{t}-0$ !

$6.00008-09$ $6.00007-01$ 6.0000 e $\rightarrow$ $6.00008-0$ 6.00002-01
1. $20002-00$ 6.39612-07 - .0012-07 $-1.71618-07$
$-.02000-07$

3. 26972-07 $3.69102-07$ $-7.65001-65$ $-1.73202-06$

3.00828-07 3.70591-06 -9.63091-00 i. 15672-07 - i.eszit-06
VPL-T at noses

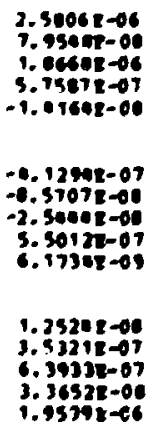

1. 07592-6

1. 1eese-07 $1.17672-06$ $-7.54302-07$
$2.16312-05$

1.00922-06 $1.9332=06$ -1. 96472-00 6.1900 t- 07 $-1.37002-07$

$-1.506 \pi-00$ 1. 26631-06 $-2.7500-07$ 2.79058-00 $-1.01438-07$ $1.11098-07$ $3,3 \times 272-00$ 2. $3942 \mathrm{E}-07$

2. 4245e-07 -1. $20922-07$ $-3.5664-01$ $-5.53872-60$
$5.59138-07$

$-2.05355-07$ $-1.61602-08$ $1.03435-06$ $1.62892-06$
$3.62762-06$ 


\section{APPENDIX C. OUTPUT (Continued)}

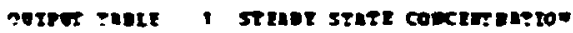

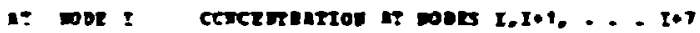

$\begin{array}{rr}1 & 0.0 \\ 17 & 0-0 \\ 17 & 0.0 \\ 33 & 0.0\end{array}$

$\begin{array}{ll}0.0 & 0.0 \\ 0.5 & 0.0 \\ 0.0 & 0.0 \\ 0.0 & 0.0 \\ 0 . c & 0.0\end{array}$

$\begin{array}{lll}0.0 & 0.0 & 0.0 \\ 0.0 & 0.0 & 0.0 \\ 0.0 & 0.0 & 0.0 \\ 0.0 & 0.0 & 0.0 \\ 0.0 & 0.0 & 0.0\end{array}$

\section{flottix coneactus}

…. ex ssfrs" vession 7.5 .....

ic. OP past niet 2

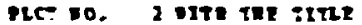

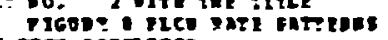

as itw connetro.

prot te. azac:

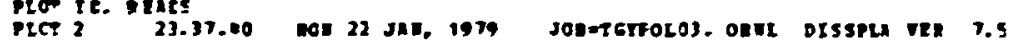

DNTS rot plo:

oc. or conves touts

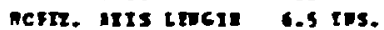

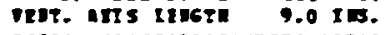

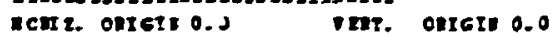

CCT2 ArT: Irsean

5718 s

viv. Aris Linzan

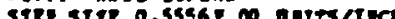

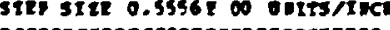

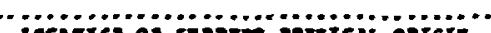

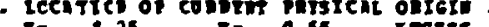

$x=$ 1.2E $T=$ O.55 $x$ menes

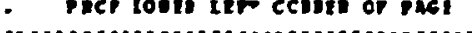

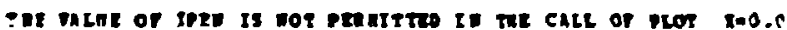

$8=0.0$

IP:P.

999

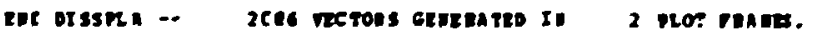


APPEMDIX C. WUTPUT (Continued)

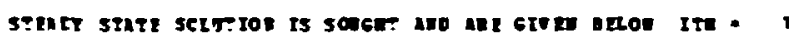

\begin{tabular}{|c|c|c|c|c|c|c|c|c|}
\hline $\begin{array}{l}1 \\
7 \\
73 \\
33\end{array}$ & 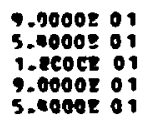 & $\begin{array}{l}7.20002 \text { 01 } \\
3.60008 \text { or } \\
0.0 \\
7.20002 \text { 01 } \\
3.60002 \text { or }\end{array}$ & 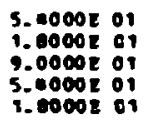 & $\begin{array}{l}3.6000=01 \\
0.0 \\
7.2000=01 \\
3.6000201 \\
0.0\end{array}$ & 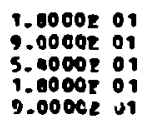 & $\begin{array}{l}0.0 \\
7.2000201 \\
3.5000201 \\
0.0 \\
7.2000=01\end{array}$ & 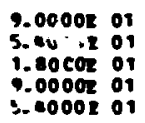 & $\begin{array}{l}7.2000 E 01 \\
3.6000201 \\
0 . \\
7.2000201 \\
3.6000201\end{array}$ \\
\hline $\begin{array}{l}01 \\
57\end{array}$ & $\begin{array}{l}1.00002 \text { or } \\
1.00002 \text { o1 } \\
5.00002 \text { 01 }\end{array}$ & $\begin{array}{l}0.0 \\
7.20002 \text { 01 } \\
3.60002 \text { 01 }\end{array}$ & $\begin{array}{l}9.00002 \text { or } \\
5.00002 \text { o1 } \\
1.00002 \text { 01 }\end{array}$ & $\begin{array}{l}7.20005 \text { ol } \\
3.6000201 \\
0.0\end{array}$ & $\begin{array}{l}5.0000201 \\
1.0000201\end{array}$ & $\begin{array}{l}3.6000=C_{1} \\
0.0\end{array}$ & $\begin{array}{l}1.06002 \text { o1 } \\
9.00002 \text { o1 }\end{array}$ & $\begin{array}{l}0.0 \\
7.2000 \text { e } 01\end{array}$ \\
\hline
\end{tabular}

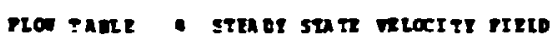

nL-X $1 \mathrm{~T}$ nopes

\begin{tabular}{|c|c|}
\hline $\begin{array}{r}1 \\
5 \\
9 \\
13 \\
17\end{array}$ & $\begin{array}{l}6.000 C E-01 \\
6.0000 E-01 \\
6.00002-01 \\
6.060 C z-01 \\
6.00002-01\end{array}$ \\
\hline $\begin{array}{l}21 \\
22 \\
29 \\
33 \\
37\end{array}$ & $\begin{array}{l}6.00002-01 \\
6.00002-01 \\
E .000 \mathrm{C}-01 \\
6.0 \mathrm{C} 00 \mathrm{R}-01 \\
6.0000 \mathrm{R}-01\end{array}$ \\
\hline $\begin{array}{l}11 \\
15 \\
59 \\
57 \\
57\end{array}$ & $\begin{array}{l}6.00302-01 \\
6.00062-01 \\
6.00002-01 \\
6.00008-01 \\
6.0000 z-0 ?\end{array}$ \\
\hline
\end{tabular}

\begin{tabular}{|c|c|}
\hline $\begin{array}{l}6.00002-01 \\
6.00002-01 \\
6.00002-01 \\
6.00002-01 \\
6.00002-01\end{array}$ & $\begin{array}{l}6.0000 \mathrm{E}-01 \\
6.0000 \mathrm{z}-01 \\
6.0000 \mathrm{z}-01 \\
6.0000 \mathrm{z}-01 \\
6.0000 \mathrm{z}=01\end{array}$ \\
\hline $\begin{array}{l}6.00002-01 \\
6.00002-0: \\
6.00002-01 \\
6.00002-01 \\
6.00002-01\end{array}$ & $\begin{array}{l}6.0000 \mathrm{E}-01 \\
6.0000 \mathrm{z}-01 \\
6.0000 \mathrm{z}-01 \\
6.0000 \mathrm{E}-01 \\
6.0000 \mathrm{z}-01\end{array}$ \\
\hline $\begin{array}{r}.00002-01 \\
6.0000 z-01 \\
6.00002-01 \\
6.00002-01 \\
6.00002-01\end{array}$ & $\begin{array}{l}6.0000 \mathrm{z}-01 \\
6.0000 \mathrm{z}-01 \\
6.0000 \mathrm{z}-01 \\
6.0000 \mathrm{z}-01 \\
6.0000 \mathrm{z}-01\end{array}$ \\
\hline
\end{tabular}

$6.00002-01$ $6.00002-01$
$6.00008-01$ $6.00002-01$
$6.0002-01$ $6.00002-01$

$6.00002-0.08$ $6.00002-01$ 6.00002-C! $6.0000 \mathrm{z}-0$ ? $6.00002-61$

6.00002-01 $6.0000 \mathrm{z}-01$ $6.1000 \mathrm{E}-01$

$6.0000 \mathrm{z}-0$ ? $6.00002-01$
$6.0000 \mathrm{z}-01$
$1.7000 z-08$ $0.54652-07$ $40012-07$ .02 45-07

3. $24972-07$ 2.69148-07 $-7.6500 \mathrm{~F}-09$ $-1.73292-06$ 2. $90312-08$

$3.00925-07$ $3.00922-07$
$2.74591-06$ $2.74591-06$
$-9.6309 \mathrm{z}-08$ $-9.63092-08$
$1.95672-67$ $1.95672-67$
$-1.05212-06$
TEL-t NT noors

\begin{tabular}{|c|c|}
\hline 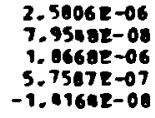 & $\begin{array}{r}1.07592-06 \\
1.36452-07 \\
1.17671-06 \\
-7.58501-07 \\
2.16312-06\end{array}$ \\
\hline $\begin{array}{r}-1.12942-07 \\
-8.9107 z-08 \\
-2.5408 E-00 \\
5.5012 z-07 \\
6.17348-09\end{array}$ & $\begin{array}{r}-1.5467-07 \\
1.26632-06 \\
-279002-07 \\
2.62212-07 \\
2.03318-07\end{array}$ \\
\hline $\begin{array}{l}1.25242-08 \\
3.53212-07 \\
6.39332-07 \\
3.36522-08 \\
1.955 ; 2-06\end{array}$ & $\begin{array}{r}2.02062-07 \\
-1.20922-07 \\
-3.5668-07 \\
-0.95871-00 \\
5.59132-07\end{array}$ \\
\hline
\end{tabular}

3. $00925-06$ $1.93325-06$ $-1.90475-01$ $6.19002-07$
$-1.37008-07$

2.7905 -00 $-1.01432-07$ 1. $1+495-07$ $3.5 \times 271-08$ 2.5992 2-07

$-2.9535=-07$ $-1.61608-08$ $1.05+3 \mathrm{z}-06$ $1.03+32=06$
$1.62892-06$ $3.6276 \mathrm{z}-00$

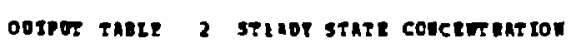

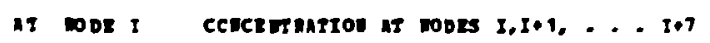

\begin{tabular}{|c|c|c|c|c|c|c|c|c|}
\hline $\begin{array}{l}1 \\
17 \\
25\end{array}$ & 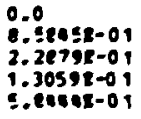 & $\begin{array}{l}0.0 \\
0.50062-01 \\
2.07472-02 \\
3.05782-01 \\
5.0484-01\end{array}$ & $\begin{array}{l}1.0000100 \\
1.40645-01 \\
7.7456 E-02 \\
6.20932-01 \\
3.26531-01\end{array}$ & $\begin{array}{r}1.0400200 \\
-1.41062-02 \\
2.7575 z-01 \\
6.20942-01 \\
1.70001-01\end{array}$ & $\begin{array}{l}0.0 \\
2.01971-02 \\
6.85532-01 \\
3.05788-01 \\
2.10502-01\end{array}$ & $\begin{array}{l}0.0 \\
2.2078 z-01 \\
6.05532-01 \\
1.3059=01 \\
3.41702-01\end{array}$ & $\begin{array}{r}-1.11662-02 \\
7.99152-01 \\
2.75752-01 \\
1.78081-01 \\
5.99001-01\end{array}$ & $\begin{array}{r}1.68608-01 \\
7.59152-01 \\
7.795118-02 \\
3.26532-01 \\
5.69002-01\end{array}$ \\
\hline 11 & $\begin{array}{l}3.017+1-01 \\
2.76818-01 \\
-6500 t-01\end{array}$ & $\begin{array}{l}2.10502-01 \\
3.62122-01 \\
.69002-01\end{array}$ & $\begin{array}{l}2.52132-01 \\
4.98992-01 \\
3.65852-01\end{array}$ & $\begin{array}{l}3.53332-01 \\
5.98097-01 \\
2.90308-01\end{array}$ & $\begin{array}{l}5.206112-01 \\
3.62122-01\end{array}$ & $\begin{array}{l}5.206112-01 \\
2.78818-01\end{array}$ & $\begin{array}{l}3.53392-01 \\
2.90332-01\end{array}$ & $\begin{array}{l}2.52132-01 \\
3.6505=-01\end{array}$ \\
\hline
\end{tabular}


APPENDIX D. INPUT AND OUTPUT AT PRAIRIE ISLAMD

$\underline{\text { INPUT }}$

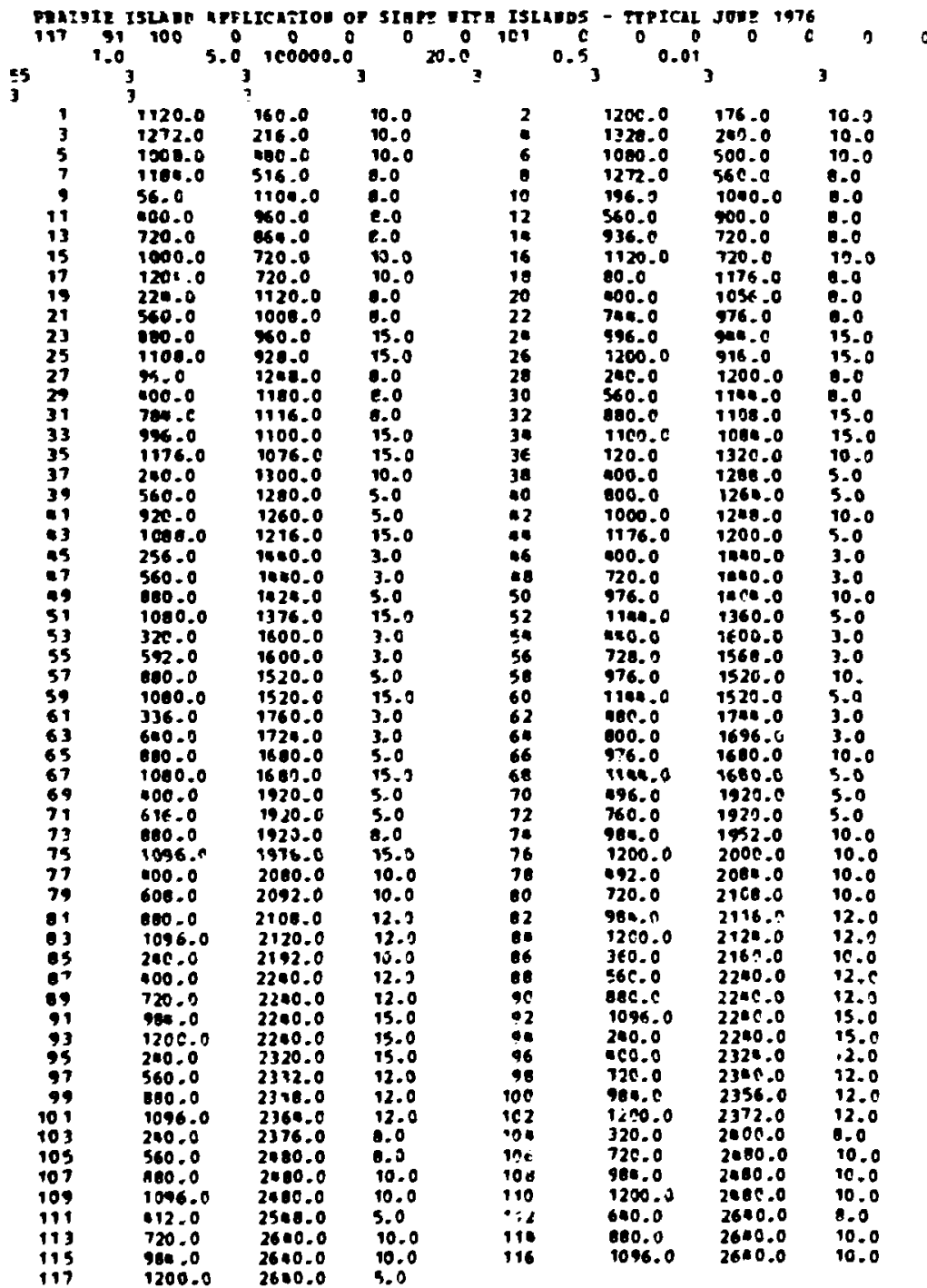


APPENDIX D. INPUT (Continued)

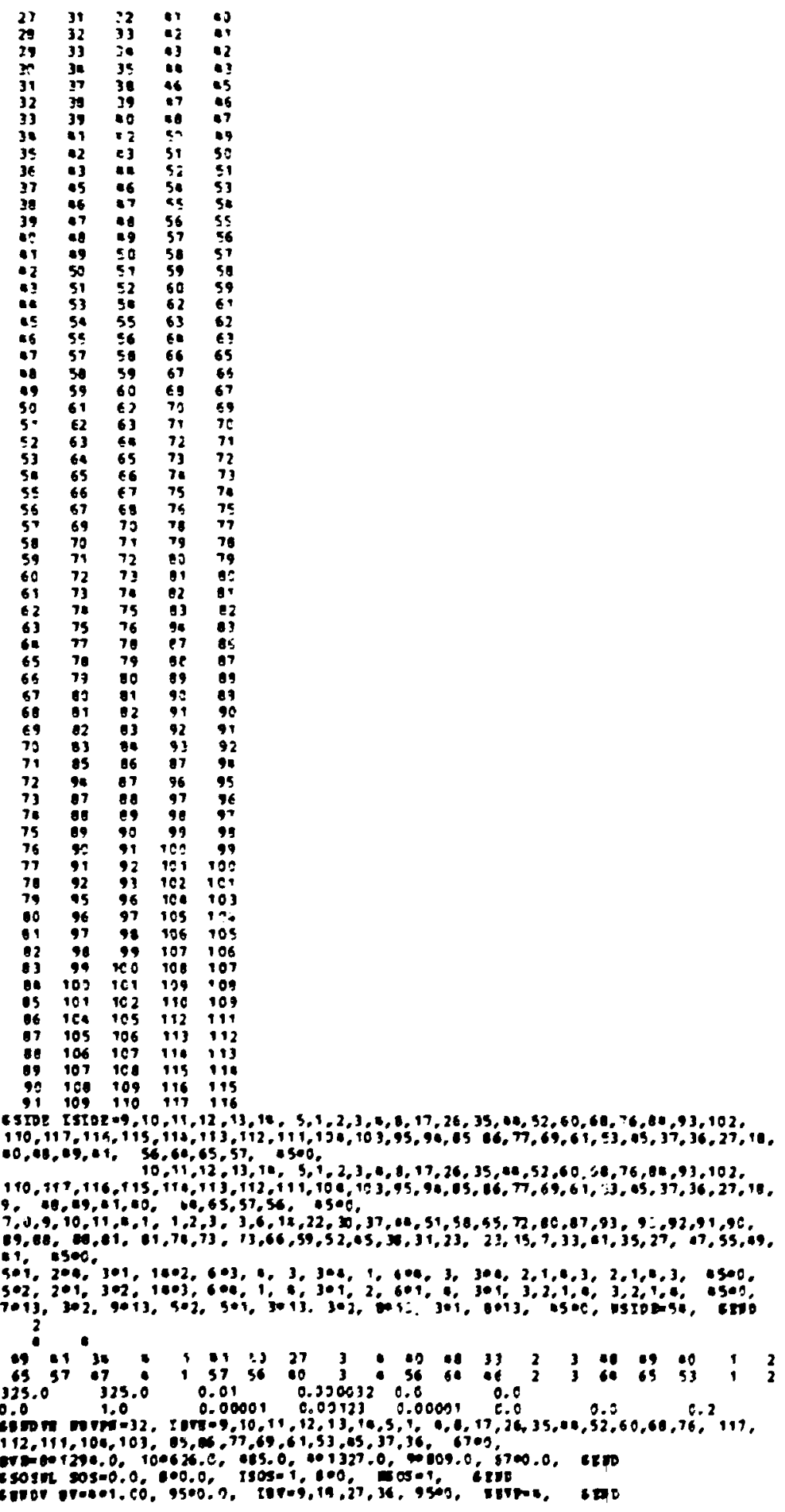




\section{APPENDIX D. OUTPUT}

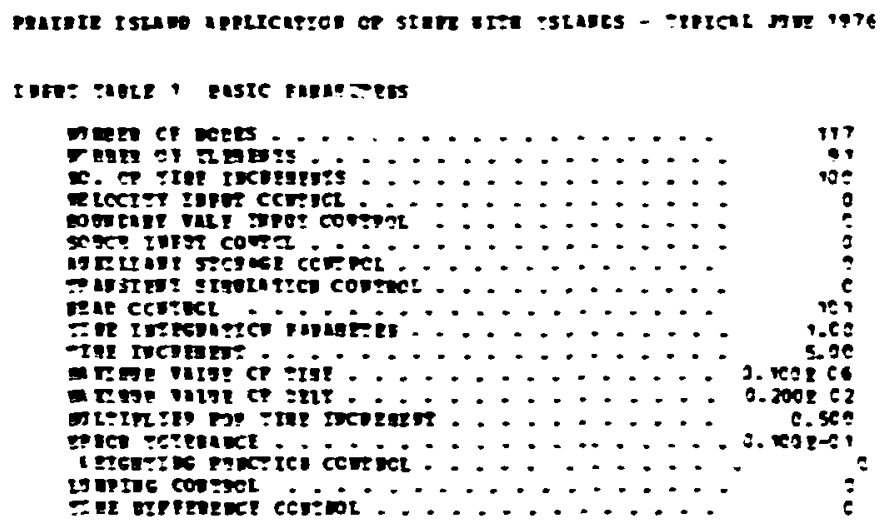

PT:

作

\begin{tabular}{|c|c|c|c|}
\hline rent & $I$ & $!$ & : \\
\hline$\vdots$ & 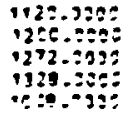 & 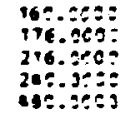 & 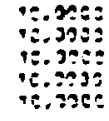 \\
\hline 4 & 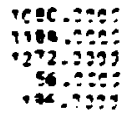 & 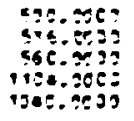 & 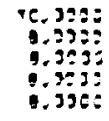 \\
\hline $\begin{array}{l}: 4 \\
3 \\
3 \\
: 4\end{array}$ & 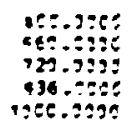 & 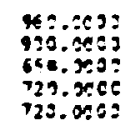 & 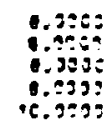 \\
\hline $\begin{array}{l}19 \\
19 \\
i 9\end{array}$ & 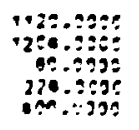 & 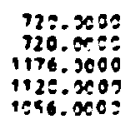 & 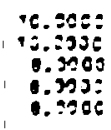 \\
\hline $\begin{array}{l}21 \\
22 \\
23 \\
29 \\
39\end{array}$ & 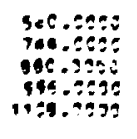 & $\begin{array}{l}1970.0595 \\
976.0939 \\
960 . x 69 \\
90.0050 \\
920 . x 09\end{array}$ & 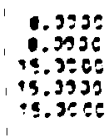 \\
\hline $\begin{array}{l}24 \\
29 \\
29 \\
29 \\
9=\end{array}$ & 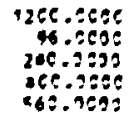 & 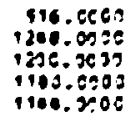 & 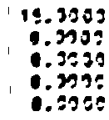 \\
\hline $\begin{array}{l}34 \\
32 \\
3 \\
3 \\
39\end{array}$ & 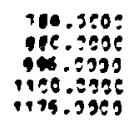 & $\begin{array}{l}111,-9 c 32 \\
1190.006= \\
1190.9095 \\
160.0000 \\
139.9000\end{array}$ & $\begin{array}{r}1.0030 \\
13.9209 \\
15.3050 \\
15.9990 \\
19.900\end{array}$ \\
\hline $\begin{array}{l}36 \\
39 \\
39 \\
39\end{array}$ & 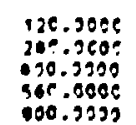 & $\begin{array}{l}1320.20050 \\
1398.9000 \\
1300.2090 \\
1280.0063 \\
1260.2000\end{array}$ & $\begin{array}{r}16.2000 \\
10.9979 \\
5.20=5 \\
5.3909 \\
5.3900\end{array}$ \\
\hline
\end{tabular}


APPENDIX D. OUTPUT (Continued)

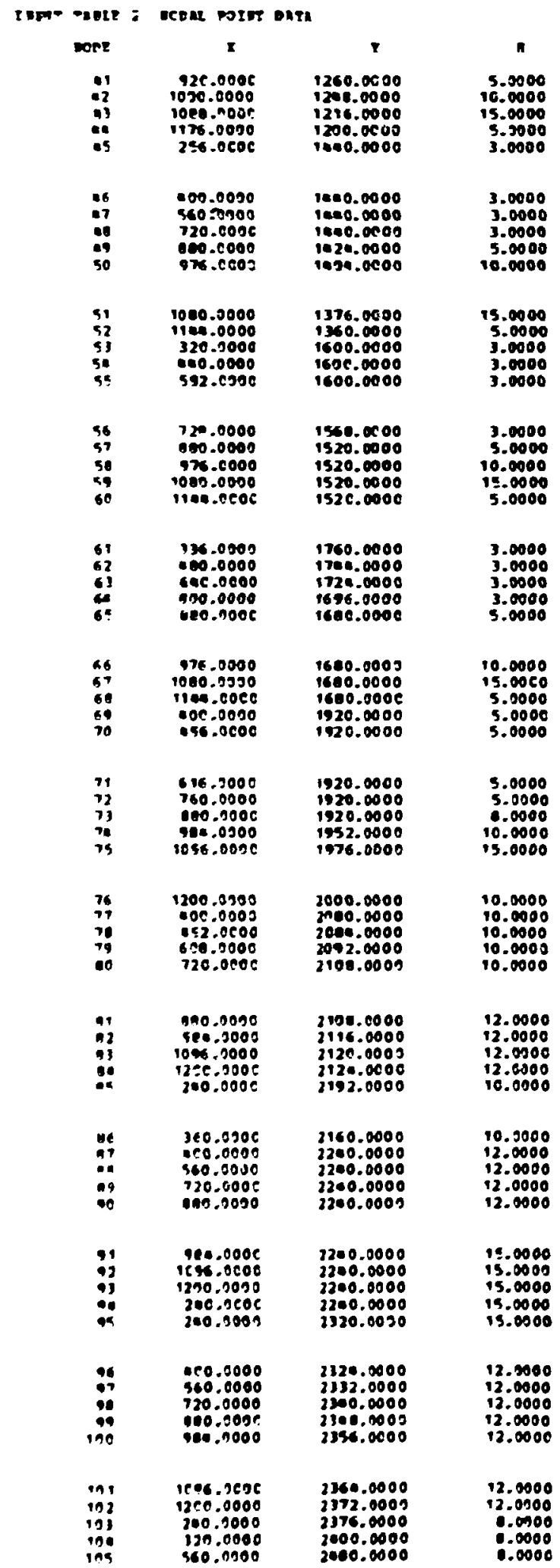




\section{APPENDIX D. OUTPUT (Continued)}

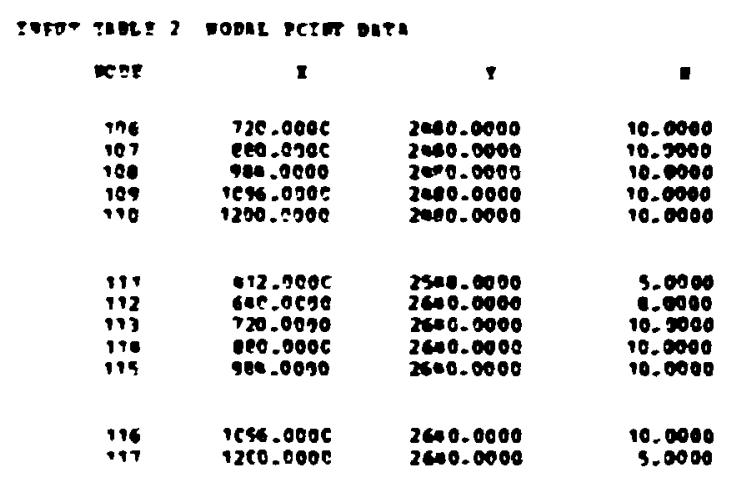

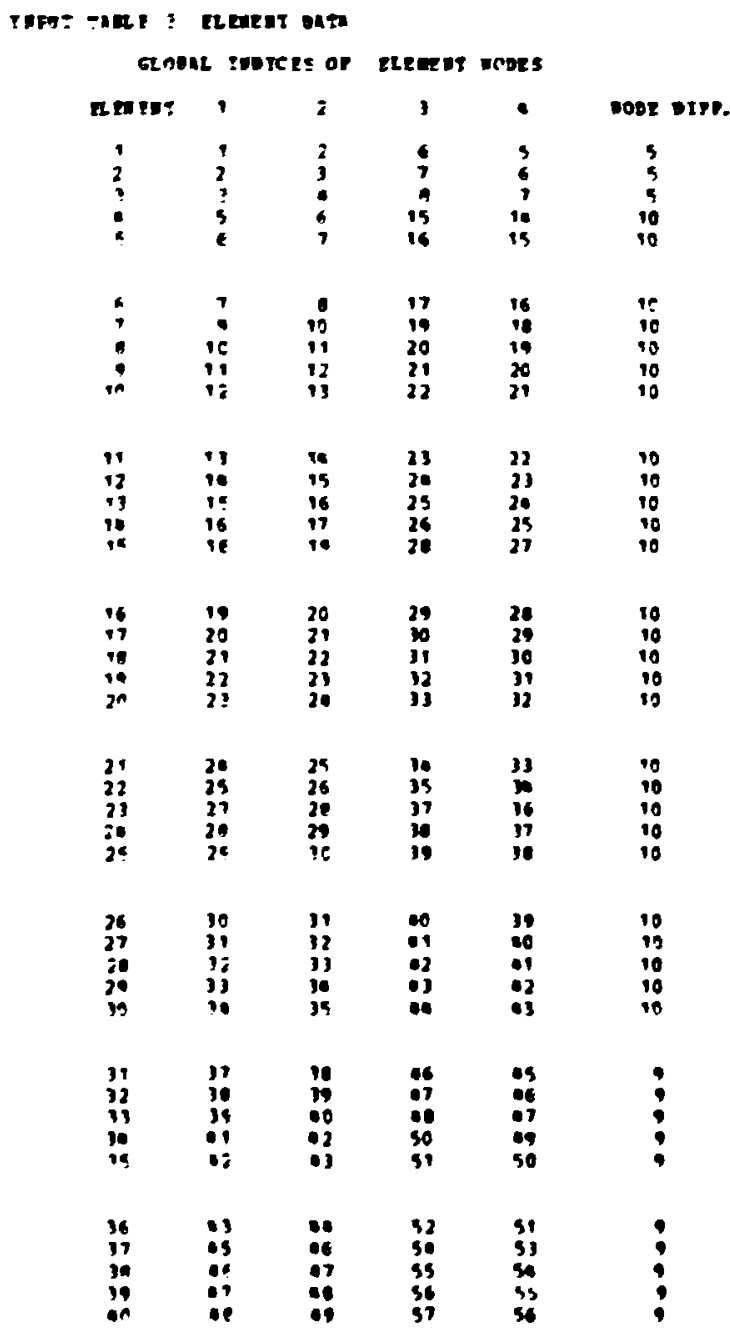




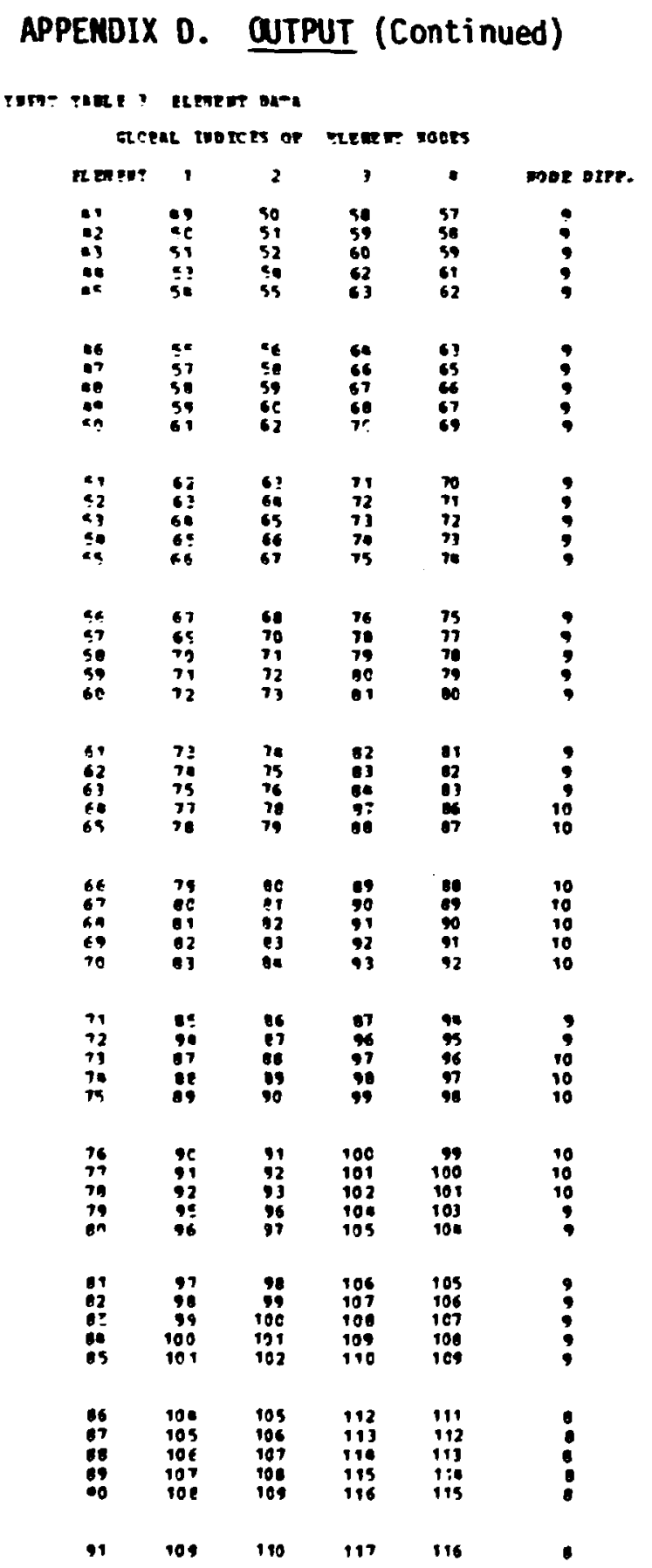


APPENDIX D. QUTPUI (Continued)

\begin{tabular}{|c|c|c|c|c|c|}
\hline $\begin{array}{r}\text { In? } \\
\vdots \\
? \\
\vdots\end{array}$ & : & $\begin{array}{l}2 \\
10 \\
11 \\
12 \\
13 \\
10\end{array}$ & : & & $\begin{array}{l}5 \\
2 \\
2 \\
2\end{array}$ \\
\hline$\vdots$ & $\begin{array}{l}10 \\
\vdots \\
3 \\
3\end{array}$ & $\begin{array}{l}5 \\
\vdots \\
\mathbf{2} \\
3 \\
3\end{array}$ & $\begin{array}{l}3 \\
\vdots \\
3 \\
3\end{array}$ & & \\
\hline 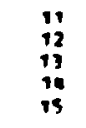 & $:$ & $\begin{array}{l}17 \\
35 \\
35 \\
010\end{array}$ & : & $\begin{array}{l}2 \\
2 \\
2 \\
2 \\
2\end{array}$ & \\
\hline $\begin{array}{l}16 \\
717 \\
170 \\
20\end{array}$ & $\begin{array}{l}54 \\
52 \\
68 \\
68 \\
76\end{array}$ & $\begin{array}{l}52 \\
60 \\
80 \\
28 \\
10\end{array}$ & $\begin{array}{l}37 \\
37 \\
31 \\
38 \\
65 \\
65\end{array}$ & $\begin{array}{l}2 \\
2 \\
2 \\
2 \\
2 \\
2\end{array}$ & \\
\hline $\begin{array}{l}21 \\
22 \\
23 \\
24 \\
24 \\
23\end{array}$ & 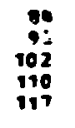 & 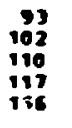 &  & $\begin{array}{l}2 \\
2 \\
2 \\
2 \\
3\end{array}$ & \\
\hline $\begin{array}{l}26 \\
27 \\
20 \\
20 \\
20 \\
30\end{array}$ & 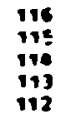 & $\begin{array}{l}115 \\
119 \\
113 \\
112 \\
111\end{array}$ & 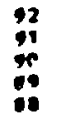 & $\begin{array}{l}\mathbf{3} \\
\mathbf{3} \\
\mathbf{3} \\
\mathbf{3}\end{array}$ & \\
\hline $\begin{array}{l}31 \\
37 \\
31 \\
36 \\
35\end{array}$ & 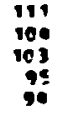 & $\begin{array}{l}100 \\
100 \\
95 \\
98 \\
85\end{array}$ & 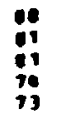 & ; & \\
\hline 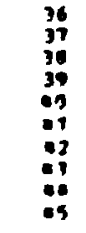 & 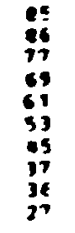 & 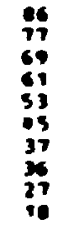 & $\begin{array}{l}73 \\
66 \\
38 \\
32 \\
63 \\
30 \\
31 \\
23 \\
23 \\
19\end{array}$ & $\begin{array}{l}! \\
\vdots \\
\vdots\end{array}$ & \\
\hline $\begin{array}{l}\because 8 \\
\because 8 \\
\because 8 \\
0\end{array}$ & 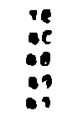 & 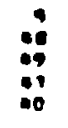 & $\begin{array}{l}31 \\
31 \\
35 \\
37\end{array}$ & i & \\
\hline $\begin{array}{l}51 \\
32 \\
31 \\
4\end{array}$ & $\begin{array}{l}56 \\
68 \\
65 \\
57\end{array}$ & $\begin{array}{l}38 \\
39 \\
37 \\
36\end{array}$ & $\begin{array}{l}31 \\
33 \\
01 \\
18\end{array}$ & $?$ & \\
\hline
\end{tabular}


APPENDIX D. OUTPUT (Continued)

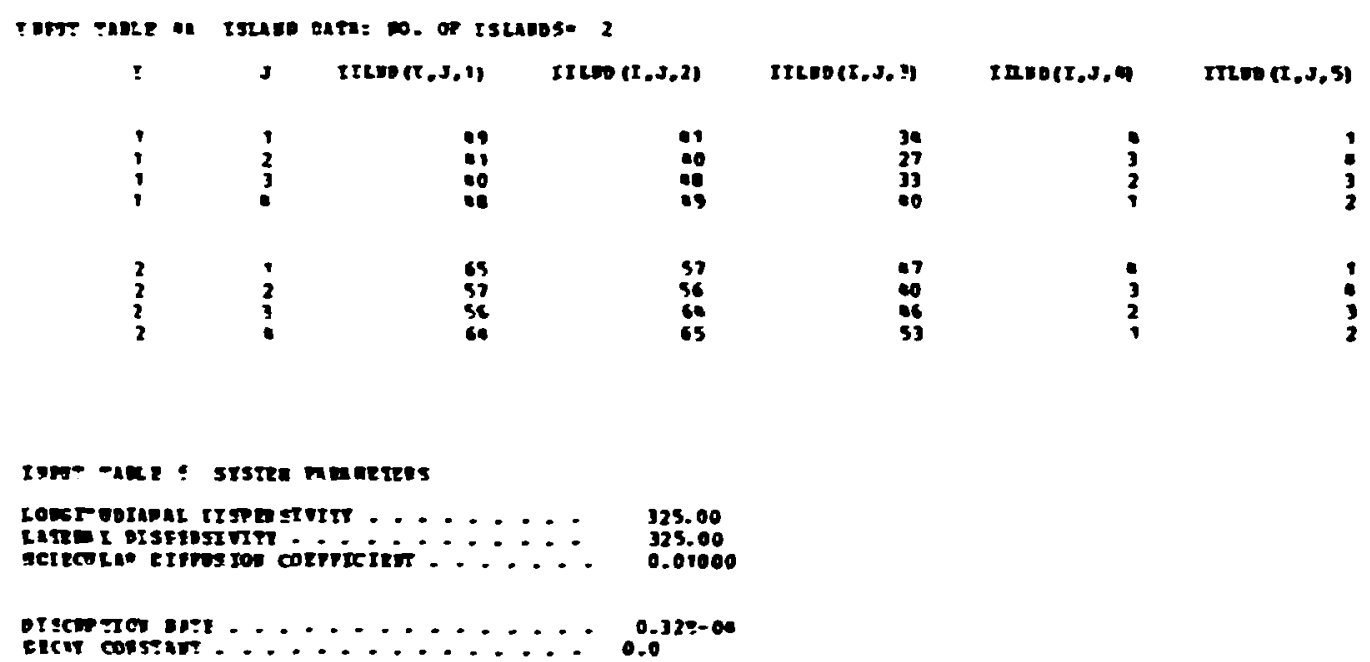

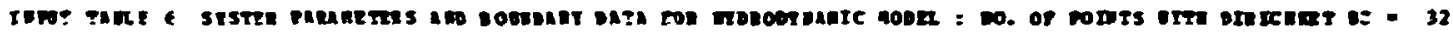

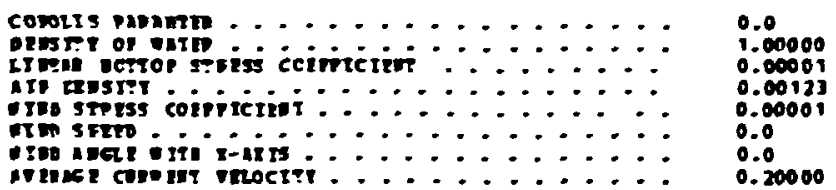

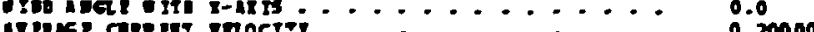

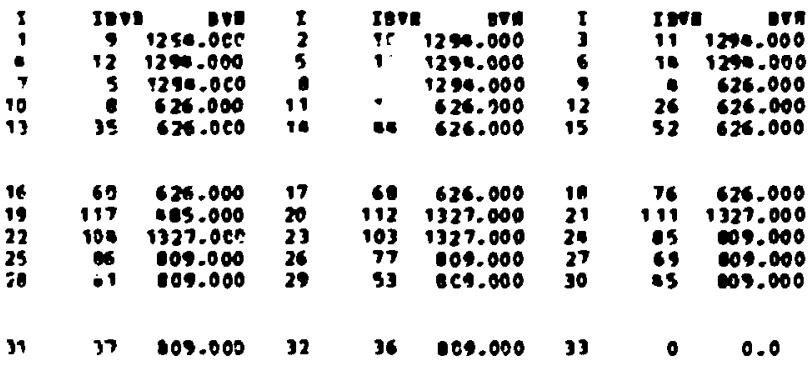

terot inate 1 scome dusa

\begin{tabular}{|c|c|c|c|c|c|c|c|c|}
\hline Wi & 1 & 2 & 3 & • & 3 & 6 & 7 & . \\
\hline $\begin{array}{l}1 \\
17 \\
25 \\
33\end{array}$ & $\begin{array}{l}0.0 \\
0.0 \\
0.0 \\
0.0 \\
0.0\end{array}$ & $\begin{array}{l}0.0 \\
0.0 \\
0.0 \\
0.0 \\
0.0\end{array}$ & $\begin{array}{l}0.0 \\
0.0 \\
0.0 \\
0.0 \\
0.0\end{array}$ & $\begin{array}{l}0.0 \\
0.0 \\
0.0 \\
0.0 \\
0.0\end{array}$ & $\begin{array}{l}0.0 \\
0.0 \\
0.0 \\
0.0 \\
0.0\end{array}$ & $\begin{array}{l}0.0 \\
0.0 \\
0.0 \\
0.0 \\
0.0\end{array}$ & $\begin{array}{l}0.0 \\
0.0 \\
0.0 \\
0.0 \\
0.0\end{array}$ & $\begin{array}{l}0.0 \\
0.0 \\
0.0 \\
0.0 \\
0.0\end{array}$ \\
\hline $\begin{array}{l}19 \\
99 \\
37 \\
65 \\
73\end{array}$ & $\begin{array}{l}0.0 \\
0.0 \\
0.0 \\
0.0 \\
0.0\end{array}$ & $\begin{array}{l}0.0 \\
0.0 \\
0.0 \\
0.0 \\
0.0\end{array}$ & $\begin{array}{l}0.0 \\
0.0 \\
0.0 \\
0.0 \\
0.0\end{array}$ & $\begin{array}{l}0.0 \\
0.0 \\
0.0 \\
0.0 \\
0.0\end{array}$ & $\begin{array}{l}c .0 \\
0.0 \\
0.0 \\
0.0 \\
0.0\end{array}$ & $\begin{array}{l}0.0 \\
0.0 \\
0.0 \\
0.0 \\
0.0\end{array}$ & $\begin{array}{l}0.0 \\
0.0 \\
0.0 \\
0.0 \\
0.0\end{array}$ & $\begin{array}{l}0.0 \\
0.0 \\
0.0 \\
0.0 \\
0.0\end{array}$ \\
\hline $\begin{array}{c}01 \\
99 \\
97 \\
105 \\
113\end{array}$ & $\begin{array}{l}0.0 \\
0.0 \\
0.0 \\
0.0 \\
0.0\end{array}$ & $\begin{array}{l}0.0 \\
0.0 \\
0.0 \\
0.0 \\
0.0\end{array}$ & $\begin{array}{l}0.0 \\
0.0 \\
0.0 \\
0.0 \\
0.0\end{array}$ & $\begin{array}{l}0.0 \\
0.0 \\
0.0 \\
0.0 \\
0.0\end{array}$ & $\begin{array}{l}0.0 \\
0.0 \\
0.0 \\
0.0 \\
0.0\end{array}$ & $\begin{array}{l}0.0 \\
0.0 \\
0.0 \\
0.0\end{array}$ & $\begin{array}{l}0.0 \\
0.0 \\
0.0 \\
0.0\end{array}$ & $\begin{array}{l}0.0 \\
0.0 \\
0.0 \\
0.1\end{array}$ \\
\hline
\end{tabular}




\section{APPENDIX D. OUTPUT (Continued)}

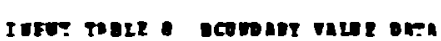

ic. Co foints erte ointchte oc.

$\begin{array}{rrrrrrr}100 & 1 & 2 & 3 & . & 5 & 1\end{array}$

mottro contientus

....................

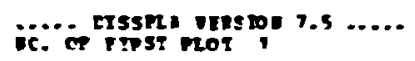

Pect sc. , gro In: ritze

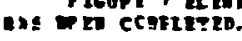

ple: :0. eenes

Dage pos pice

oc. or courz: tanes

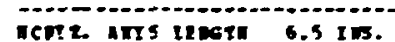

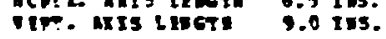

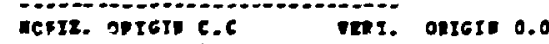

nopix. aris imeal

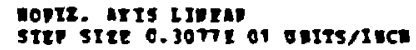

vevt. aIts tiones

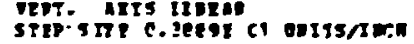

...............................

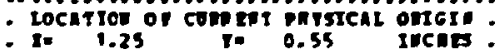

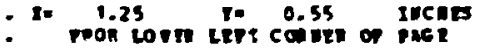

- poon lover lete conter or pher

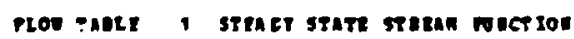

\begin{tabular}{|c|c|c|}
\hline 3 & 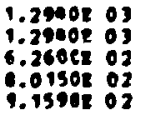 & 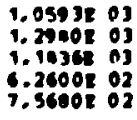 \\
\hline 87 & $\begin{array}{l}1.0222103 \\
1.0325803 \\
1.23218 \text { o2 } \\
7.23272 \text { o3 } \\
1.041 e 1 \text { o2 }\end{array}$ & 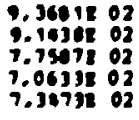 \\
\hline 1 & $\begin{array}{l}1.0021202 \\
1.2163802 \\
1.0925103 \\
1.23358 \\
1.16428 \text { e? }\end{array}$ & 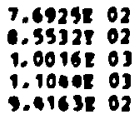 \\
\hline
\end{tabular}

$0.290502 \quad 6.2600=02$

1.29402 of

1.1654 os

1.0027503
6.2600503

1. 2000R 6

¿. 114612 03

1.03702 o3
1.05002 of

7. 15: 02

7.1652202

6.7616 E 02

6.3155802
6.80592 o2

6.2600202

6.2600202

6.20001 oz

6.2600202
6.2600102

7.34602 o2

- coser 02

?.2135 02

0.3020 102

9.30205
.21002
1.6701262
0.30001

c. 20071 02
$6.603220 ?$
1.29002 o 3 1.29602 oj 1.1070203 1.0293103 ..0500r oz

0.09002 02 0.0900102 0.0900102 .0900102
.0900802

6.09005 02 1. 3367 E 02 7.715702 7.3015202
. .05602 o2 1.0705e 03 1.29005 o3 1.20028 os 1.06921
9.30998

C.3191 02 .2020102 -oense oz 7.96551
0.2625102

- 0900 02 9.3620502 7.016502
7.0006102
0.1033 o2

1. 16138 03

1.127203

1.0773503
9.5670 02

- 73118 02

-.227at o

T.Tanie

7. 1425
6. 3029

9.70958 02

..14511 0

1.3270503

1. $32 \% 1$ os
$6.2600 \mathrm{r} v 2$ 6.62072 02 -.0175 02 1.03612 oj
1.0222103

1.0222101 7.2327102 7.2327502 7.555302
. .3233202

๑.700es 02 $1.1317=03$ 1.38701 03
$i .32708$ ol 


\section{APPENDIX D. OUTPUT (Continued)}

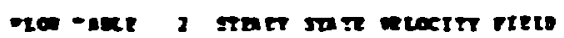

et-r ar wass

\begin{tabular}{|c|c|c|c|}
\hline $\begin{array}{l}1 \\
5 \\
3 \\
1 \\
1\end{array}$ & 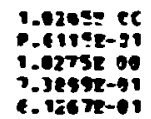 & 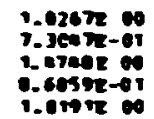 & 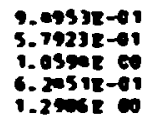 \\
\hline $\begin{array}{l}\mathbf{x} \\
\mathbf{2 5} \\
\mathbf{x} \\
\mathbf{3}\end{array}$ & 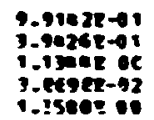 & 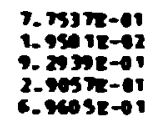 & 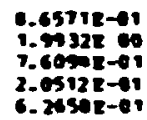 \\
\hline $\begin{array}{l}1 \\
5 \\
53 \\
53\end{array}$ & 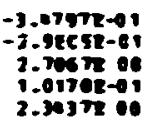 & 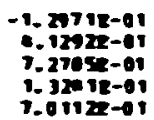 & 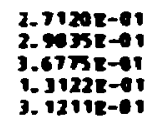 \\
\hline $\begin{array}{l}61 \\
69 \\
63 \\
n\end{array}$ & 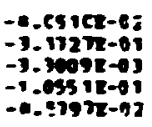 & 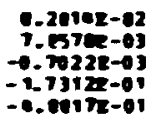 & 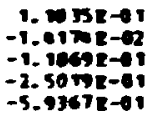 \\
\hline ד) & 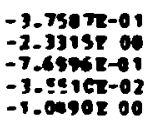 & 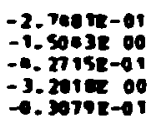 & $\begin{array}{l}-3.5972=-01 \\
-1.7159200 \\
-2.92728-01 \\
-2.9172000 \\
-3.29332-01\end{array}$ \\
\hline $\begin{array}{l}3 \\
17\end{array}$ & $\begin{array}{r}1.60992-01 \\
-6.09792-01 \\
-.70972-01 \\
-3.76992-01 \\
1.5170200\end{array}$ & $\begin{array}{r}1.1925 E-01 \\
-5.60022-01 \\
9.96212-01 \\
-0.10622-0\} \\
-8.7999200\end{array}$ & 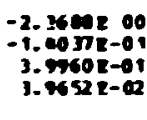 \\
\hline
\end{tabular}
$5.6000 \mathrm{e}-1$

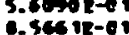
-. $120 \mathrm{er}-\mathrm{Cs}$ $.72685-68$
1.2309

$0.39392-8$ 2. 1 isse 6 2.5 3.3035

1. esese-er

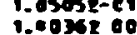
1.72T1z-6 i.ezaje ed -9.-icesect

t.ecser-ar S. $9004 \mathrm{E}-0 \mathrm{z}$ $-1.26221-0$ $-5.0656-6$

$4-09728-9$ $-1,13332$ $+-63012-02$

$-0.5189 \mathrm{e}-4$ $0.6095-\mathrm{e}$

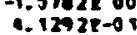

Ta-t at wes

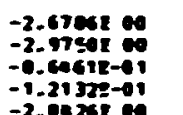

$-2-\cos 6500$ $-2 . \cos 5200$

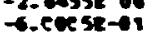
$\rightarrow$ recor 0 $-5.0070-01$

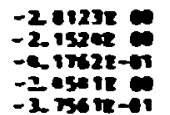

$-3.37 c e r e 0$ $-1.557200$ $-2-c a s=1$ $-2-63332$
$-3-2 x \in E-1$

$-1.2005-101 \quad-2.902 \pi-01$

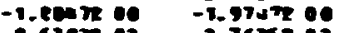
$-0.63002-02$ $-1.3039200$ 2.16J5e-0. $-\cos x x_{0} \rightarrow 1$

$-0.9515 e-01$ - axise- Leiste1.00238-en

-1.57zor $\rightarrow .0 \times x<-1$ $7.000 \mathrm{x}-1$ 1. $3252-1$

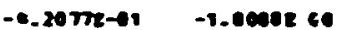
$3.65658-09$ i.tsenter $3.55102-01$

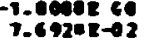
$1.69256-02$ $-1.02050$ -1.

$-1-\operatorname{men}$ $62 m 32-0$ $-7.22032$ -2. 16 cese

$-1.10912 .0$ 7.6xinger $-1.20052$ $-1.33585$

$2.25301-02$ 0.0072 $-1.60 \mathrm{cs}-0.1$ $-1.50618-01$

$-1-02550-0$

$-25312-01$

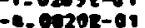
$-3.2126=-01$ s. -3 10jce-02

-1-71278-09 - -3637e $\rightarrow$ 1 $-8.26252=0$ ? $-63792$

$-2.56702-01$ $1.60255-9$. C.3jor-01 $-6.9304202$

$-3.5052-0$.

$-2.437 x-0$

1.2029E 00

- zente-a -.0525:-01 $-2.611 \mathrm{n}-01$

$-1.23918-61$

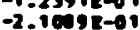
-2.0532-01 - - S257e$-.2505 \mathrm{R}-01$

$-3.5903 x-01$ $-7.16732-01$ $-6.070101$ $-7.3800200$

$-9-2033 x-04$ $\rightarrow-15202-0$ ! -1. IcTuE ol

-1.09ezE 00

3. $91332-0$ $-1.236 \pi$

$+6.65001801$ $-6071 z-01$ $-1.5013200$

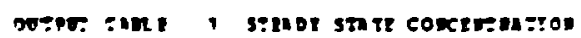

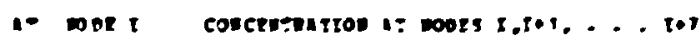

:

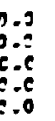

$$
\begin{aligned}
& 1.0 \\
& 0.0 \\
& 0.0 \\
& 0.0 \\
& 0.1
\end{aligned}
$$

$\begin{array}{ll}01 & 0.9 \\ 0 & 0.0 \\ 57 & 9.0 \\ 65 & 9.0 \\ 13 & 0.5\end{array}$

0.0
0.0
0.0
0.0
0.0

$\begin{array}{rr}11 & 0.0 \\ 9 & 9.0 \\ M 1 & 9.0 \\ 105 & 9.0 \\ 11 & 0.0\end{array}$

$$
\begin{aligned}
& 0.0 \\
& 0.0 \\
& 0.0 \\
& 0.0 \\
& 0.0
\end{aligned}
$$$$
\begin{aligned}
& 0.0 \\
& 3.0 \\
& 0.0 \\
& 3.0 \\
& 0.3
\end{aligned}
$$

$$
\begin{aligned}
& 0.0 \\
& 0.3 \\
& 0.3 \\
& 0.5 \\
& 0.0
\end{aligned}
$$

$$
\begin{aligned}
& 0.3 \\
& 0.3 \\
& 0.3 \\
& 0.3 \\
& 0.3
\end{aligned}
$$

0.3
0.0
0.0
0.0
0.5

0.0
0.0
0.0
0.0
0.0

0.3
0.0
0.0
0.0
0.0
0.5
0.8
$c .8$
0.0
0.6

$0 . c$
0.0
0.0
$c .8$
$0 . c$

0.0
0.0
0.0
$c .0$
0.0

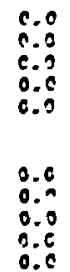

0.0
0.0
0.0
$0 . c$
0.0

0.0
0.0
0.0
0.0
0.0
0.0
0.0
0.0
0.0

0.0
0.0
0.0
3.0
0.0

0.10
0.0
0.0
0.0
0.0
0.0
0.0
0.0
0.0

0.0
0.0
0.0
0.0
0.0

0.0
0.0
0.0
0.0 
APPENDIX D. OUTPUT (Continued)

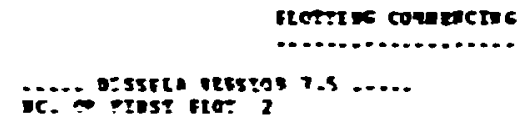

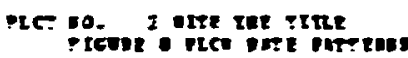

ins ter contrits.

PLe IC. Miex:
PEC ?

Desa ror pras

ce. op cunve canes a

costr. ars i terese

vest. itrs teme

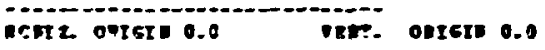

cever

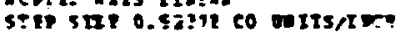

150.000

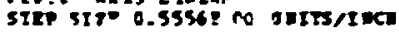

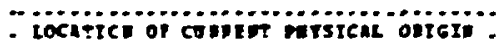

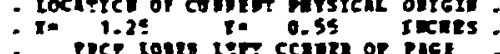

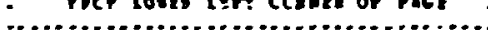

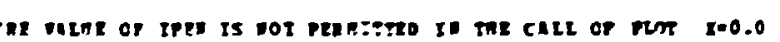

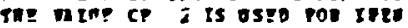

$T=0.0$ IPE.

939

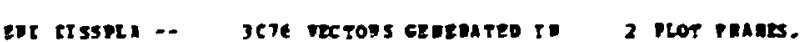

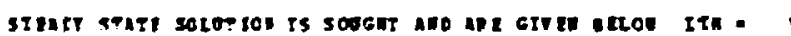

rece - int, J sthet sthe stiean rocerton

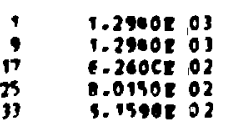

1.0493103

1. 2xigr $C$

1.1636803

6.3002
7.5602
02

6.2600202

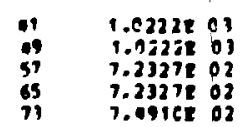

4. 364 12 02

9. 1430 62

7.750720

7.06332
7.30732

6.2600102

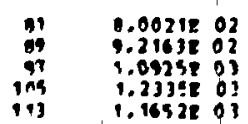

$1.69250^{02} \quad 7.3090202$
0253202

0.35328 ol

.001620

T.10ner os
1. 29001 02

1. 29408 C3

1.1196203

1.0027503
6.2600502 1.2 vere cj T. Thie 03 1.0375203
.0900202

1.07322 02

7.16522 of

6.7616102

6.51558
6.9459

0.2600202

6.2600802

6.2600202

6.2600802

0.0068.02

0.9701202

7.2139202

7.6701202

- .300er c2

0.2047262
6.6432202

1.29202 03

1.2900803

. 19702 03

1.0293803
$6.09 \cos 02$

.2100102
0.05005 02

0.0900202

.0900202

6.0900202

1.0900202

0.090020

1. 5367 o2

7.71570 .02

7.3005202
6.05002 o2
1. crese 03

1.2900203

$1.20 n 2203$

1.0602203
$9.1009=02$

-. 3019: 02

$\because 202020$

0.040520

7.965520

0.2625102

0.0900202

9.36202 or

7.6076 o2

$7.0006 \mathrm{E}$
-. 10131 02

1. 16132 oj

1.1272203

1.0773503
$.5670 \times 02$

6.2600202 0.6207202 P.:5751 07 $1.036 ? 2$ 0
1.02222 o3

-.73118 02

0.2274802

$7.74418 \mathrm{C2}$

7.01921 o?
†. ja292 02

1.0222803

$1.2327 \times 02$

7.2327202

7.654502
., 3233802

0.7045802

i.tesiz os

1.j3708 03

9.7aces 02

Tisite:

i.3rioe 03 
APPERDIX D. OUTPUT (Continued)

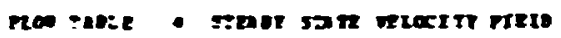

DLL-I it noes

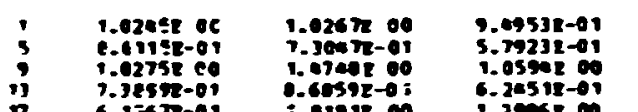

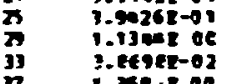

$n \quad 1.330 .200$

$21-3-679 \pi-01$

$\rightarrow \quad-7-2005 x-c 1$

2.7067200

2.30372 00

-.619ve 0

i.zose os

7.75372-01

$1.95018-02$

2.ThI -01

G. pcosz-a

-.6571:-01

1.5932x 60

1. $\operatorname{cosec} 5-1$

$2.65122-01$
$6.25502-01$

-.. xา12-01

-. $2092 x-01$

$7.27052-01$

$1.3201 E-01$
$1.01022-01$

ล.7120E-0

2- $435 \mathrm{~s}=6$

3.6775 2-01

1. 21228-0
3. $12118-01$

$0.20102-02$

7. $55702-03$

$-.70222-03$

$-1.73122-01$

1. TOSE-01

$-1.0178-02$

$-1.10698-01$

$-2.50198-01$

- 4. ve1

$-5.93672 \rightarrow 1$

$-2,796$ tz- 01

$-1.5003200$

$-3.30702-01$

$-3.75072-61$

$-2.3315200$

$-7.6945 \rightarrow 1$

$-3.50108-02$
-1.0090200

-3.2010200
$-4.30740-01$

-1.7159200
$-2.92728-01$

$-2.917200$

$-3.29338-01$

1. 1925z-01

$-2.3561200$

-.64908-0.

- *.5798-0

1.2557-01

1.51702 00

$-5.6424-01$

9.962 IE-01

$-1.10622-03$
-1.7999100

$-1.0037 \mathrm{~L}-21$

$3.9960 \mathrm{z}-01$
$3.9652 \mathrm{z}-6 \mathrm{R}$
Tet-t a nots

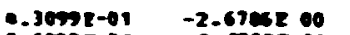

5.603 $7-0$

-7rear-e

1.2309500

-2-ngor a

- -

$-2.0025200$

c. $3030 \mathrm{E}-0$

2.12068 60

2.53nt-01

3.3030100
$-2.0506-01$

- :- 20001-01

- - mane oo

$-8.63822-0$

5- $3542-01$

1.05osz- C1

1.0436 of

1. Tरा पर्०

:-12038 00

- - 20m-01

$3.6565 \mathrm{E}-1$

- 1. I975E o0

3-65 $6 \mathrm{~m}-02$

2. $5310=-01$

$-4.0 .02-61$

5.0006 $8-02$

$-1-26222-01$

$-3.59238-01$
$-3.06558-01$

$2-25302-02$

C. $077 \mathrm{E}-02$

- 1.6005e-0

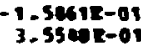

$-0.09728-01$

$-1.1353200$

-1. $\cos \mathrm{E}-01$

-2.20971 of

$-2-56702-01$

$1.60252-01$

$-0.3330 \mathrm{z}-01$

$-6-4058-02$
$-5,3808-08$

$-0.5119 \mathrm{z}-31$

$0.6094=02$

$-1.0702200$

$-3.58032-01$

$-7.16752-01$

$-6.07102-01$
$-1.2432-01$

$-1.32258-0$

-1. 1670 e 00

$-20123 \pi$ $-2.1524$ $-2172 \mathrm{x}$ -3 T5 $12-01$

$-3.37608$ -1.5\%s? 0 - - cansi-0 $-3.02602-1$

$-2.9027-69$ $-1.974700$ 2.7635:-92 -. ovs32-a1

$-0.36+5 x-01$ - L 19p 101 - 1. T5ses 0 1.60232-01

-1.57zez ea - etec5-9 -7.erc5-01 -1.00068 of 3.0325I-01

$-1.0004=00$

$7.6924 \mathrm{E}-02$
$-7.020 \mathrm{~s}-00$

$-1.6206200$

-1.7 is $32-0$ ?

$-1.9992200$ 6. 24a 3e-0r - 1-92032 00

$-2-\operatorname{coc} 2-01$

- i. iscre

-1. 1097200

1.45028-01

-1.24552 00

$-1.2336200$

$-5.6295-01$

$-1.0255 \mathrm{E}-01$

- $-00202-01$

$-2 x 31 z-01$

$-5.21205-01$

-1.0:77p-ar

$\begin{array}{ll}-3.23912-01 & -5.2651 \\ 1.27352-01 & -5.1636 z-02\end{array}$

$-1.71272-01$

$-3.36372-01$

$-1.26252-01$

$-6.63798-09$

$-1.5126 \mathrm{z}-01$

-3. $\operatorname{ses} 2-01$ 1.26295
$-.2617=0$

$1.50372-01$

$-2.037 x-01$

-1.239180 1 3.0520E-01 -4. 4925E-61 $-2.6117-01$ $-6.0112 z-01$

-2.10058-01 $-2.05532-01$ $-6.52572-01$ $-.25052-01$

-5. $16148-01$ $-1.0902200$

$3.91335-0$

$+.65048-01$ $\rightarrow .60718-01$ $\rightarrow-33032-01$

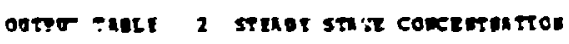

at wet $t$ concentation at wors $1, T+1, \ldots$. I0)

1 5.260ez-01 5.269az-01 5.2009z-01

$1.0030200 \quad 9.51952-01$ C.6946-01

5.306ez-01 $1.0000200 \quad$ 9.09est-01

$\$ .250 C 2-01 \quad 5.26342-01 \quad 1.0000200$

$5.07252-61 \quad 5.06397-01$

$3.3002=0.01$

7. $92778-c 1$

$0.0119=-11$

5. $26032-01$

6. 6065E-01

- . 75762-01

1.5000 co

$.00755-01$
$9.34258-01$

5. 28102-01

$5.51048-0$

6.7716 E-0

$0.70922-01$
c. 45932-01

5. 20cas-0

5. 47182-01

5. 15sez-0

$6.65302-01$
$7.6542 x-61$

5. 2733201

$5.36012-01$

5. 4500z-0

5. $66132-01$

$.66612-0$

$0.00302-01$

c. 11602-0 1

1. $\operatorname{cesn} 2-01$

$0.03032-01$

.

6. ผ61:-01

$6.2931 \mathrm{z}-01$

$0.55062-01$

$7.36602-0$

C. $51752-01$

- Aract-o

2.7659

3. 9ess 201

$3.06858-21$

6. $6711-0$

3. 9110e-0

$1.45952-01$
$5.78592-02$

$5.73772-0$

-.00soz-01

$3.65052 \rightarrow 2$

s.

5.56et-0?

$3.33098-02$

$5.43532-02$

$5.05 \times 2-02$

$5.69712-02$

$3.61158-02$

$-121108 \rightarrow 2$

6.760es-02

3.79272-02

$\operatorname{lol}_{1.863} \sum_{-02}$

$3.00928-02$

$3.63058-02$

$1.01738-02$

$3.56262-02$

3. $1702-0$

$3.01908-02$

2. $30618-02 \quad 2.09002-02$

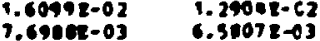

5. $4328-01$

5. 77532-01

1. 16648-02 
APPENDIX E. LISTING OF FORTRAN PROGRAM

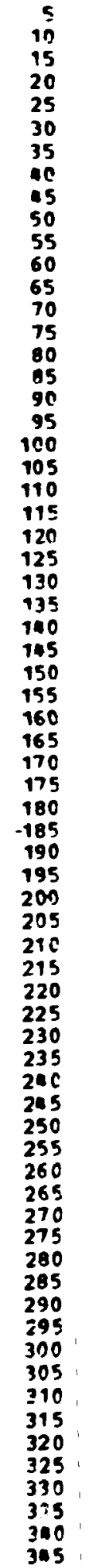

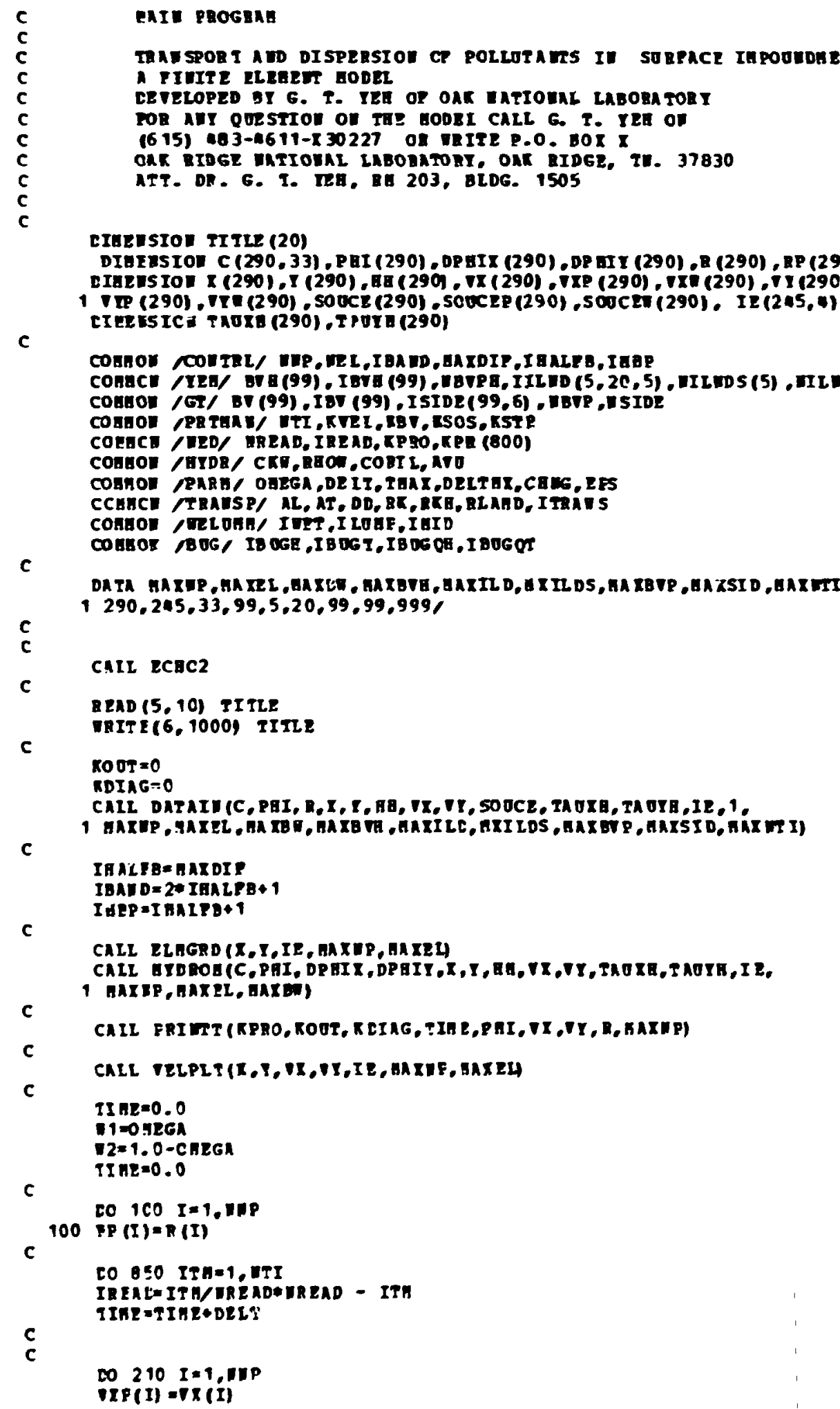

maI 005 aAI 010 TAII 015 GA: 020 GAI 025 GAI 030 GAI 035 GAI OAO GAI 0as BaIN 050 GAI 055 Gar 060 DIEFESIOI C (290,33), PAI (290), OPEIX (290), DP DI (290), R (290), RP (290) EAI O65

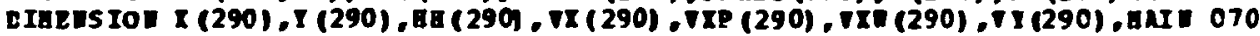
(245, a) aII 075 GAIT 080 GAI 085 aAII 090

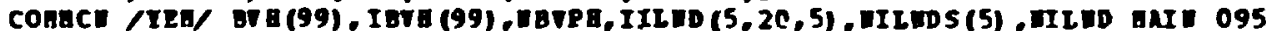

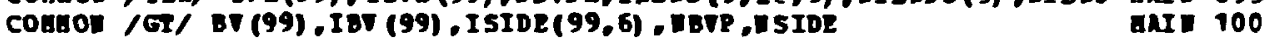
GAII 105 anis 110 aAI 115 GaI 120 EAI 125 GAI 130 GAIT 135 GaI 190 GaIs ias GAII 150 GAI 155 GAIN 160 HAII 165 GAI 120 GAII 175 MAII 180 aAI 185 GAII 190 BAI 195 Bar 200 DAII 205 MAIN 210 GAI 215 GAII 220 maII 225 MAII 230 HAII 235 GAII 200 GaII 2as hAII 250 HAII 255 mAI 260 जAII 265 HAIT 270 HAIV 275 IAII 280 MAII 285 GAII 290 MAII 295 ARI 300 DAII 305 Hart 310 BAIV 315 GAII 320 HAII 325 hary 330 ตAII 335 HAII 3*0 GAII 345 
APPENDIX E. (Continued)

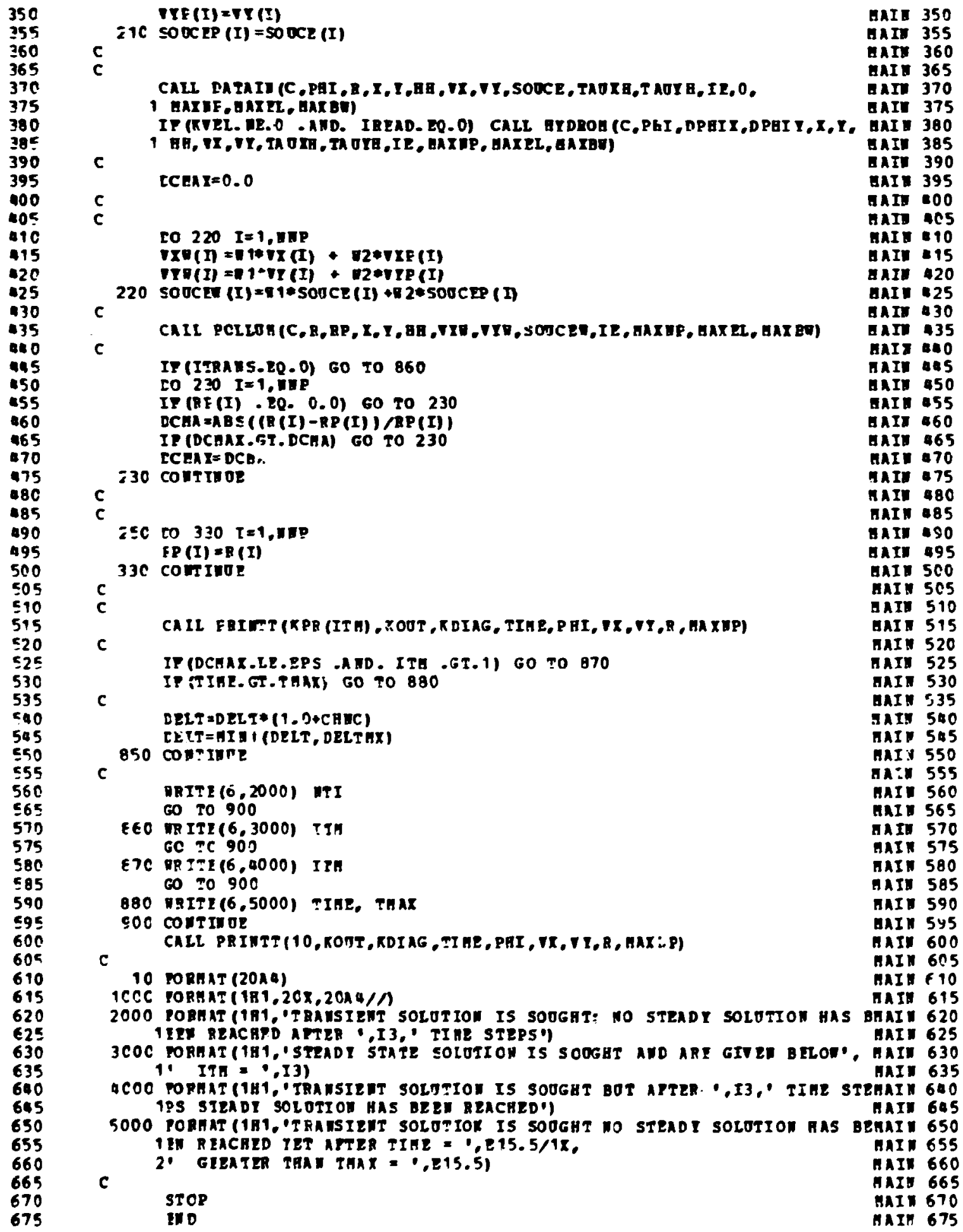


APPENDIX E. (Continues)

c

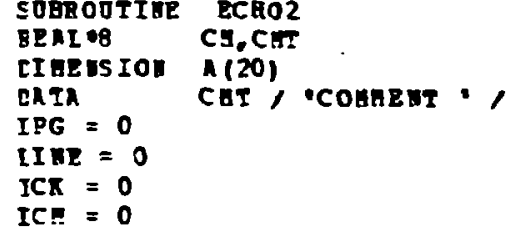
$3.678901234567890123456789012345678901234567890123456789012345^{\circ}$ ECFO 175

ECBO 005 ECEO 010 ECBO 015 ECEO 020 ECAD 025 ECHO 030 ECEO 035 RCBO 040 ecRo 045 ECED 050 ECRO 055 ECEO 060 ECEO 065 ECEO 070 RCuO 075 BCEO 080 ECEO 085 ECEO 090 ECWO 095 ECEO 100 ECBO 105 EC 110

ECEO 115 zсао 120 EC BO 125 ECBO 130 ECEO 135 ECEO 140 EC 80145 ECEO 150 ECEO 155 ECHO 180 ECHO 185 RCEO 190 ZCHO 195 ECBO 200 ECEO 205 ECHO 210 
APPENDIX E. (Continued)

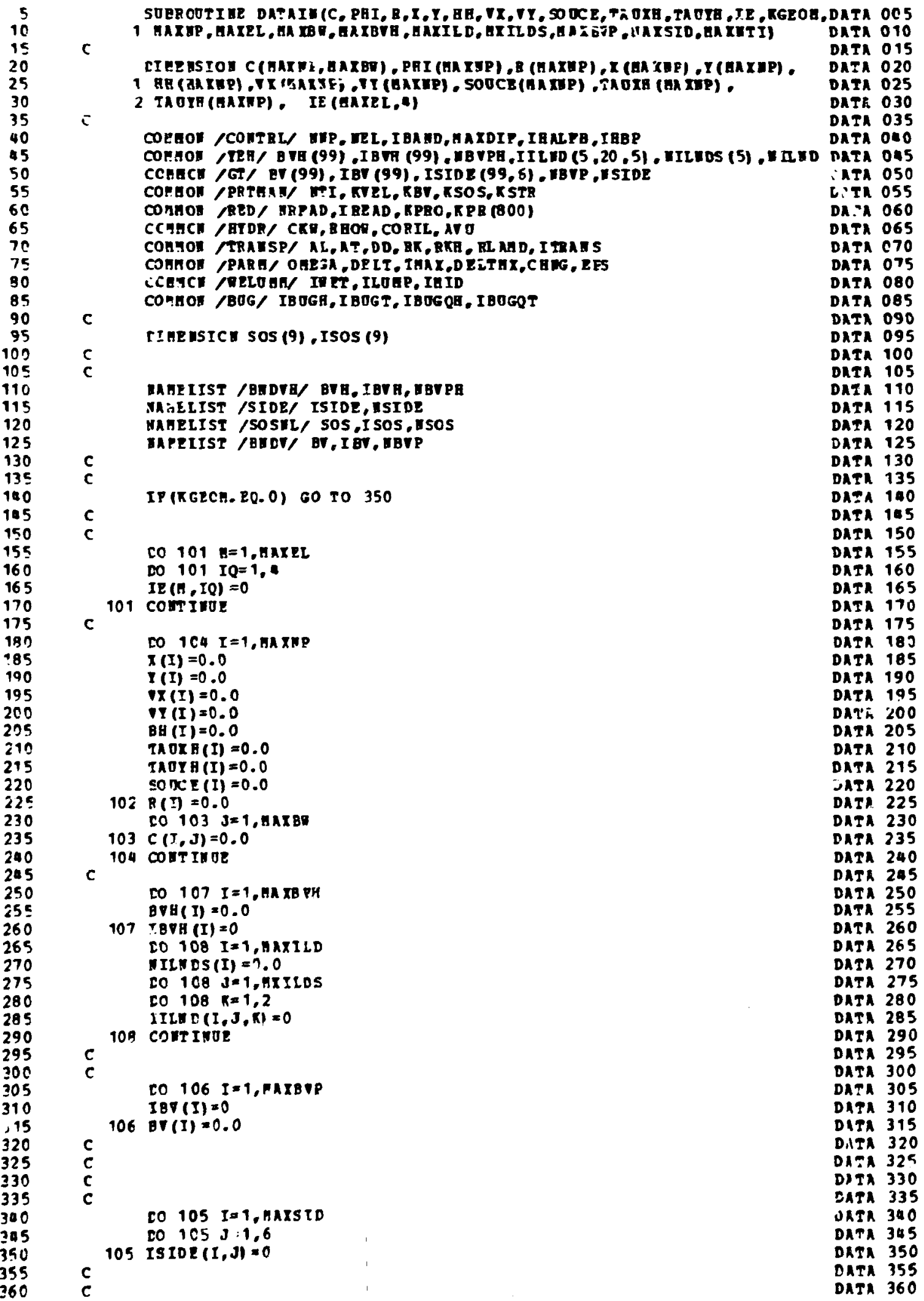


APPẼNDIX E. (Continued)

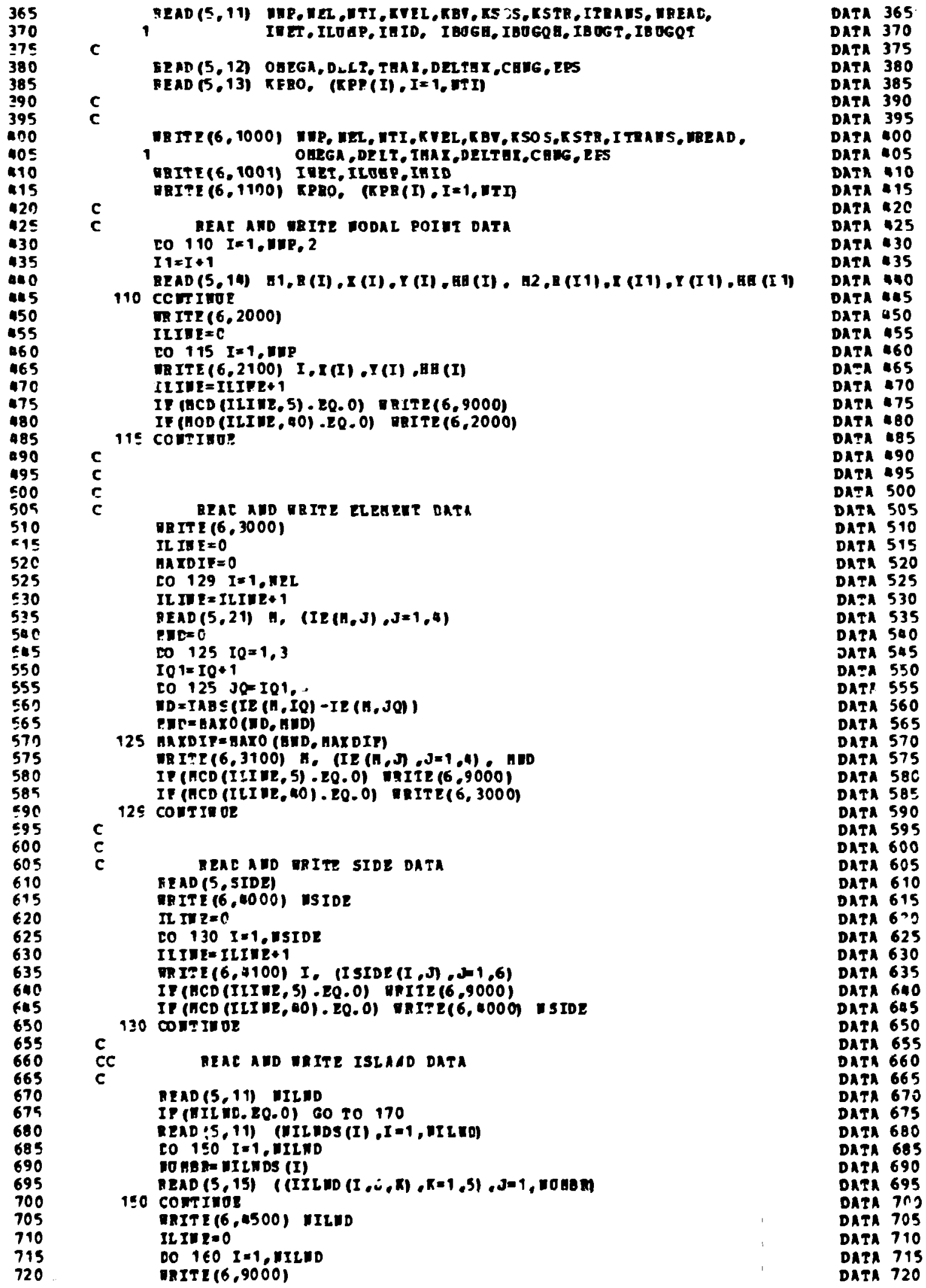


APPENDIX E. (Continued)

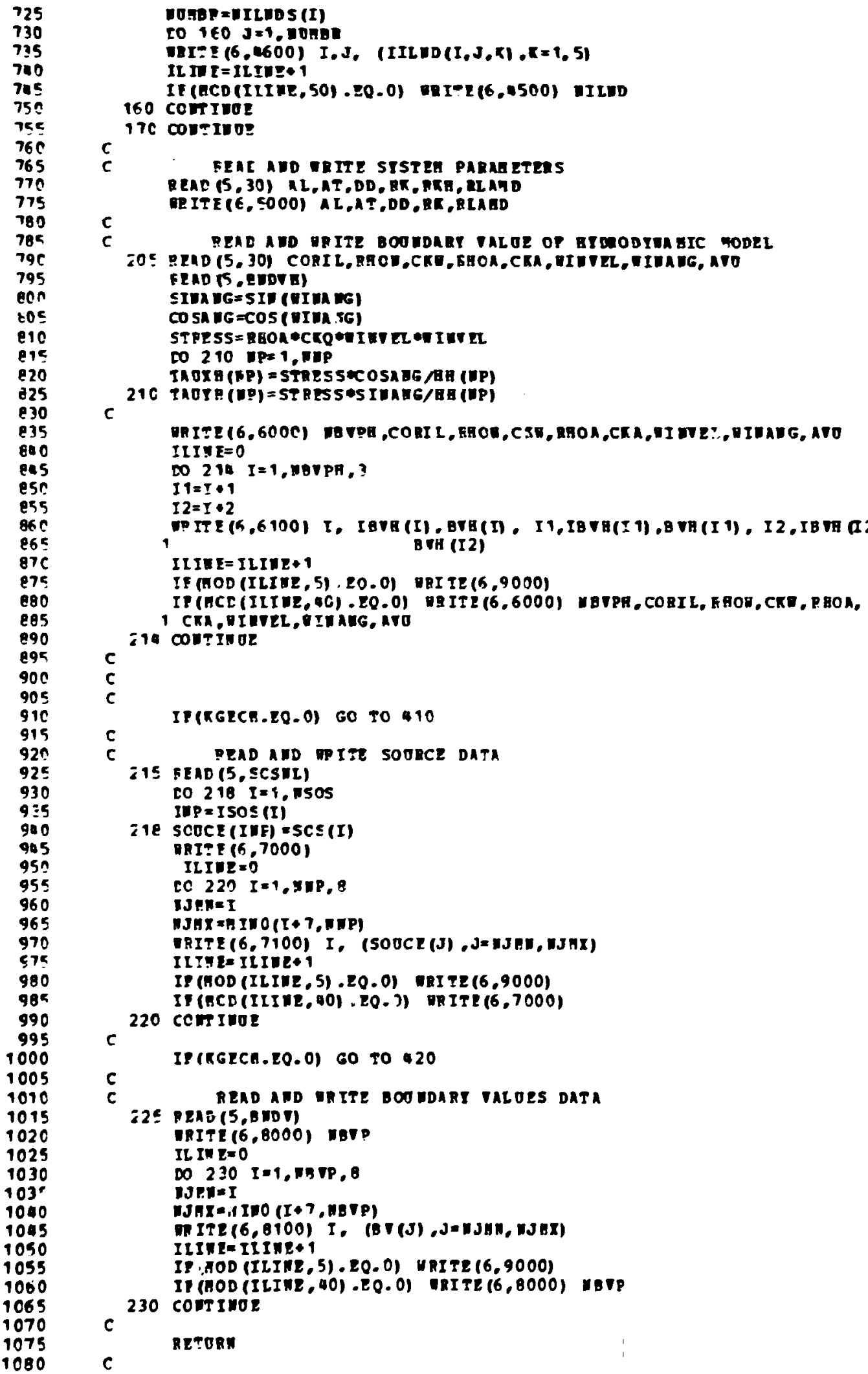

DAFA 725

DATa 730

DATA 735

DATA 700

DAEA 745

DATA 750

DATA 755

DATA 760

DATA 765

DATA 770

DATA 775

DATA 780

DATA 785

DRTA 790

DATA 795

DKTA 600

DATA 805

DA=n 810

DATA B15

DAsA 020

DATA 825

DAFa 830

DA?A 835

Data 840

DAT 845

DAT 850

cita 855

dnTA 860

DATA 865

DNT 870

OATR 875

DATA 880

DAT 885

DAra 890

DATA 895

data 900

DA:A 905

DATR 910

DATR 915

DATA 920

DAm 925

DATA 930

DATA 935

DATA 940

datr 945

DATA 950

DATA 955

DATA 960

DATA 965

DATA 970

DATA 975

DATA 980

Data 985

data 990

DATA 995

DAs 1000

DATA 7005

DATATO10

DATA 1015

DATA 1020

DATA1025

DATA 1030

DATA 1035

DATA1000

DATA 1045

DATA 1050

DATA1055

DATA 1060

DATA 1065

DATA 1070

DATA 1075

DATR 1080 


\section{APPENDIX E. (Continued)}

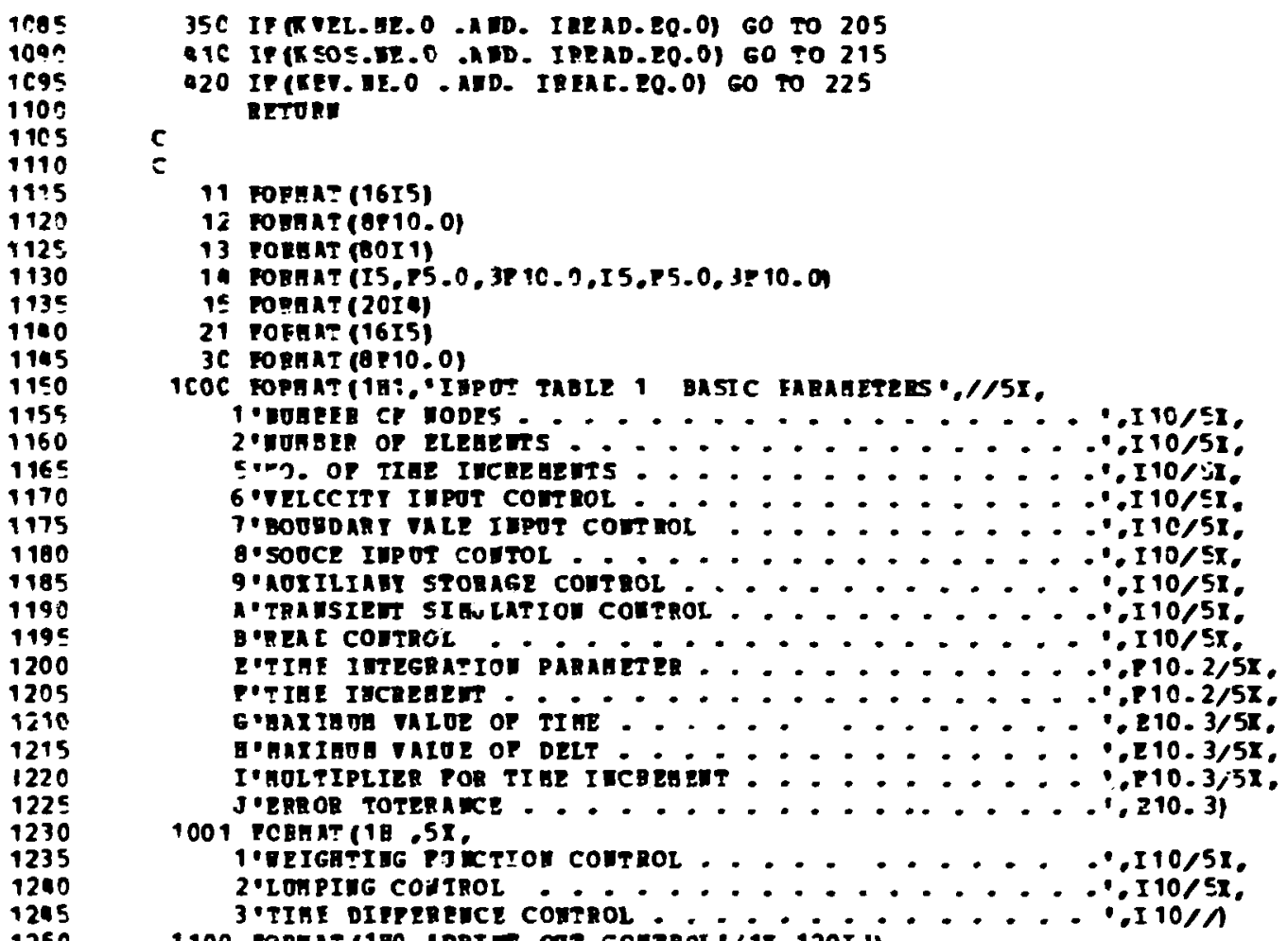

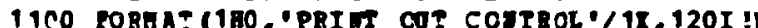

2000 FOBHAT (1R1. 'IUPOT TABLE 2 MODAL FOI OATA $114 x_{0} \cdot 1 \cdot, 14 x_{0} \cdot \pi \cdot n$

2100 POAHAT (1A I I 10,3 P15. A)

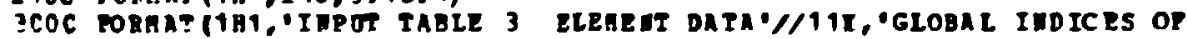

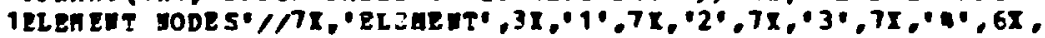
2 PICDE DIFT. $/ 1$

3100 FORART (I 10, I8, I10)

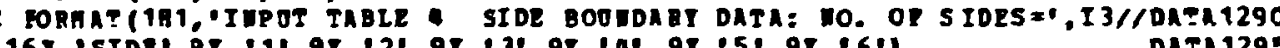

400 Pophat (11, $5 x, 14,6510)$

DRIR1085

DA=A 1090

DATA 1095

DATA1100

DATRTios

Dara1110

DATA1115

DATA 1120

DATA1125

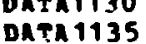

Dara11ao

Datal1as

DATA1150

Data1155

DArat160

DATA1165

DAta1170

DATA1175

DATA1180

DATA1185

DATA1190

DATA1195

DATa1200

DRTR1205

Data1210

data 1215

DATA1220

DATA1225

DATA 1230

DATA1235

DATA 1240

DATA 1245

DATA1250

DATA1255

DATA 1260

DATA 1265

DATA1270

DATA 1275

DATA1280

DATA1300

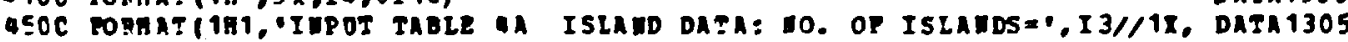

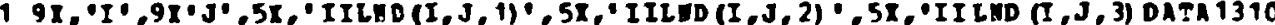

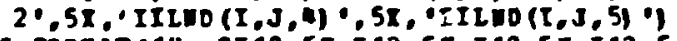
1 Longrtodianal oIspensitrat

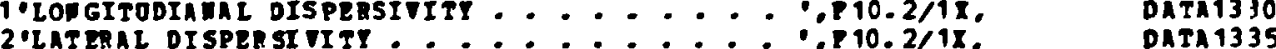

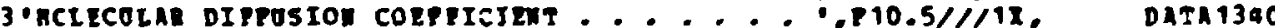

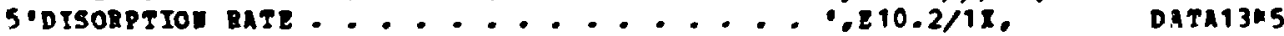

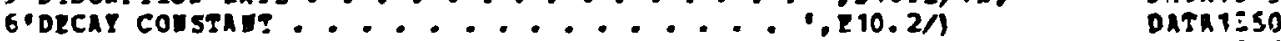

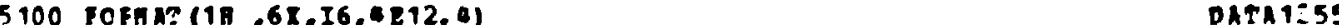

6000 FORAAT (1H1. IUPOT TABLE 6 STSTEM PARAMETERS AHD BOOHDARY DATA PORDATA1360

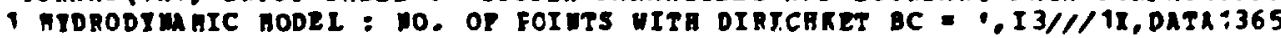
2 'CCRCLIS PARAMTER . . . . . . . . . . P12.5/1X DATA1370

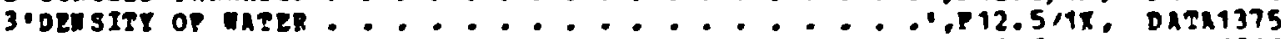

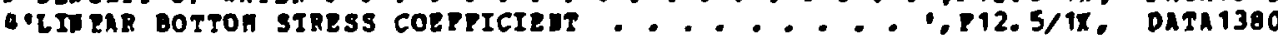

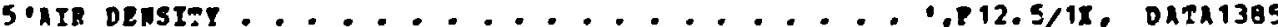

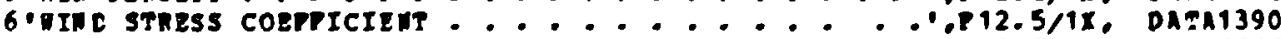

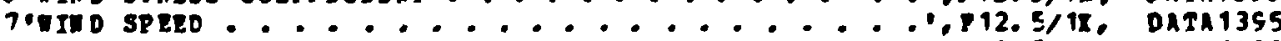

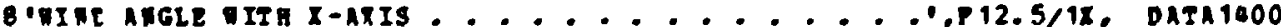

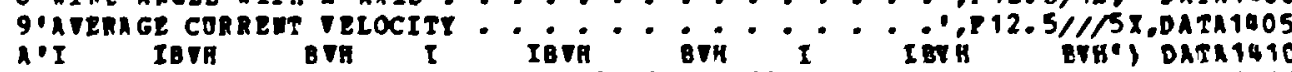
6100 POBHAT(1H , I5,I7, $710,3,15,17,710,3,15,17,110.3)$ DATA1415 7000 FORART (1B1. IUPTT TABLE 7 SOURCE DATA I/1R. DATA1A20 10 NUP
2 $7100^{2}$ rosints (18, $\left.15,8 \times 10.2\right)$ 
ORNL-5522

APPENDIX E. (Continued)

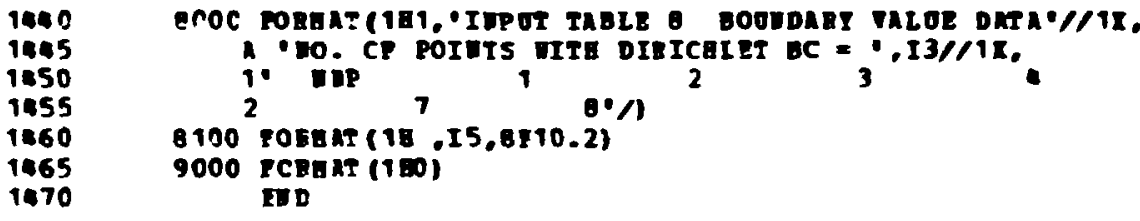

Daraiano

DATa 1945

6Darateso

Daraies5

Data 1960

DATa1465

DAtaye7o 
APPENDIX E. (Continued)

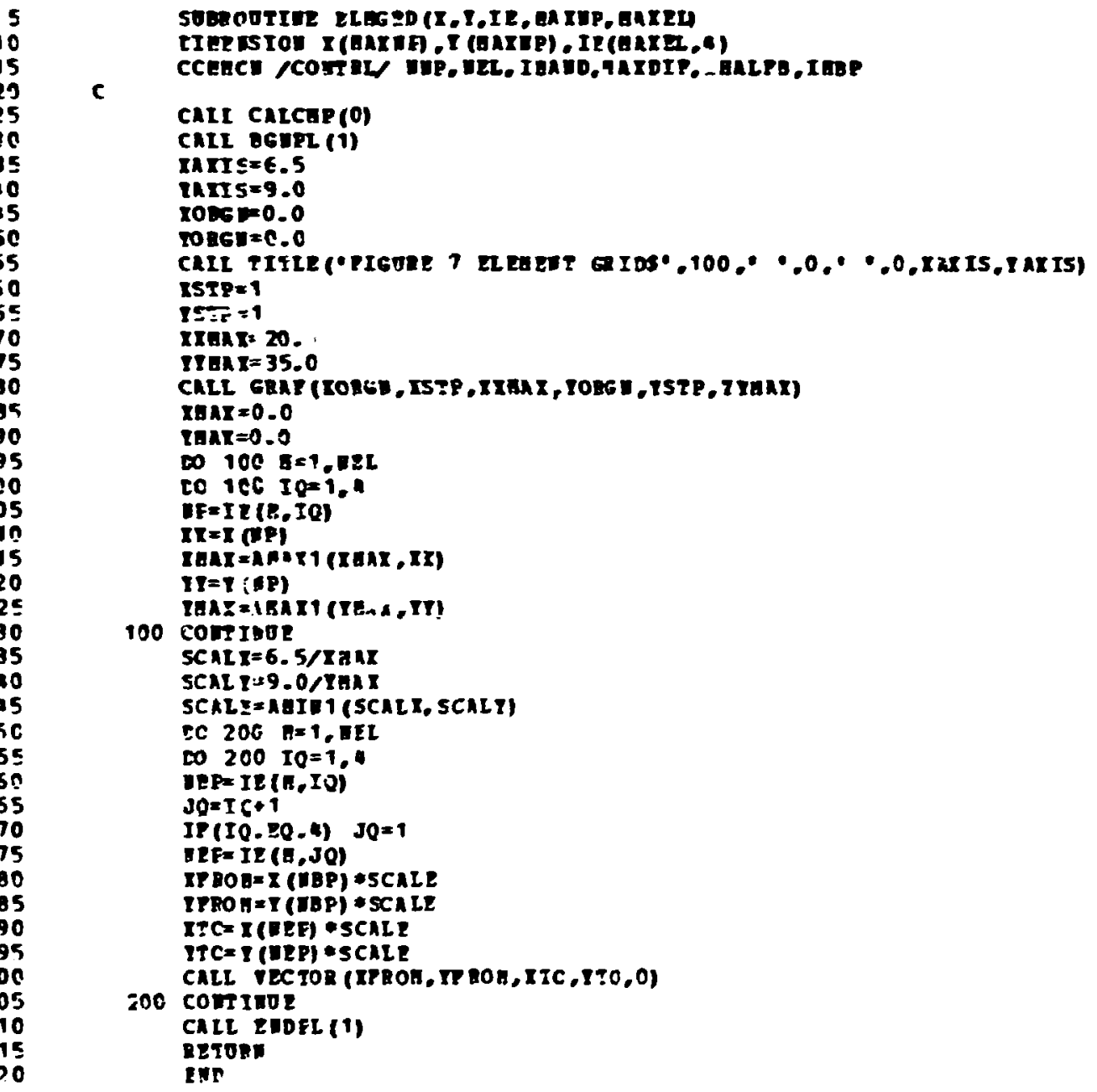

Zas 005 Zac 010

ELes 015

ELA6 020

EIAF 025

ELes 030

Hac 035

eIfe 0AO

etoc 025

ELE 050

Elac 055

EIES 060

ELG 065

ELE 070

ELEG 075

LIAC 080

EIEG 085

LLES 090

IIEG 095

LAE 100

ELas ies

ELEG 110

EIEG 115

ELE 120

EIIG 125

EnE 130

ELES 135

EAG 100

ELAG 145

ELAG 150

ELEG 155

AnG 160

ELAG 165

LEG 1:0

EIIE $17 \%$

ELAG 180

ZLAG 165

A1.6 190

ELEG 195

ZLEG 200

ELEG 205

ELTE 210

ThE 215

RHE 220 
APPENDIX E. (Continued)

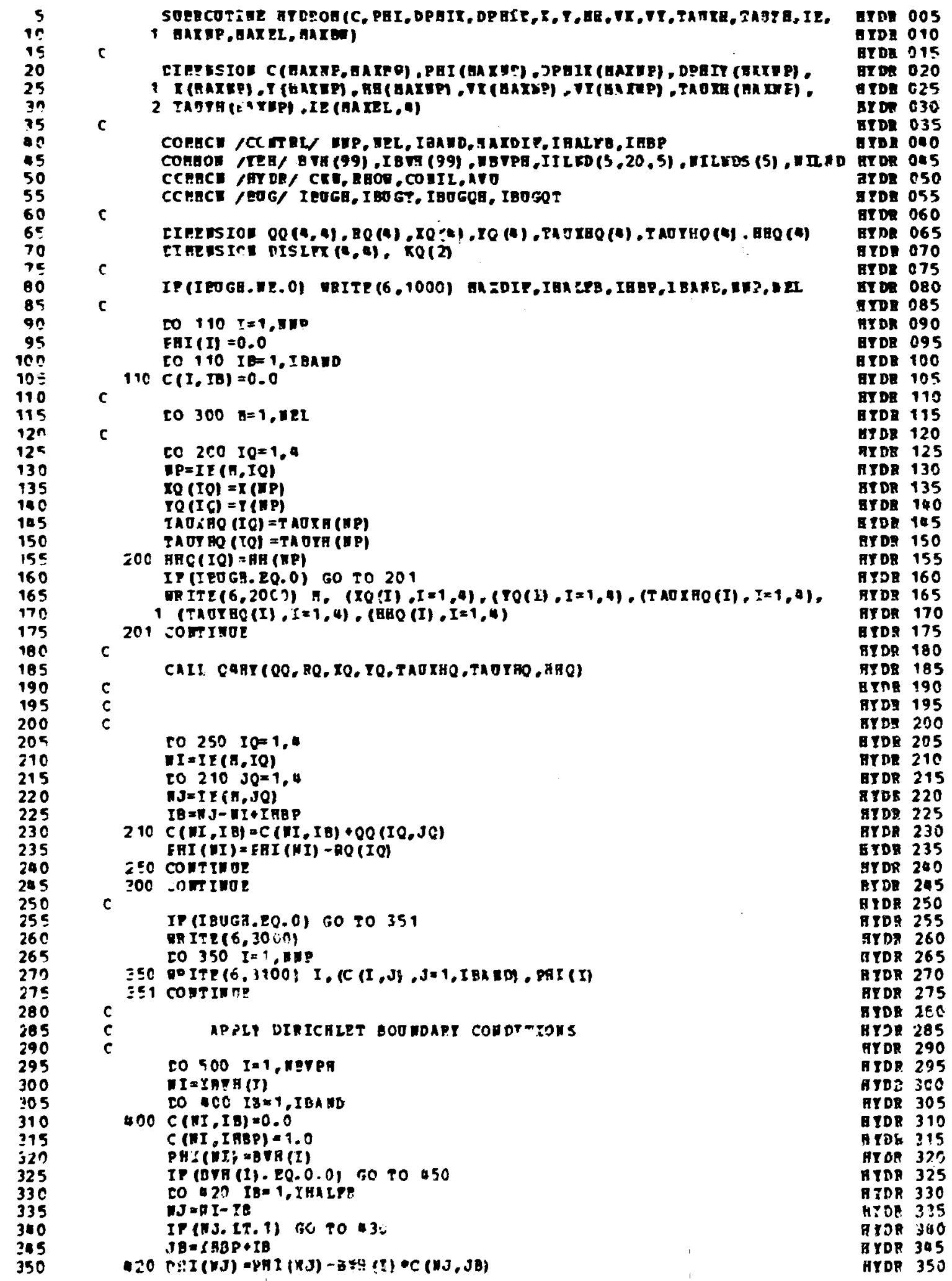


APPENDIX E. (Continued)

- 30 IC $\triangle 40$ IB= 1, IARLPB

$B J=T+I B$

IF (BJ.6I.⿴囗十P) 60 T0 450

$J E=I$ QP $F-I B$

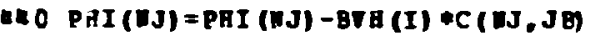

ESC TO EEO IB= , IHALPB

$M=I-I E$

IF (U.J.LT. 1) $60 \div 0 \div 70$

$J E=I B B P+I B$

$460 \mathrm{C}(\mathrm{W}, \mathrm{J} \theta)=0.0$

$\triangle 70$ to $: 80$ IB $=1$, IAA LPB

$\mathbf{M}=\mathbf{I}+\mathbf{I B}$

IP (BJ.GI. WEP) 60 T0 $\$ 90$

$J ?=I$ BBP - IB

MEC $C(D \mathrm{~J}, \mathrm{JB})=0.0$

190 CONT INOR

c

500 conTINOE

IP (I EOGB. EQ.0) GO TO 551

DR IT $2(6,0000)$

so $5 \leq 0 \quad I=1$, IUP

550 DRITI $(6,3100) I,(C(I, J), J=1, I 8 A M D)$. P RI (I)

c

551 CONT INOE

C

IP(IILD.EQ.0) GO TO 700

POR IHE PIRST POI T OP EACH ESLAWD THE CORRES POMDIHG BOA

CP C(LP, ZE) GAS TO BE HODIPIED

DO $6 \in 0$ IL=1, שILUD

10 B $\mathrm{B}=$ IILUS (IL)

LO 650 IS $=1$, $10 \mathrm{MBR}$

II $=$ I ILDD (IL, IS, 1$)$

XJ I I ILD (I L, IS, 2)

$\mathrm{E}=$ II IND (IL, IS , 3)

RO (I) $=\operatorname{IILDD}(I L, I S, 4)$

$\pi Q(2)=\operatorname{IIIND}(I L, I S, 5)$

$X L I G=X(M J)-X(Y I)$

TLWG $=$ T (UJ) - T (WI)

ALIG $=S$ CBT (XLWG*XLWG+YLWG*TLEG)

AUGL $L=A T A \| 2$ (ILMG,XL:G)

DO F 10 IO $=1,4$

$T E=I E(B, I Q)$

$x 0(I C)=x(N P)$

C

610 TQ IIQ) $=\mathrm{I}$ (NP)

c

$c$
$c$

CALL OUISL (OISLPX, XO, YQ,KO,ALYG, AMGLE)

ASSEHBL TOD BOONOARY GATRIX TO YORA THE GLOBAL BOOUDAB WATAL

Do $62010=1,2$

$L Q=R Q(I Q)$

$M I=I \sum(H, L Q)$

20 $620 \quad 3 Q=1,4$

$\omega J=I \sum(n, 30)$

$I B=\mathbb{T}, J-I+I B B P$

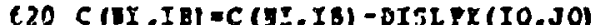

$65 C$ CONTIN DZ

$c$

660 COMI IOE

c

C

c

POR ALL OTRER I SLADD POIMTS OF EACH ISLAHD SET THE TALOE OP EACB POINT ROOATL TO THE PIRST POIN?

LPPLIING ISLAHO BOOPDART COMDITIONS

G TnR 355

B TOR 360

HY DR 365

B TDR 370

GTDR 375

HY D? 380

BTD 385

B TDR 390

HY DR 395

BTDR 400

B TDR 405

EY 410

G TDR 415

B TDB 20

ITD 25

G 70840

H YDS $\propto 35$

GTDE 400

G TDR 455

E YDR 45r

AY DR 455

GTDR 460

BYDR 465

HIDR 970

B TDR 475

ETDI 480

TY DR 485

A TDR 490

G TDR 495

GY DR 500

ET DE 505

F TDB 510

HIDR 515

EY DR 520

F IDB 525

GI DR 530

GTDR 535

B TDR 500

HT DR 505

GT DR 550

B TDR 555

AT DR 560

AY DR 565

E TDR 570

FIDR 575

TI DR 580

BTDR 585

AT DR 590

AI DR 595

B TDR 600

HI DR 605

II DQ 610

BTDR 615

HI DR 620

BI DR 625

BTDR 630

ATDR 635

RIDR 640

A YDR 645

HT DR 650

HY DR 655

GIDR 660

AIDR 665

HY DR 670

GYR 675

HY DR 680

RY DR 685

HIDR 690

HI D. 695

HE DE 700

G YOR 705

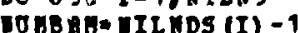

CO $680 \mathrm{~J}=1,1$, IRBRA 
APPENDIX E. (Continued)

715

720

$I=I I L D D(I, J, I)$

DJ=I ILDD $(I, J, 2)$

PHI (EJ) $=0.0$

ro $67 \mathrm{C}$ je=1, IDAmb

$C(1 J, J B)=0.0$

ETC CorTIJOE

$C$ (A), IBEF) $=1,0$

$I B=I-4 J+I B B P$

$C(1, . I B)=-1.0$

eec costinos

c

690 Comring

770

775

780

785

790

795

800

805

810

อ15

820

825

835

840

845

850

es5

860

265

e70

e75

e80

885

890

895

$90 \mathrm{C}$

905

$91 \mathrm{C}$

IF (IBUGE.20.0) 60 To 696

IBIT E (6.5000)

Do $695 \quad I=1$. IVP

ESE DR IE $(6,3100) I,(r(I, J), J=1, I B A D D), \operatorname{PHI}(I)$

c

696 corringe

c

7CC cortrisoz

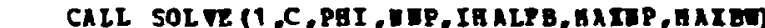

CALL SOL VE (2,C,PII, ETP, IBALP, GAIUP, GAZBA)

C

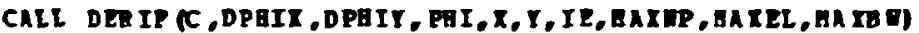

C

LO $900 I=1, \mathrm{DEF}$

$\mathrm{VI}(\mathrm{I})=-\mathrm{DPBII}(\mathrm{I})$

$V F(I)=D P$ HI $T(I)$

900 covtrigo

BETORE

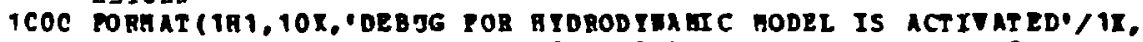

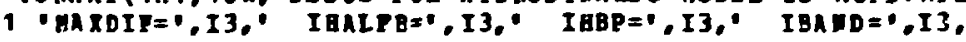

2 - $\quad \mathrm{TP}=0, I 3, \quad \mathrm{~T} I=1, I 3)$

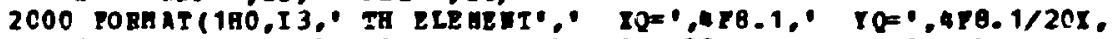

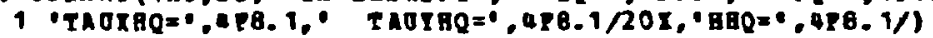

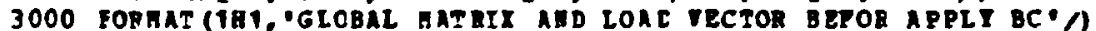

3 IOC FORGAT(1RO.I3, (11E11.3))

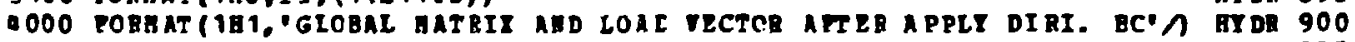

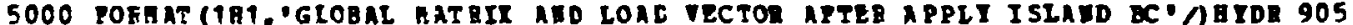
III E 


\section{APPENDIX E. (Continued)}

(2)

$2 \mathrm{C}$

25

35

?

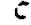

c

$c$

LO $100 \mathrm{IC}=1$.

BQ (IQ) $=0$.

Do ICC $J 0=1,4$

$100 \mathrm{CQ}(\mathrm{I}, \mathrm{JQ})=0.0$

$x 12=10(1)-10(2)$

$x 13=x C(1)-10$ (3)

$714=x 0(1)-x 0(4)$

$\times 23=x 0(2)-x Q(3)$

$\times 24=x 0(2)-x Q(a)$

$x 30=20(3)-10$ (a)

$11=\operatorname{IC}(1)-\operatorname{IQ}(2)$

$1+3=10(1)-10(?)$

$714=10(1)-10(4)$

$123=\operatorname{rc}(2)-10(3)$

$129=10(2)-10(4)$

$734=70(3)-70$ (4)

DRI $\Lambda=0.0$

to $400 \quad 17=1,4$

$55=P * 5(\pi G)$

$T I=P * T$ (RG)

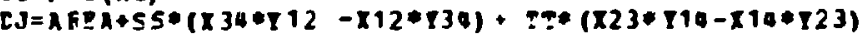

CJAE $=0 J / A, 0$

B. IA $=A$ Q IA $+0 J A C$

CJI $=1.0 / 0 \mathrm{~J}$

$S H=1,0-5 S$

$S P=1.0+5 E$

$T H=1,0-T T$

$T O=1.0+T T$

CRI $(1)=(-\times 24+X 36 * 55 * \times 23 * T \pi) * 0 J$

CसT $(2)=(x 13-x 36 * 55-x 14 * T T) * 0 J I$

$C \forall Y(3)=(x 24-x 12 * 5 S+I 14 * T T) * 0 J I$

CII (a) $=(-x 13+x 12 * 5 S-\times 23 * I I) * 0 J 1$

$\operatorname{CrX}(1)=(124-\mathrm{T} 38 * 55-123 * \mathrm{TT}) \bullet \mathrm{OJI}$

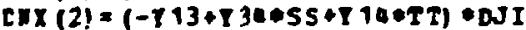

CNX(3) $=(->24+712655-714 * T \mathrm{~T}) * 0 \mathrm{JI}$

INI (4) $=(\mathrm{T} 13-\mathrm{T} 12 * 55+123 * \mathrm{TT}) * 0 \mathrm{JI}$

$n(1)=0.25 * 5 H * 2$.

$\pi(2)=0.25 * 5 P * T$

$N(3)=0.25 * S P * ? P$

$c$

$N(i)=0.25 * 5 \% * T P$

ᄃнхK $=0.0$

CATK $=0.0$

ARK $=\mathrm{C} .0$

DO $200 \quad I 0=1,0$

$P A K=$ GRK + T(IO) + HKO (IO)

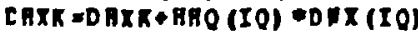

200 CATK=DATK \& HAO (IO) *DNT (10)

IP (IDTGOR. NE. O) WRITE $(6,1000)$ RG,ARK, DAXK, DATK, (N (I) ,I=1,0),

$1(0) x(I), I=1,4),(D) I(I), I=1,4)$

C

$20300 \quad 10=1,0$

$\therefore 300 \mathrm{JQ}=1,4$

DUXO

CATDNT= DNT (IO) PDET (JO) PD.TAC

DON $x=1(I Q) \bullet D Y X(J Q) * D J A C$
OART ces

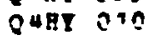

Q4AT C 15

Q4AT 023

Q4AT 025

Q4月 0 T 0

Q4日 035

Q 4AT 040

Q4A Y 045

o4n 350

Q4BY 055

Q4月 Y C60

Q4hY 065

Q4AT 070

Q4RT 075

Q4B I 080

24) 085

0ब 1 I 0.0

ca月r 095

Q4AY 100

Q4RT 105

O4AT 110

Q4AI 115

Oan 120

QAFT 125

Q ART 130

QBA 135

O4RT 100

Q4A 145

Q⿻日土 150

Q4 月र 155

O4hY 160

Qष 165

Q⿻ 月र 170

Q⿻日月 175

os 1 T 180

Q4 RT 185

ด๑ก 190

Q⿻日⿰丨丨丁 195

QART 200

Q 4AT 2C5

Q AT 210

O4 RT 215

Q

Q4HY 225

Q⿻ 月R 230

04RT 235

Q⿻日⿰㇒夫 240

Q4 HT 205

Q 4RT 250

Q4A 255

00 R 260

Q4R厂 265

Q4月 Y 270

0987 275

Q4H 280

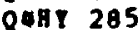

Q4 B 290

Q 4月T 295

Q4AT 300

Q4 मा 305

Q4月 310

Q4ก 315

Q4 BT 320

Q4 RT 325

Q4ก 330

04 A 335

ontr 340

$048 Y 345$

2n 350

Q4AT 345 
APPENDIX E. (Continued)

360
365
370
375
380
285
390
395
400
495
410
155
220
425
430
435
440
445
450
455
460

DEET $=(I C) * D E T(J Q) * D J A C$

Q48 Y 360

$09(T 0, J Q)=0$ TrDEX

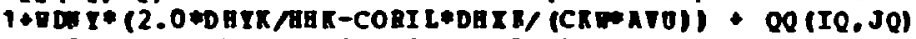

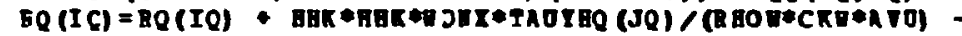

Q⿱日一⿻口卄. 370

Q4A 375

Q4⿴囗十 380

ece cosermoz

c

IF (IBUGQH. 2Q.0) GO TO 351

ORITI (6,2000) KG,ARIA

DO $350 \quad I=1$.

$350 \operatorname{Rr} I T(6,2100) I,(00(I, J), J=1,4), \operatorname{RQ}(n)$

EST COSTIY OE

00 COITIMOE

Q4BY 385

Q4BT 390

OA日 I 395

Q4EI 400

Q4BI 405

Q4B 1910

Q4ET 415

Q4a 1420

Q4ET 125 RETORI

Q4BI 430

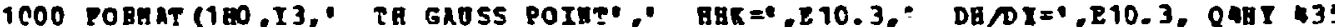

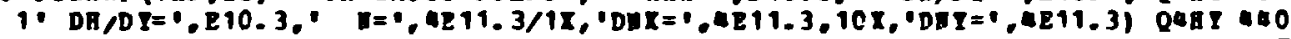

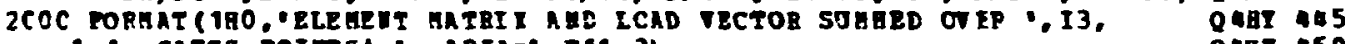
1. GAOSS POINTSC, AREA=?,E11.3)

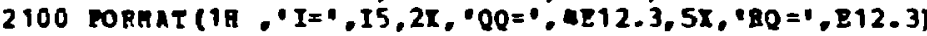
IMD 
APPENDIX E. (Continued)

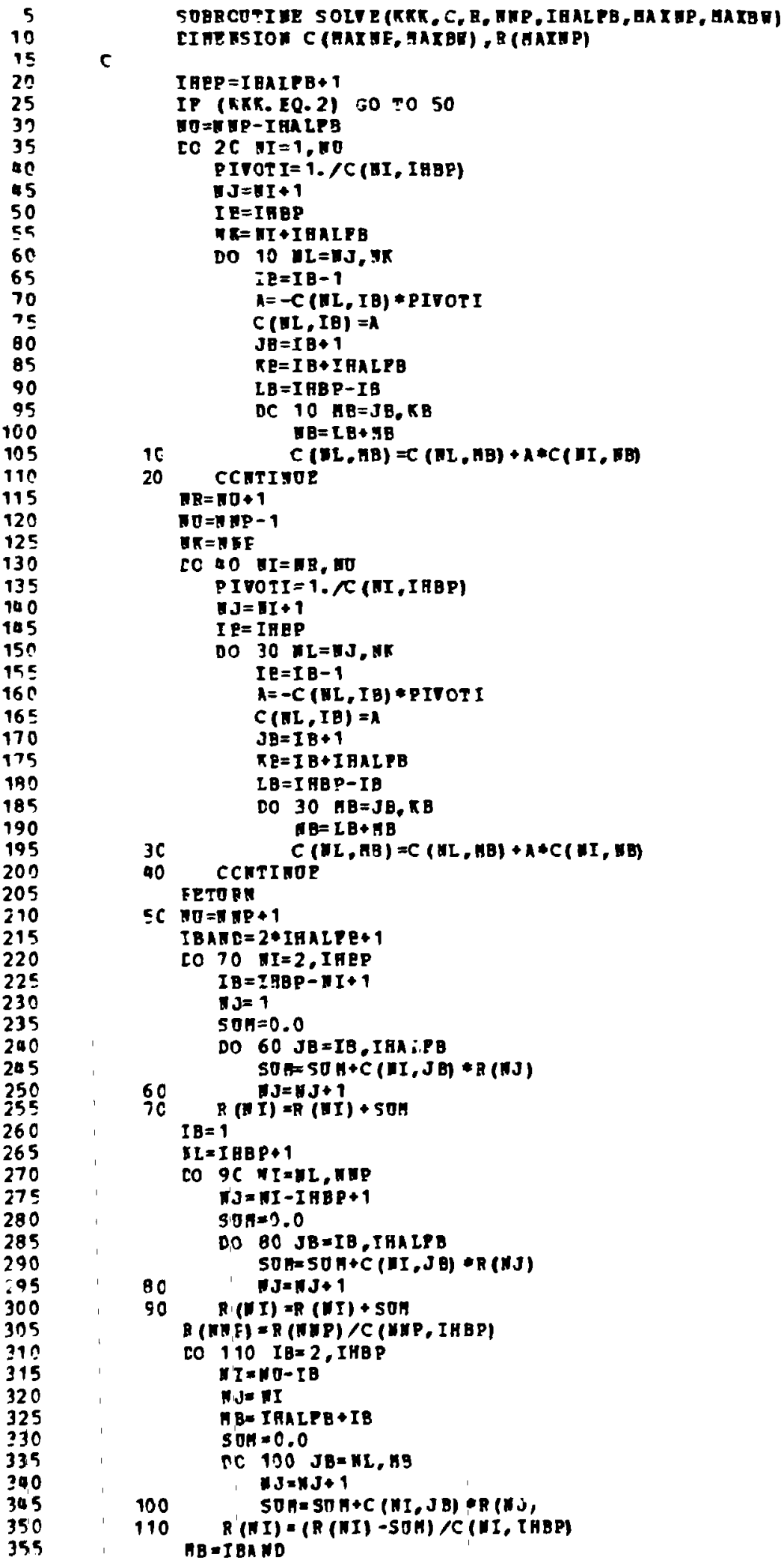

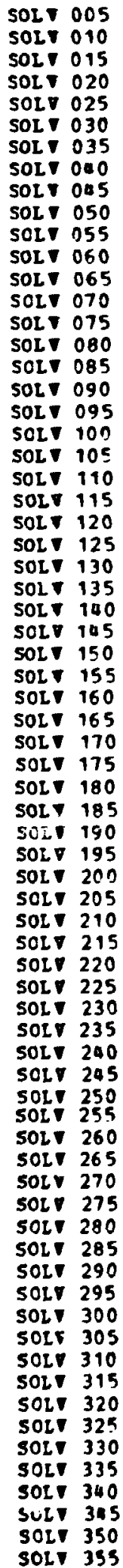

SOL 005 SOIV 015

SOLV 020

SOL 030

SOL 035

SOLV 085

SOL 1050

sot? 055

SOL 065

SOLV 070

SOL 080

SOLT 085

SOLV 100

SOLV 105

SOLV 110

SOL 120

SOL 125

SOLV 130

SOL 140

SOLV 145

SOLV 150

SOLV 165

SOLV 180

SOL 185

SOLV 195

SOL 200

OLV 205

SOL 215

SOLV 220

Sol 7225

SOLV 240

SOLV 260

SOLV 275

$50 L 280$

OLV 285

50L 295

SOL 300

solr 305

LD 310

SOL 320

325

SOLV 335

solv 333 
APPENDIX E. (Continued)

\begin{tabular}{|c|c|c|}
\hline $\begin{array}{l}360 \\
365\end{array}$ & & $\begin{array}{l}1 \geq 0 \quad I B=M L, M B P \\
I=\theta D-I \theta\end{array}$ \\
\hline 370 & & $\therefore I=B I$ \\
\hline 375 & & $S 0 \mathrm{OH}=0 . \mathrm{C}$ \\
\hline $\begin{array}{l}380 \\
385\end{array}$ & & 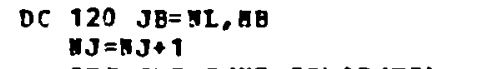 \\
\hline & $12 j$ & SOE $=S O A+C(E I, J \theta) * \mathrm{~B}(\mathrm{KJ})$ \\
\hline 3 & 130 & $R(n I)=(8(n I)-50 R) / C(B I, I B B P)$ \\
\hline 00 & & TOBN \\
\hline
\end{tabular}

SOL 380

SOL 385

SOL 390

SOLT 395

SOL 100

SOt? 05 
APPENDIX E. (Continued)

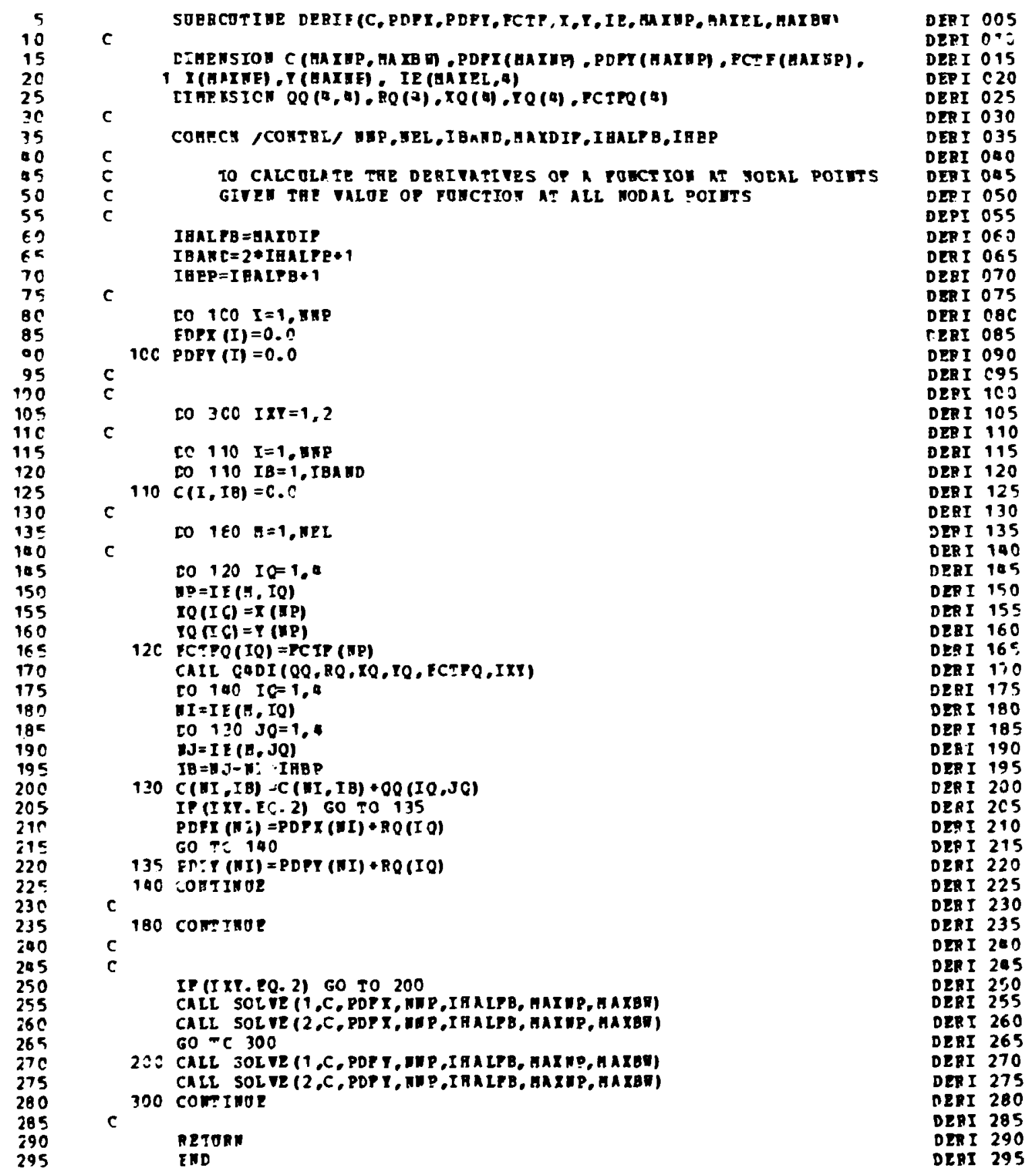


APPENDIX E. (Continued)

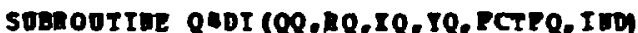
DEAL Da (a)

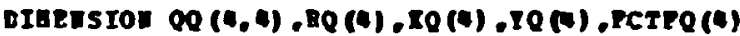

c

c

ch Th $P / 0.577350$

cxtA $5 /-1.0,1.0,1.0,-1.0 /, 1 /-1.0,-1.0,1.0,1.0 /$

to $100 \quad 10=1$,

Me $(T C)=0.0$

DO $100 \mathrm{~J} 0=1.0$

c

$10 G 00(I 0 . J Q)=0.0$

$112=20(1)-x_{0}(2)$

$x 13=20(1)-x 0(3)$

$\operatorname{I10}=\mathrm{xO}(1)-\mathrm{xQ}$ (4)

$\pi 23=20(2)-x 0(3)$

$124=\pi 0(2)-x Q(4)$

I34x $80(3)-x_{0}(4)$

$112=10(1)-1 Q(2)$

$113=20(1)-10(3)$

$114=20(1)-10(0)$

$123=10(2)-10(3)$

$124=10(2)-10(4)$

$130=10(3)-10(4)$

c

$A B=\times 13 * 124-\times 24 * 113$

to $\$ 00$ Re 1.4

SEMP*S (RG)

TI=P $=T$ (RG)

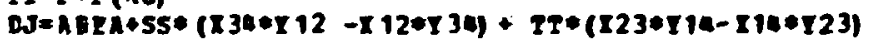

IJAC $=D J / 8.0$

CJI $=1.0 / \mathrm{CJ}$

$S:=1.0-5 S$

$S P=1.0+5 s$

$T=1.0-T T$

$T P=1.0+T T$

DI $I(1)=(-\times 24+\times 34 * 55+\times 23 * \tau T) * 0 J I$

LII (2) $=($ I13-R 34*3S-RIA *TT $*$ DJI

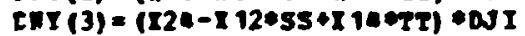

EV $Y(4)=(-x 13+x 12 * 55-x 23 * T \pi) * D J I$

$\operatorname{CNR}(1)=(724-734 * 35-123 * \mathrm{TT}) * 0 . J T$

LRI (2) $=(-I 13+[3 * * 5 S+I 14 * T T) * D J I$

$D P X(3)=(-124+112 * 55-\Gamma 14 * I T) \cdot D J I$

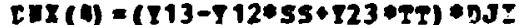

I(1) $=0.25 * 98 * T$.

(1) $=0.25 * 3 P * T H$

$H(3)=0.25 * s p+T$

c

(c) $=0.25 * 5 n \rightarrow p$

$\operatorname{crIR}=0.0$

EFIK $=0.0$

Do 200 IQ: 1,0

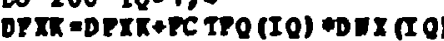

200 IPIR=DTYI + TCT TO (IO) *DIT (IO)

c

I- IID. EC. ?) 60 TO 320

$\infty 300 \quad 30=1,4$

RC (IC) $=80(I 0)+\pi(I 0)$ DRTR* DJAC

to 3 CO Jo- 1,

$00(I 0, J 0)=0 Q(I Q, J Q)+1(I Q) \bullet(J 0) * 0 J A-$

c corisor

co to 340

320 D0 330 IO-1. $R Q(I Q)=R Q(I O)+M(I Q)$ DP IKODJAC
Q⿻日土d 035

QADI 010

Q4DI 015

Q⿱ D) 020

QADI 025

Q4DI 030

Q4DI 035

04cI 040

Q4DI 045

Ch DI 050

QADI 055

Q4DI 060

Qed 065

Q4DI 070

Q4DI 075

Q4DI 080

04DI 085

QeDI 090

0ADt 095

04DI 100

Q40I 105

Q4DI 110

QADI 115

QADI 120

Q4DI 125

QADI 130

QADI 135

QHDI 100

OADI 145

OA DI 150

QADI 155

OADI 160

OMDI 165

OA DI 170

QADI 175

Q⿻D DI 180

nADI 185

OADI 190

ONDI 195

Q*DI 200

OADI 205

OADI 210

Q⿻ DI 215

OADI 220

OADI 225

QA DI 230

OADI 235

OADI 280

QADI 205

OADI 250

OADI 255

OADI 260

QHDI 265

OADI 270

OADI 275

QADI 280

OADI 285

OADI 290

QADI 295

OADI 300

OADI 305

Q40I 310

QADI 315

Q⿻日土 DI 320

QHDI 325

OADI 330

GDI 335

QADI 340

OADI 345

OADI 350

ocor 355 
APPENDIX E. (Continued)

\begin{tabular}{|c|c|c|}
\hline $\begin{array}{l}360 \\
365 \\
370 \\
375 \\
380 \\
385 \\
390 \\
395\end{array}$ & $C^{330} \begin{array}{l}300 \\
000\end{array}$ & 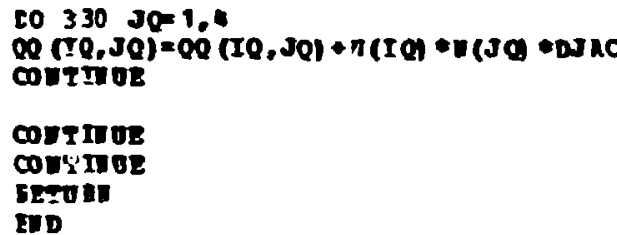 \\
\hline
\end{tabular}

QADI 360

QDDI 365

QHDI 370

Q4DI 375

Qmid 380

oAd 385

Q4DI 390

Q4 DI 395 


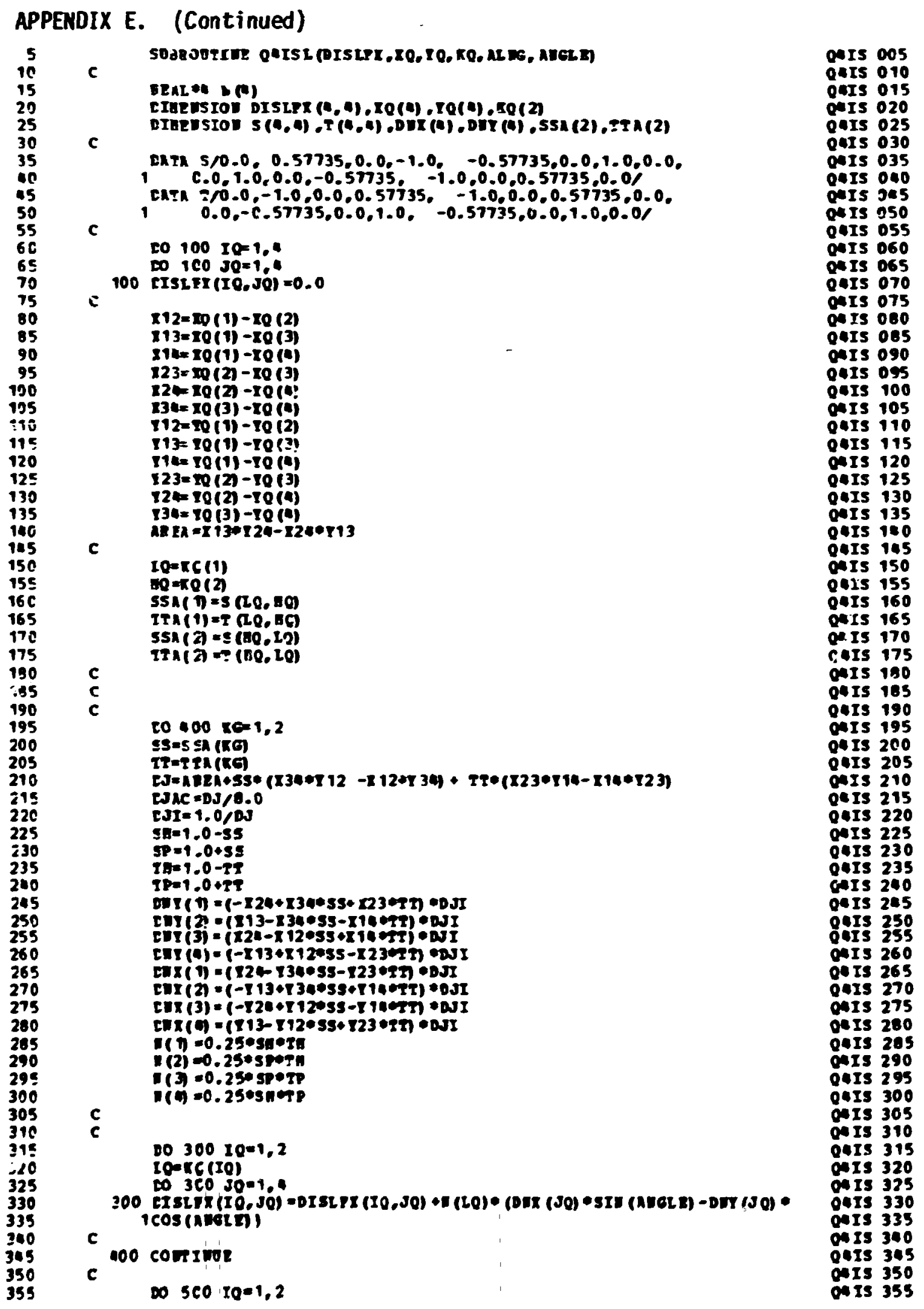


APPENOIX E. (Continued)

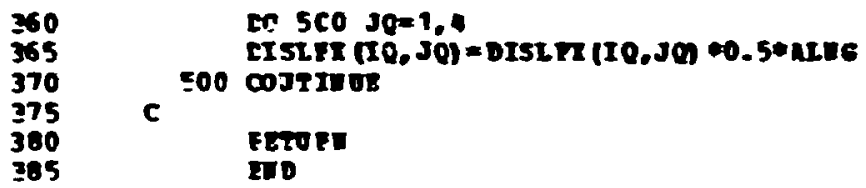

Q4Is 360

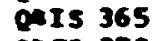
CIIs 370

Q4I5 375

Ders 380 .

oe Is 385 
APPENDIX E. (Continued)

5

15

15

25

$3 \mathrm{C}$

35

5
5OBROUTIE RLPLT (X, T, TX,TY,IE, GATER, GRTK)

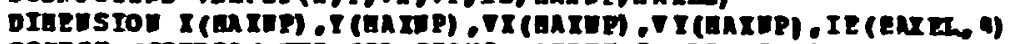

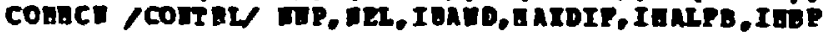

C

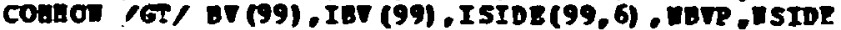

c

$$
\text { CAIL DGEFI(2) }
$$

$\operatorname{xarI} 5=6.5$

IArIs $=9.0$

TORe=0.0

rover $=0.0$

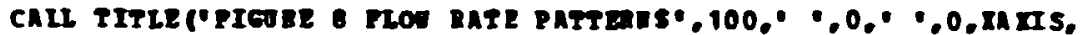
Iraris)

ISTP $=1$

ISTP=1

IThK I=6.0

TYan $x=5.0$

C
C

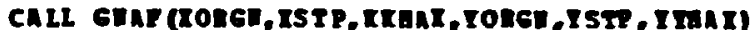

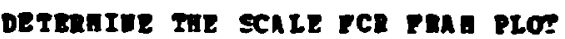

$\operatorname{Ian} x=0.0$

$\operatorname{Tan}=0.0$

LO 100 as 1, DEI

Do $100 \mathrm{IQ}=1.9$

WP $=12(A, I Q)$

$x \mathrm{x}=\mathrm{x}$ (I)

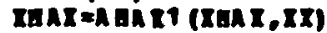

TT $\rightarrow$ I (DP)

TARI= ABATI (TAR , IT)

TCC contrim or

scai $x=6.5 \tan x$

SCALFe9.0/Tan

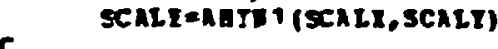

c cLTERIEE SCALE POE TEOCITY PLOT

$$
\text { c }
$$

c

SCal $7=0.06$

to 2 CO $I=1,8950$

ITD IS IDE $(I, 6)$

IF (IND. 27. 10) 60 T0 200

$n=I S 19 E(I, 3)$

IIsISIDE (I. 1)

$\omega=I$ SIDR $(I, 2)$

Irnot= I (UI) 由seale

IFOOE I (II) HSCALE

ITO-I (TJ) OSCALE

T20-1 (UJ) escare

CAIL TECTOR(x ROA, I T2OR, XTO, I20,0)

c

200 corritur Das plon are vecton

ro $390 \quad H=1,02 L$

iv $x=\mathrm{C} . \mathrm{C}$

TrFec. 0

IPBO: 0.0

TrTh $=0.0$

LO $31010=1,0$

ITr 11 (D., I0)

ximon-xinowex (up)

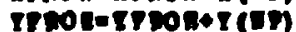

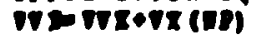

ingevertr (4)

310 comsing

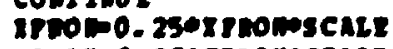

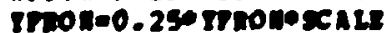

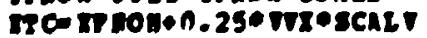

rice rrieno. 23* viroscalt

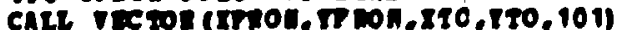

390 COTrINE

carl zDor :21

Call BoTtor

อรT)

ITD
TELP 005

VEP 010

TELP 015

TELP 020

TEP 025

VELP 030

VELP 035

THP 040

VELP 045

VEIP 050

VEAP 055

VELP 060

TELP 065

VAP 070

VELP 075

TELP 080

TEP 085

VEZP 090

TELP 095

VEP 100

VELP 105

VELP 110

verp 115

VELP 120

TELP 125

TEP 130

TELP 135

TELP 140

VEP 145

TELP 150

TELP I5S

TEP 160

TELP 165

tela 170

VEP 175

TELP 180

TELP 185

VEP 190

TELP 195

TELP 200

VIP 205

vala 240

VELP 215

TIP 220

VET 225

VELP 230

VIP 235

TELP 240

VLLP 205

TEP 250

TEP 255

VELP 260

VIP 265

VIP 270

VELP 275

TRP 280

VIA? 285

VILP 290

IIP 295

TEP 300

TEL 305

TEP 310

TIP 315

TELF 320

veP 325

veP 330

vel 335

TIP 340

TeP 345

VEL 350

vat 355

TII 360

VEL? 365

ITP 370

-a. 375

VEL? 300 


\section{APPENDIX E. (Continued)}

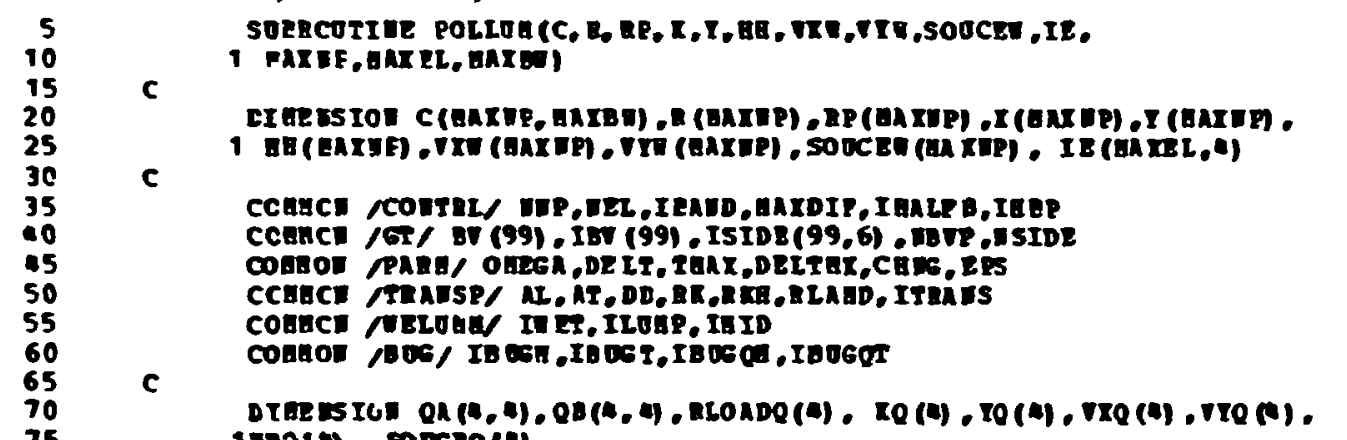

c

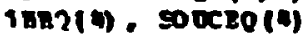

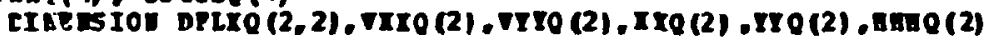

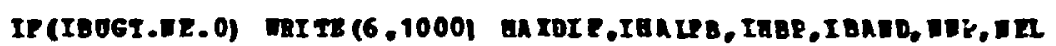
[EI? I=1.0/DELT

ธ1ะ0ีE

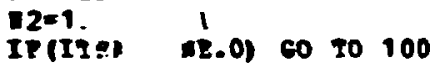

EEITI $=0.0$

$\forall 1=1.0$

c

$2=0.0$

$c$

c

Do $360 \quad n=1, D 2 L$

DC $200 I Q=1,0$

TP $=$ TE (n, IQ)

GHQ (IQ) $=$ Ga (DP)

$x Q(\mathrm{IQ})=\mathrm{x}(\mathrm{IP})$

ro (IO) $\mathrm{P}$ (ID)

VG (IQ) $=V T$ (DP)

$\nabla r Q(I Q)=V T V(D P)$

souceg (IO) = Sovegn(IP)

200 c0TITI

IP(IBUGT.EQ.0) G0 T0 201

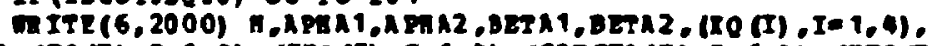

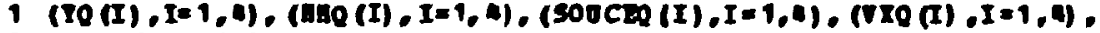
$2(\mathrm{TPQ}(\mathrm{I}), I=1,0)$

c 301 COITIU OL

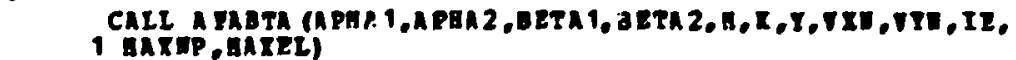

c

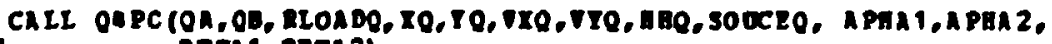

c 1

IF(IETB. 52.0) 6020260

c

20 $2: 0 \quad 10-1,0$

$I=I E(1,10)$

$00210 \mathrm{JQ}=1,4$

T. IE $=2 ., 30)$

CA $(I C, J Q)=0 A(10, J 0)$ OLLTI

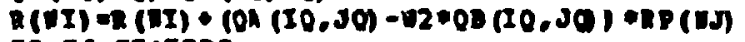

IB- 1 J-II Ine

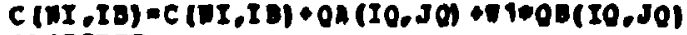

¿10 00\%ร INOZ

$B(I I)=n(I I)-n L O R D Q($ IQ $)$

250 cominoz

c

co 30300

260 cotrinos

co 280 s0=4,

$I=I I(n, I 0)$
POL. 005

PCLL 010

POLL 015

POLL 020

POLL 025

POLL 030

POLI 035

POLL 040

Potr 045

POLL 050

POLL 055

PJL 060

POLL 065

POLL 070

POLL 075

POLL 080

poll 085

POLL 090

POLL 095

POLL 100

eOLL 105

POLL 110

poll 115

POLL 120

porL 125

PCLL 130

POLL 135

POLI 140

Potr 145

POLL 150

POLL 155

POLL 160

POLI 165

PCLL 170

POLL 175

POLL 180

PoLL 185

POLI 190

POLL 195

PCLL 200

PŨL 205

POLL 270

POLI 215

POLI 220

POLL 225

POLL 230

POLL 235

POLL 240

POLL 245

POLL 250

poLl 255

POLI 260

POLL 265

POLL 270

POLI 275

POLL 280

pors 285

poLl 490

POLL 295

poll 300

poL2 305

POLL 310

poll 315

POLL 320

POLL 325

Poll 330

POLL 335

POLL 340

POLL 345

PotL 350

poLs 355

POLL 360

POLL 365 


\section{APPERDIX E. (Continued)}

375

380

385

390

195

900

405

410

415

420

425

430

435

40

nes

450

455

460

465

470

075

480

485

990

495

500

sos

510

sis

520

52

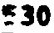

535

sin

545

550

555

560

565

570

$\$ 75$

580

585

s91

595

600

605

610

619

620

625

630

635

60

ces

650

655

60

15

670

675

600

c.5

80

695

700

205

710

715

720

Do 270 Jer.

$\omega=I 2(4,00)$

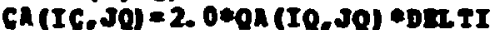

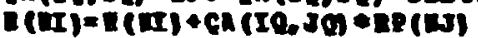

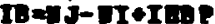

270 caterit

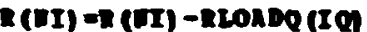

$c$

aEc Corritu

C

00 CorrTo:

IP (I.UG_.20.0) 00 To 351

DIP2(6, 3000)

$20390 \quad I=1, \mathrm{DP}$

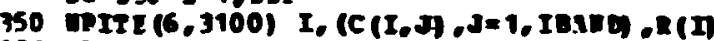

c

1 corrit

C

IP(EDVR. EQ.0) 5020600

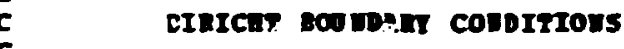

Do $560 I=1, D B T$

$\mathrm{I}=\mathrm{I} T(\mathrm{I})$

$50000 I \% 1$, IBNEB

NoC C (RI, IB) $=0.0$

C(II, Inet $=1.0$

(III) $=0$ (I)

IP (I) $\cdot 20.0 .0) \div 0>0450$

$00.40 I B=1$, In LPS

$I=I I-I B$

IF OJ.L2. 1) 60 To 130

JE=IBDP $\mathrm{IB}$

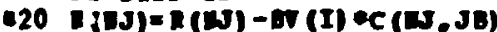

430 50 $440 I=1, I m A L T$.

$25=1 \cdot I$.

IF (aj. OT.

JDEITE-I.

c

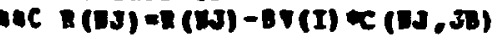

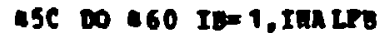

IN $=15$

IF (1).IT. I) 60 To 470

JE=IMPe 1

aec $C(D, . J D)=0.0$

470 te 880 IE 1 , IMALP

$\mathrm{IJ} \times \mathrm{T}+\mathrm{IS}$

IF(1J.6I.DTP) 60 to 490

JE-IU⿴囗十 - I

$\triangle 80$ C (1) .JB) $=0.0$

a9e coming.

e

500 corsing

IF (Iever. 00.0$) 60$ so 551

OAIT2 6,0000$)$

Do $550 \div=1,0$ IT

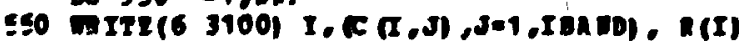

c

551 corerto.

600 IP(TSIDS. B0.0) 00 30 760

c

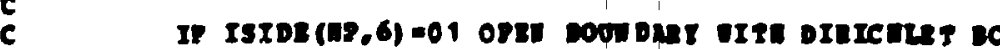

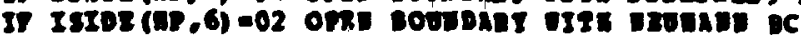

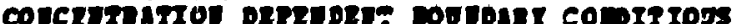

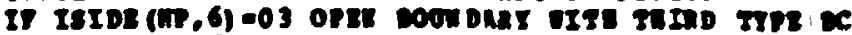

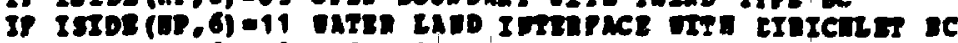

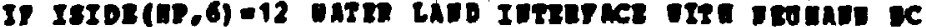

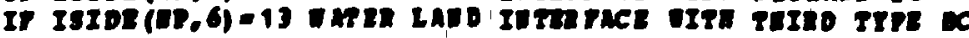

POLL 370

POLL 375

POLL 380

PoLl 305

POLS 390

$\cos 395$

20LL 100

roLL 105

POLI 110

porl 415

POLL $\$ 20$

POLL 25

Porl 130

porl a 35

pots 900

port ass

roLs 450

POLI 455

$\cos 1660$

porl as5

POLL 170

POLL 75

POLI 480

POLL 195

FCII 990

Fol as5

POLI 500

P0IL 505

POLL 510

Porl 515

POLL 520

POLL 525

POLL 530

POLL 535

PoLl 5 A0

Poll 545

poll 550

PoLL 555

POLL 560

PoIL 565

porl 570

POLL 575

POLL 580

POLL 585

POLL 590

POLI 595

POLL 600

POLL 605

POLL 610

POLL 615

PoLI 620

Porl 625

FOLL 630

PoLL 635

rots 640

poll gas

CoLl 650

OLL 655

Porl 660

FoLL 665

POLL 670

POLL 675

NOLL 680

POLL 685

rorl 690

pors 695

DOLL 700

pols 705

PLL 110

POLL 715

coLL 720 
APPERDIX E. (Continued)

\begin{tabular}{|c|c|c|c|c|}
\hline $\begin{array}{l}725 \\
730 \\
735 \\
740 \\
725 \\
750 \\
755 \\
760 \\
765 \\
770 \\
775 \\
780 \\
785 \\
790 \\
795 \\
900 \\
805 \\
810 \\
815 \\
920 \\
825 \\
230 \\
235 \\
840 \\
845 \\
850 \\
855 \\
650 \\
865 \\
270 \\
675 \\
800 \\
805 \\
890 \\
295 \\
900 \\
905 \\
910 \\
915 \\
920 \\
925 \\
930 \\
935 \\
940 \\
945 \\
950 \\
955 \\
960 \\
965 \\
970 \\
975 \\
980 \\
985\end{array}$ & $\begin{array}{l}602 \\
600\end{array}$ & 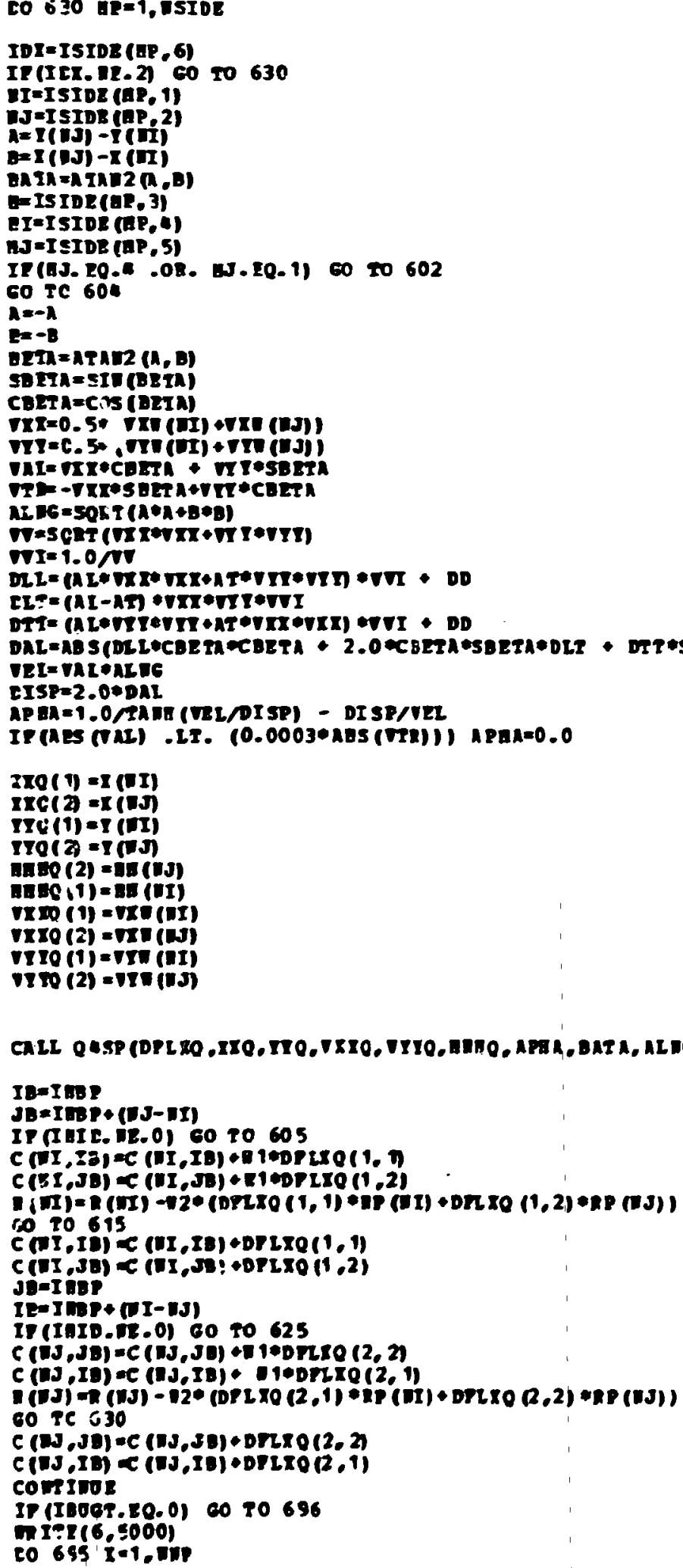 & SELTANS BETA) & 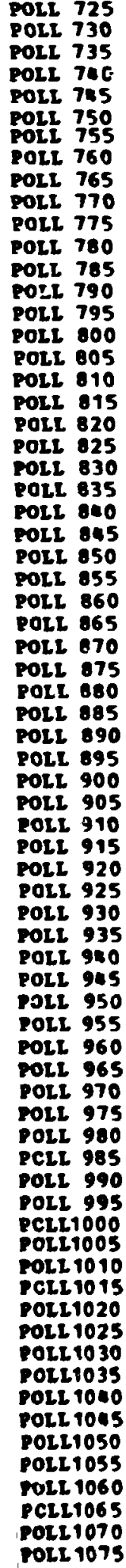 \\
\hline
\end{tabular}




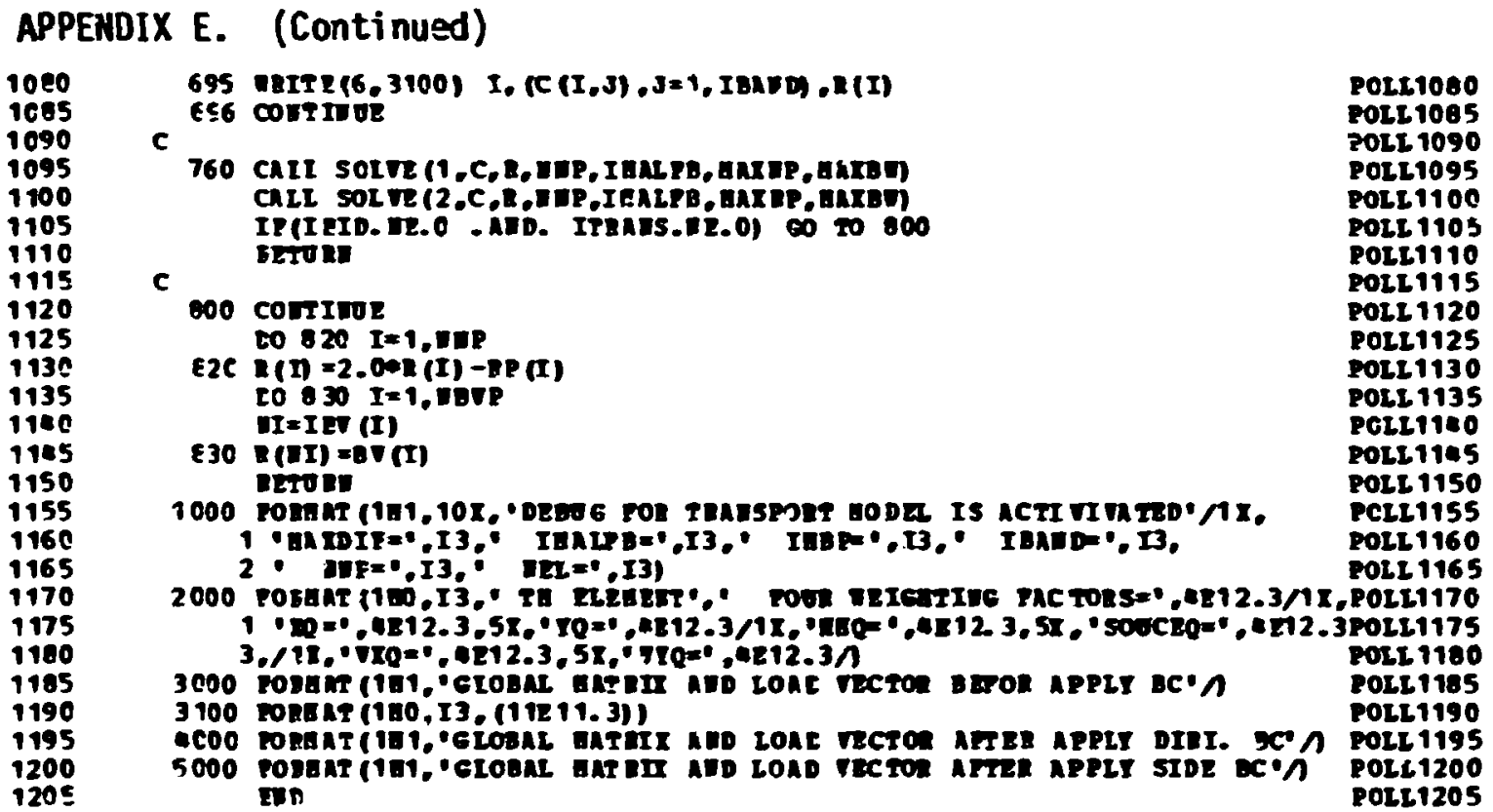

1020

1685

1090

1095

1100

1105

1110

1115

1120

1125

1134

1135

1180

11e5

1150

1155

1160

1165

1170

1175

1180

1185

1190

1195

1200

1205

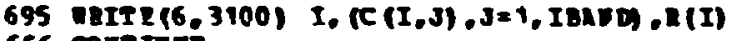

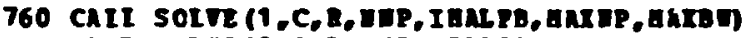

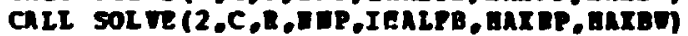
IP(I EID. IE.0 - ADD. ITBAIS.RE.0) 00 To 800

c BETU RI

000 CoTrIne to $820 I=1, \ldots 10$

$E 2 C)(n=2.00 R(I)-R P(I)$ LO $830 \quad I=1,007 P$ UI=IET (I)

E30 $\mathrm{R}(\mathrm{II})=0 \vee(\mathrm{I})$ DETO DI

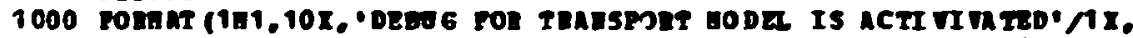

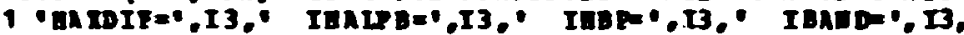

2 - INF=0,I3, ILL=0.I3)

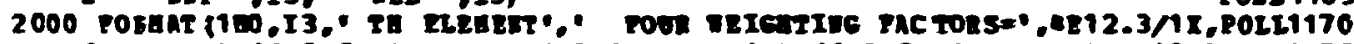

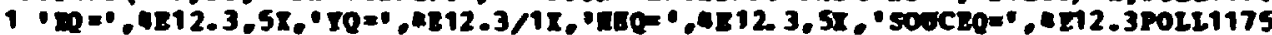

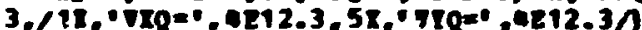

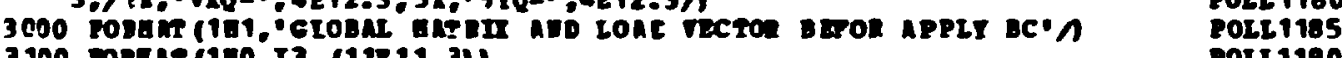

3100 ronEA (180, I3 (11211.3)

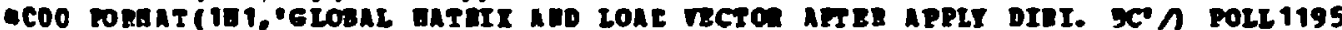

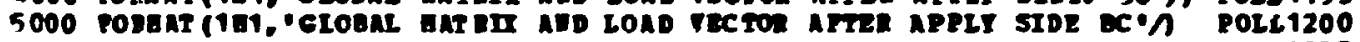
En

POLL1085

POLL 1090

P0LI1100

POLL 1105

PorL1115

POLI1120

P0LL1125

(2)

PCLL11 0

PorI1150

PCII1155

20LI1160

PoLL1205 
APPENDIX E. (Continied)

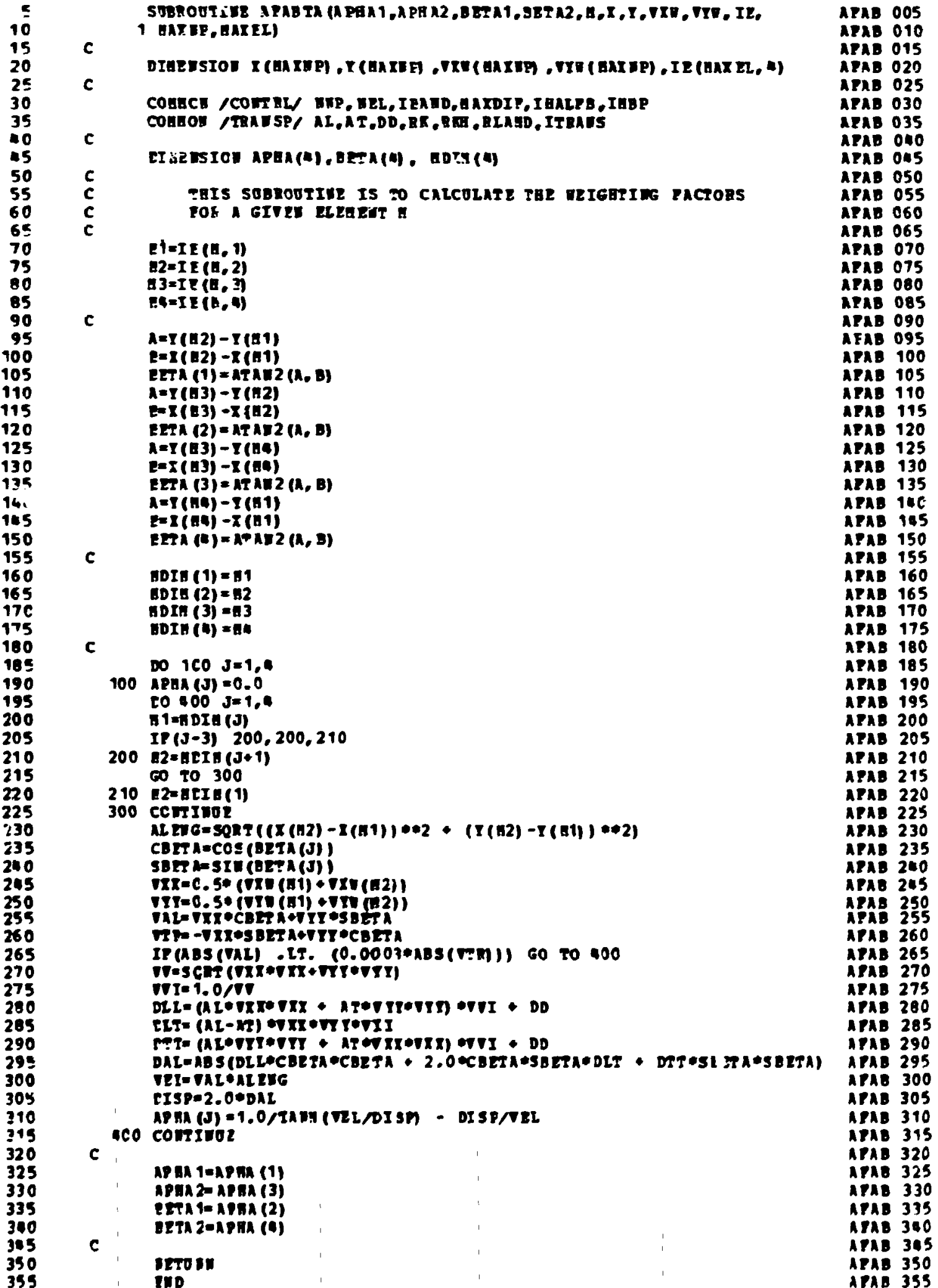


APPENDIX E. (Continued)

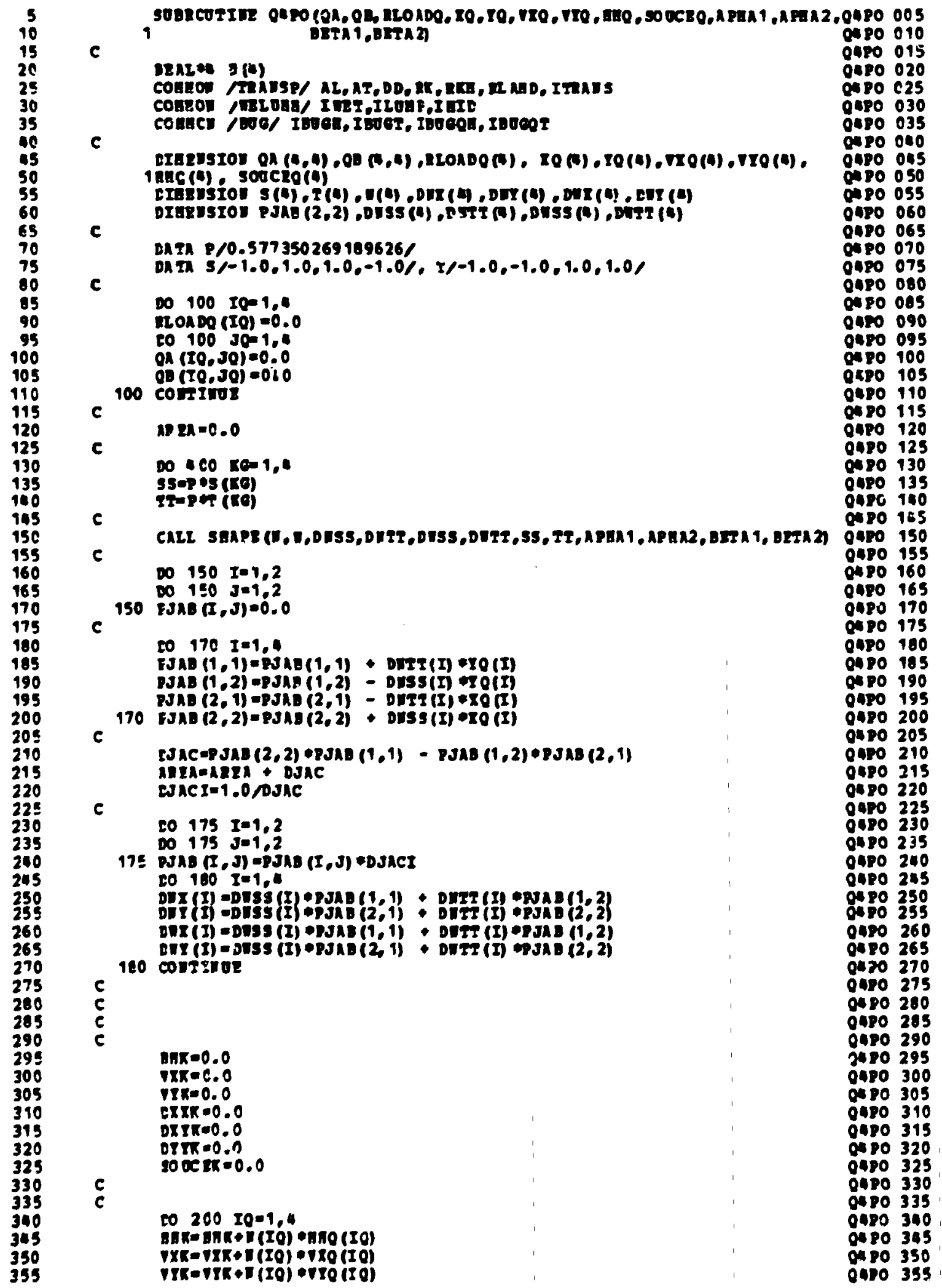


APPENDIX E. (Continued)

c 200 contritos

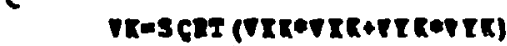
VR I $1.0 / 7 \pi$

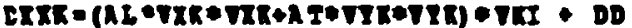

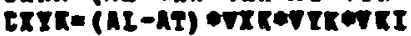

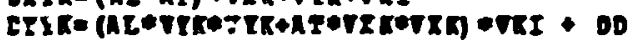

Q480 360 c90 365

0480370

Q4P0 375

or 300

Qupo 305

Q4P0 390

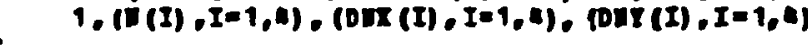

Lo $360 \quad I 0=1,4$

DO 290 Joe 1,

III $=$ (IQ) +1 (JQ)

ETYDHY DIT (IO) कDT (JO)

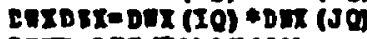

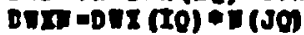

EIIT $=0 \pi R(I 0) * \pi(J 0)$

CTTDUR= DHY (IQ) * OLK (JO

DTXDET $\approx D H X(I Q) * D$ UI (JC)

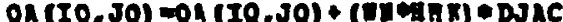

Q4P0 105

oxpo 4 io

040 4.5

Q4P0 120

Q4Po $\$ 25$

0 QPि $\lcm{30}$

0490435

arpo 140

000 ats

o4po 450

gepo 155

c

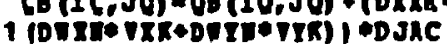

$-9490090$

(290

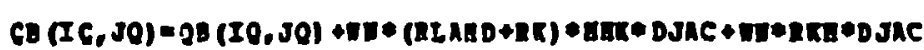

$0130 \div 75$

290 cotrinos

300 Corstros

co 350 IOe 1,

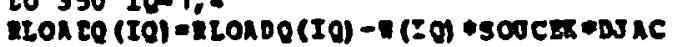

3 30 COTTIU OR

IP(E20095.20.0) 00 T0 361

WRITE $(6,2000)$ Ke, AIRA

Do $3 \in 0$ I $=1$.

$360 \operatorname{mit}(6,2100)$ I, $(Q 2(I, J), J=1,4),(08(I, J), J=1,4), \operatorname{RLnADQ}(I) \quad$ QUPO 525

c

100 COMINOE

IP(ILORE. E.0) 60 TO 10

Rrioan

410 Comsno

ERI $=0.0$

DO $420 I=1,4$

DO $\bullet 20 \quad j=1,4$

IF (I. IE.J) 00 To $₫ 20$

QREA-anEA+QR (I, J)

120 Contrute

20 $30 \quad I=1,4$

DO $430 \quad 3=1.4$

GR $(I, J)-O R(I, J)$ anReh/sREA

IF (I. I. . J) OA $(I, J)=0.0$

430 contritos

\section{BETORI}

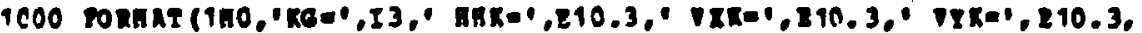

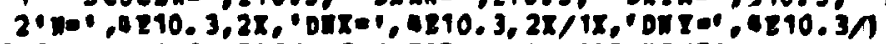

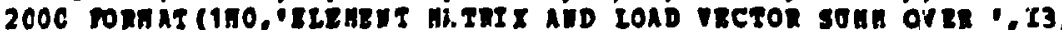

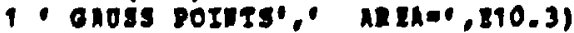

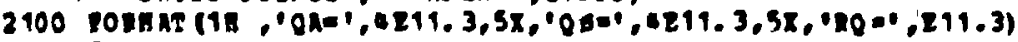
170

04PO 535

Q080 540

Q480 545

0epo 550

Q4Po 555

Q4PO 560

0483565

Q $0 \% 0570$

G*10 575

0.Po 580

Q4P0 505

0480590

Q4P0 595

0480600

Q4PO 605

Q4PO 610

Q4P0 615

Q4PO 620

Q4po 625

arpo 633

04po 640

Q4P0 645

Q4P0 650

Q4P0 655 


\section{APPENDIX E. (Continued)}

$1 \mathrm{C}$

15

20

25

20

35

10

45 1

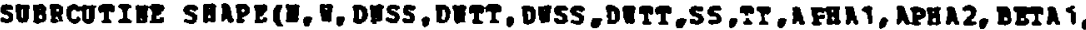

19.

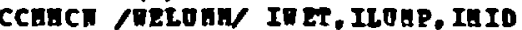

c

$S E=1.0-5 S$

$S P=1.0 \cdot 5 S$

$T B=1.0-T T$

TP- 1.0.TT

$T(1)=0.25 * 54 * T 4$

$\mathrm{I}(2)=0.25 * 5 \mathrm{~s} * \mathrm{Tn}$

$M(3)=0.25 * 5$ P*T

$\Pi(4)=0.25 *$ Sin $* 72$

CESS (1) $=-0.25 *$ T

DUSS (2) $=0.25 * T$

CNSS (3) $=0.25 * 21$

CESS (4) $=-0.25 * \mathrm{TP}$

DTTT (1) $=-0.25 * 5$

DII II (2) $=-0.25 * \mathrm{SP}$

DITr (3) $=0.25$ *

D.TT $(4)=0.25 * 5 \%$

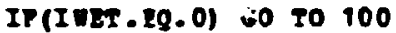

$\eta(1)=0.0625 *($ TP* $(3.0 * B E T h *(-$ IA) -2.0$) * 4.0) *(S P *(3.0 * A P H A 1 *(-S A)-$ 1 $2.01+4.01$

$\nabla(2)=0.0625 *($ PP* $(3.0 * B E T A) *(-I H)-2) * 4.0 *.(5 P *(3.0 * A P A A 1 * S . * 2.0))$

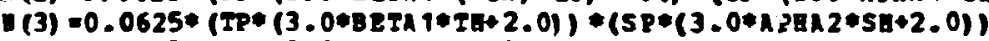

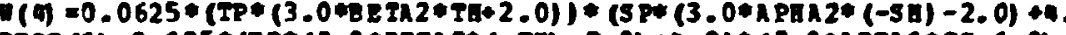
CESS (1) $=0.125 *(\mathrm{TP} *(3.0 *$ BETA $*(-\mathrm{TH})-2.0)+4.0) *(3.0 * A$ PBA $1 * 55-1.0$

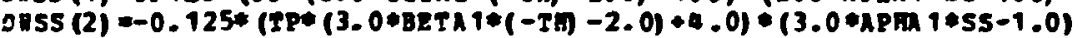

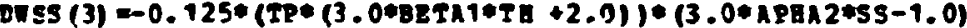
DESS (A) $=0.125 *($ TP* $(3.0 * B E T A 2 *$ Tr +2.0$))(3.0 *$ APHA $2 * 5 S-1.0)$

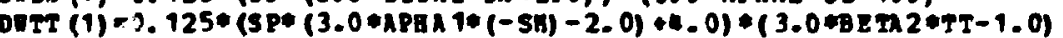
CETT (2) $=0.125 *(S P *(3.0 * A P B A T * S A+2.0)) *(3.0 * B E * A 1 * 2 T-1.0)$

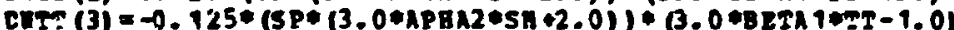

C

100 Do $260 \quad I=1.0$

(I) $=(\mathrm{I}(\mathrm{I})$

Cuss (I) $=$ Dnss (I)

c

200 ENTI (I) $=0$ TIT (I)
SHAP 005 SanP 010 SanP 015 SanP 020

SBAP 025 SEAP 030 SHAP 035 SanP O40 stine oes SARP 050 SARP 055 SBAP 060 SERP 065 SHRP 070 Sane 075 SER० 080 SERP 085 skine 090 SBRP 095 SARP 100 SARP 105 SRIP 110 SHAP 115 SHRP 120 SHAP 125 SHAP 130 SRAP 135 SBAP 140

SIAP 145 SBAP 150 SEAP 155 SAAP 160 SARP 165 SBAP 170 SEAP 175 SiAP 180 SRAP 185 SANP 190 SALP 195 SAAP 200 SAAP 205 SNAP 210 SARP 215

SFIP 220 SANP 225 SRAP 230

SBAP 235 SBAP 240 SEAD 245 
APPENDIX E. (Continued)

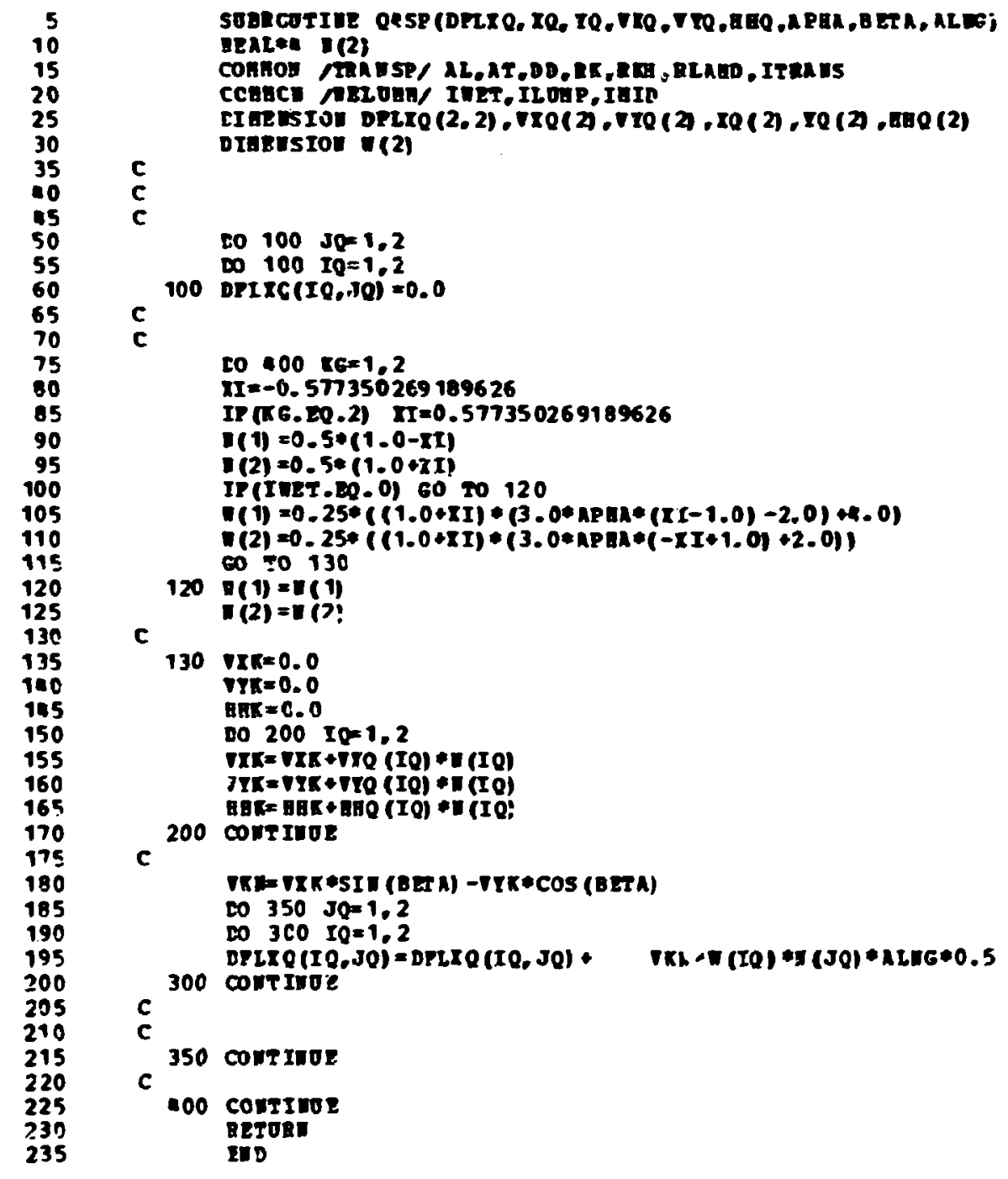

025P 005 025P 010 Q2SP 015 Q25P 020 Q25P 025 025P 030 Q25P 035 025P 0no Q25P 005 025P 050 Q25P 055 Q25P 060 Q25P 065 Q25P 070 Q2SP 075 Q2SP 060 Q2SP 085 Q25P 090 Q25P 095 025P 100 Q25P 105 025P 110 Q2SP 115 Q2SP 120 Q25P 125 Q25P 130 Q25P 135 Q2sP 1100 Q25P 145 Q25P 150 Q2 SP 155 Q25P 160 Q25P 165 Q25P 170 02sP 175 Q2SP 180 Q2SP 185 Q2SP 190 Q25P 195 Q25P 200 Q25P 205 Q25P 210 Q25P 215 Q25P 220 Q2SP 225 Q2-p 230 Q25P 235 
APPENDIX E. (Continued)

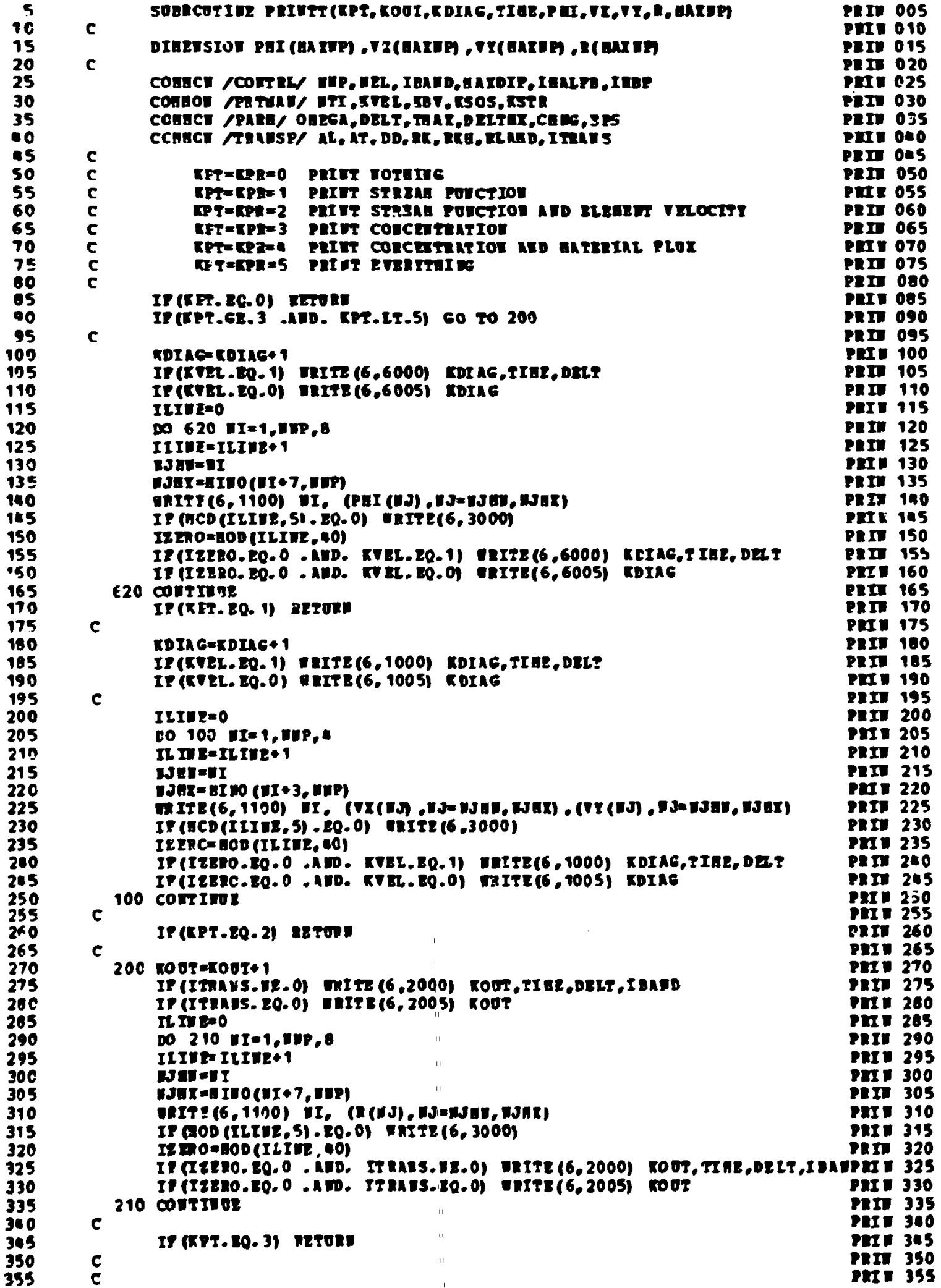


APPENDIX E. (Continued)

$36 n$

365

370

375

300

305

390

395

100

105

49

175

120

425

130

435

400

45

450

is? c mite antegini prox

$\equiv 10$ ContTIUR

c DETS DH

1000 0Bg (111.

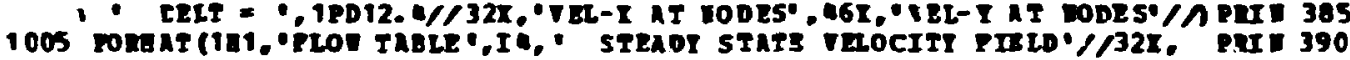

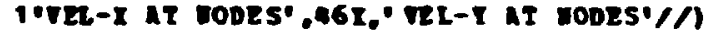

1100 POPAAT (I7,8 (1PD 15, 9)

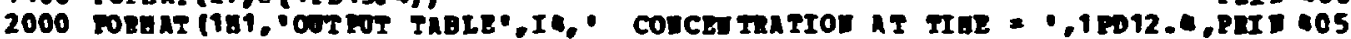

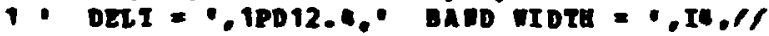

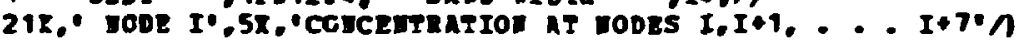

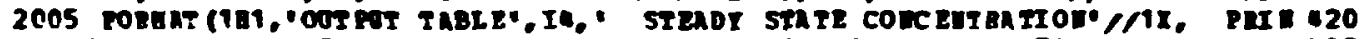


3000 TOESR (1MO) PRII

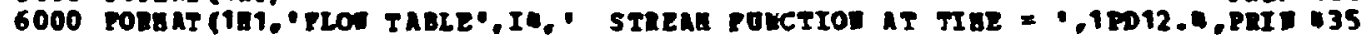
1 - DELT $=\because$ 1PDI2-01n

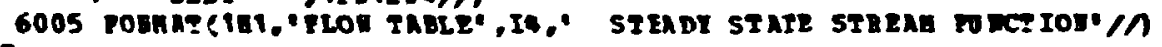
c IXD 